PROPERTIES OF CONCRETE CONTAINING RECYCLED CONCRETE AGGREGATE OF PRESERVED QUALITY

by

\author{
Jonathan Andal \\ B.Eng, Ryerson University, 2012
}

\author{
A thesis \\ presented to Ryerson University \\ in partial fulfillment of the \\ requirements for the degree of \\ Master of Applied Science \\ In the program of \\ Civil Engineering
}

Toronto, Ontario, Canada 2015

(C) Jonathan Andal 2015 


\section{Declaration of Authorship}

I hereby declare that I am the sole author of this thesis. This is a true copy of the thesis, including any required final revisions, as accepted by my examiners.

I authorize Ryerson University to lend this thesis to other institutions or individuals for the purpose of scholarly research.

I further authorize Ryerson University to reproduce this thesis by photocopying or by other means, in total or in part, at the request of other institutions or individuals for the purpose of scholarly research.

I understand that my thesis may be made electronically available to the public. 


\title{
PROPERTIES OF CONCRETE CONTAINING RECYCLED CONCRETE AGGREGATE OF PRESERVED QUALITY
}

\author{
Master of Applied Science, 2015 \\ Jonathan Andal \\ Department of Civil Engineering \\ Ryerson University
}

\begin{abstract}
Today, there is a growing need for the implementation of sustainability in construction. Continuous construction and rehabilitation projects have begun to deplete virgin aggregate sources. The use of recycled concrete aggregate (RCA) in concrete has been regarded as a sustainable and environmentally friendly alternative aggregate source. This thesis focuses on producing RCA of preserved quality through the use of a new protocol aimed at maintaining the original properties of returned-to-plant concrete. The performance of RCA with preserved quality and commercially available RCA when used in concrete was compared. Different concrete properties were evaluated including the fresh, hardened and durability characteristics. Results showed that the RCA with preserved quality performed better in many categories, including strength, drying shrinkage and salt scaling resistance compared to the commercial RCA. The use of $30 \%$ preserved-quality RCA as partial replacement of coarse aggregate produced concrete of comparable quality to that produced with virgin aggregate.
\end{abstract}




\section{Acknowledgements}

I would like to thank Dr. Medhat Shehata for his support and dedication throughout my years at Ryerson University. His guidance during this study has been much appreciated. It was an honour to work with him and I hope to instil everything he has taught me in my future career.

I would like to thank my family for their love and support throughout university. My accomplishments are as a result of their continued guidance and encouragement.

I would also like to thank those who have helped me with my research along the way especially the research team of Dr. Shehata for their help and support in the lab over the years.

I would also like to extend a special thanks to the Civil Engineering technicians; Min Yao, Domenic Valle and Nidal Jaalouk for their technical help during my research. 


\section{Table of Contents}

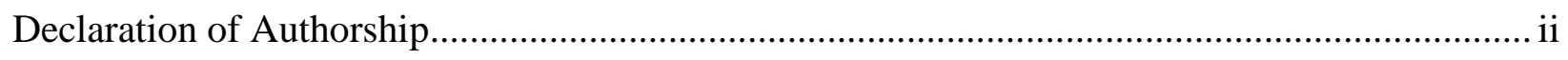

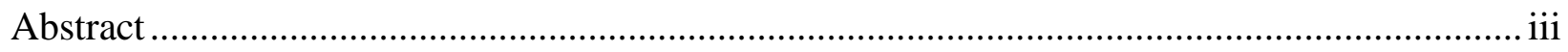

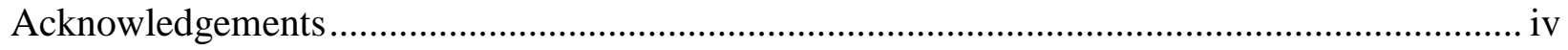

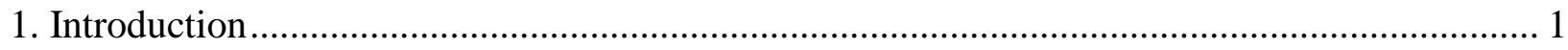

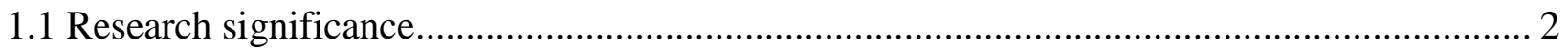

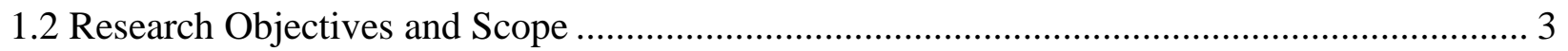

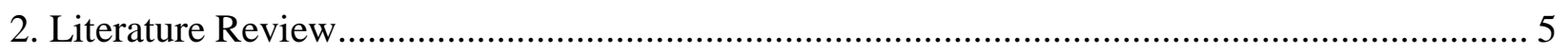

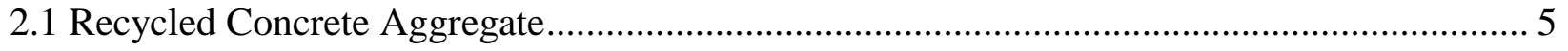

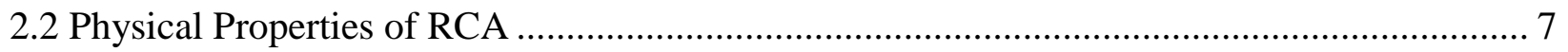

2.3 Hardened Properties of Concrete containing RCA ............................................................ 8

2.4 Fresh Properties of Concrete containing RCA ............................................................ 19

2.5 Durability of Concrete Containing RCA ...................................................................... 21

3. Materials and Experimental Methods ............................................................................... 26

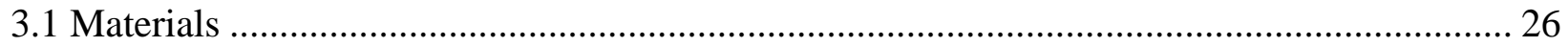

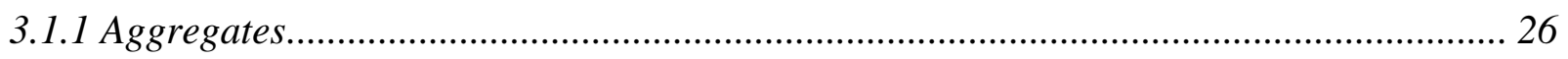

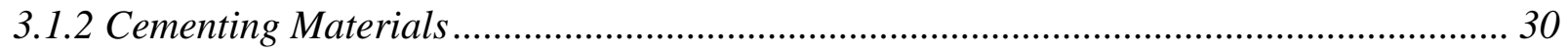

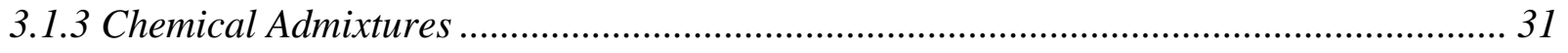

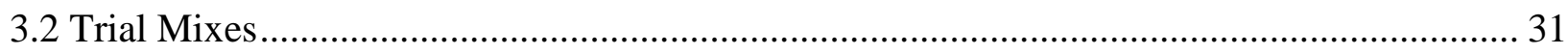

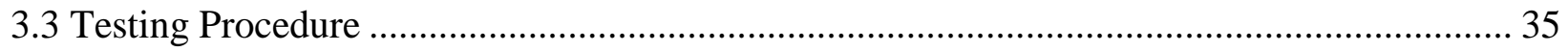

3.3.1 Batching and Fresh Properties ............................................................................ 35

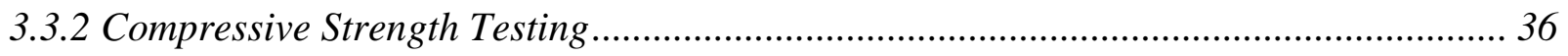

3.3.3 Splitting Tensile Strength Testing .................................................................... 37

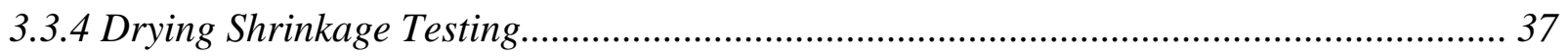

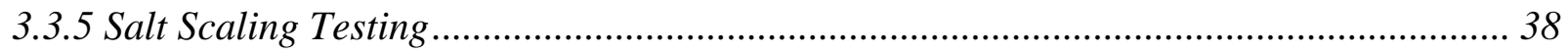

3.3.6 Rapid Chloride Permeability Testing $(\mathrm{RCPT})$.......................................................... 40

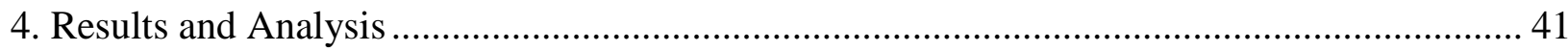

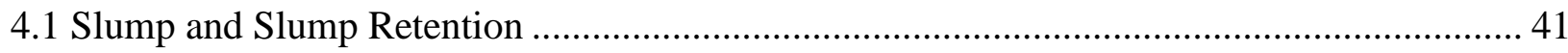

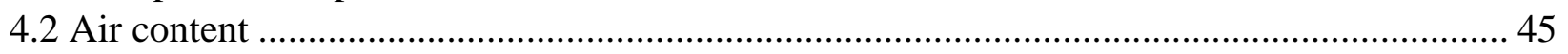

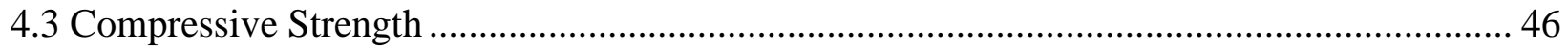

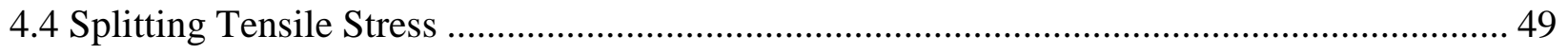

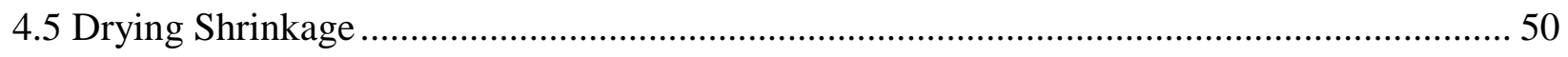

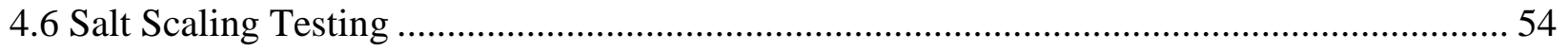

4.7 Rapid Chloride Permeability Test ............................................................................. 57

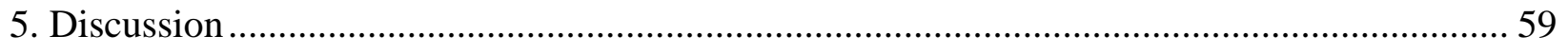

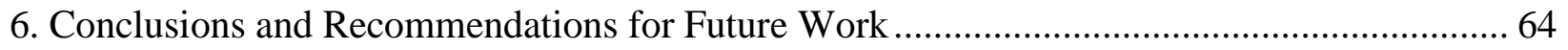

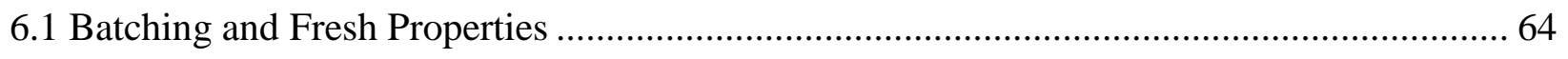

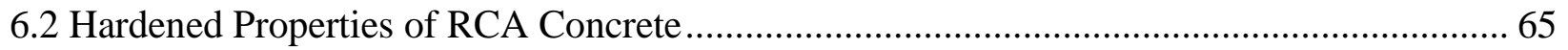




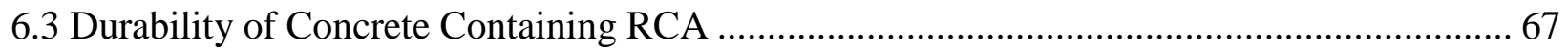

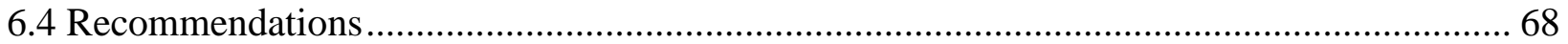

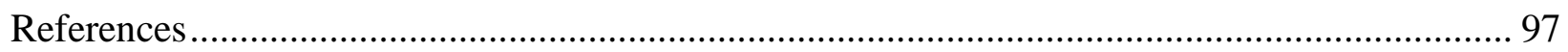




\section{List of Tables}

Table 1: Physical properties of virgin aggregate and RCA (ECCO, 1999) ............................... 8

Table 2: The effect of RCA on hardened properties of concrete (Safiuddin et.al, 2012) ............ 19

Table 3: The two-stage mixing approach (TSMA) mixing procedure (Tam Gao \& Tam, 2005) 21

Table 4: The chloride ion penetrability based on charge passed (ASTM C1202) .................... 25

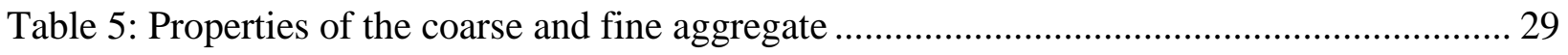

Table 6: Chemical analysis of the cementing materials....................................................... 30

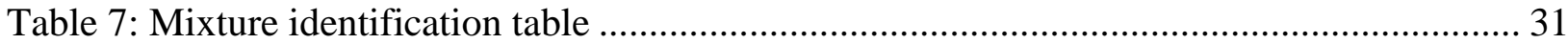

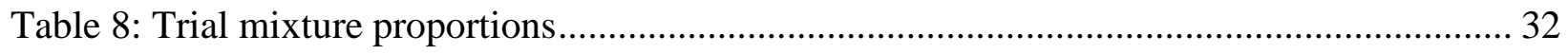

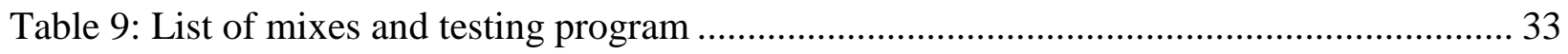

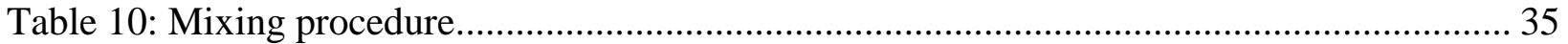

Table 11: A comparison of Class C2 concrete containing commercial RCA and RCA of

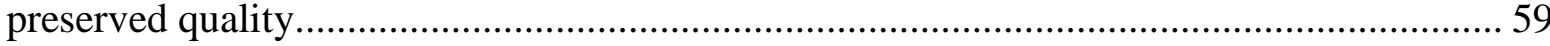

Table 12: T-test of RCA of preserved quality Vs. Commercial RCA for various tests .............. 63

Table 13: Salt scaling specimens through 0, 25 and 50 freeze-thaw cycles ............................. 69 


\section{List of Figures}

Figure 1: Concrete containing RCA (Gokce et al., 2003)................................................... 7

Figure 2: The average compression strength of concrete containing a various percent of RCA

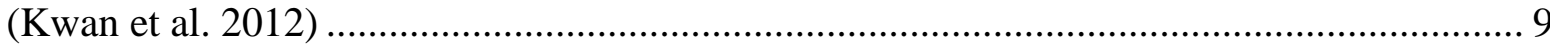

Figure 3: The Effect of RCA on compressive strength (Nelson, 2004)................................. 10

Figure 4: The compressive strength over time of concrete incorporating RCA (Salau et al., 2014)

Figure 5: The relationship between RCA replacement and the reduction in 28 day tensile strength (Qasrawi \& Marie, 2013)..................................................................................... 12

Figure 6: The influence of RCA replacement on drying shrinkage (Guo et al., 2013) .............. 13

Figure 7: The influence of RCA replacement on the porosity of recycle aggregate concrete (Guo et al., 2013)

Figure 8: The shrinkage of specimens with a variety of RCA replacement (Missouri University, 2014) 15

Figure 9: The drying shrinkage of concrete containing limestone and gravel (Faithifazal et al., 2001) 16

Figure 10: The drying shrinkage of concrete containing RCA (Faithifazal et al., 2001) ............ 16

Figure 11: The drying shrinkage of concrete with 25\% RCA (Salau et al., 2014)..... 17

Figure 12: The drying shrinkage of virgin aggregate (VA) and RCA concrete containing SRA (Sucic, 2013). 18

Figure 13: The mass change of specimens incorporating 100\% RCA for 300 freeze-thaw cycles

(Hwang et al., 2012)

Figure 14: The length change of concrete specimens due to freezing and thawing (Huda \& Alam, 2015) 23

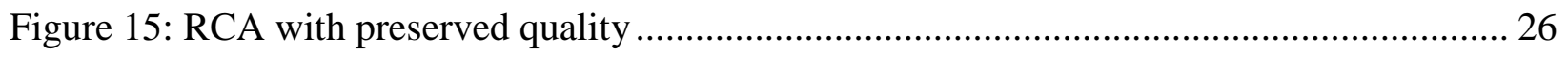

Figure 16: A Close-up of RCA with preserved quality ................................................... 27

Figure 17: Gradation of the Dolostone aggregate .................................................................. 28

Figure 18: Gradation of the coarse commercial RCA and RCA with preserved quality ............. 29

Figure 19: Specimen under compressive strength testing................................................... 36

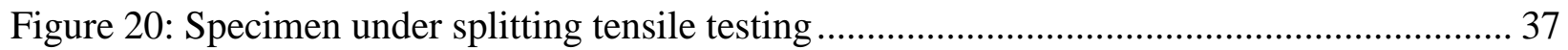

Figure 21: Drying shrinkage measurement of a concrete specimen using a length comparator .. 38 
Figure 22: Salt scaling specimen

Figure 23: Slump retention of Class: $15 \mathrm{MPa}$ specimens containing RCA with preserved quality

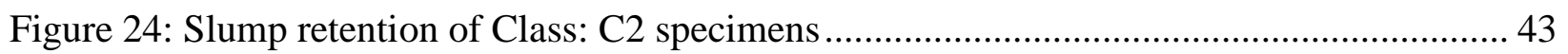

Figure 25: Slump retention of Class: C2 specimens …………………………………......... 43

Figure 26: Slump retention of Class: F1 specimens …………....................................................... 44

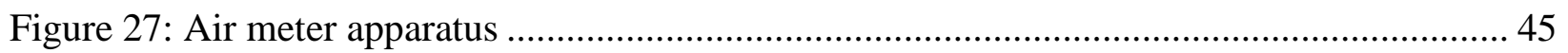

Figure 28: Compressive strength of C2 specimens................................................................. 46

Figure 29: Compressive strength of $15 \mathrm{MPa}$ specimens....................................................... 48

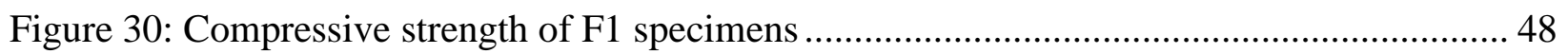

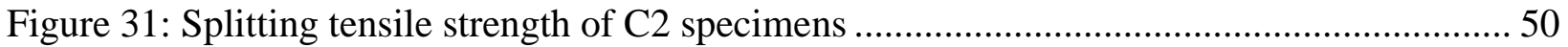

Figure 32: Drying shrinkage of C2 specimens …………........................................................... 52

Figure 33: Drying shrinkage of C2 specimens tested at Ryerson University .............................. 53

Figure 34: Drying shrinkage of C2 specimens tested at an external facility ................................ 54

Figure 35: Salt scaling of C2 specimens containing RCA with preserved quality ........................ 55

Figure 36: Salt scaling of C2 specimens containing commercial RCA ...................................... 55

Figure 37: A close-up of salt scaling samples containing 100\% commercial RCA …………...... 56

Figure 38: The mass loss of all C2 specimens after 50 cycles.................................................... 57

Figure 39: The rapid chloride permeability of specimens at 56 days ............................................. 58

Figure 40: The shrinkage of RCA of preserved quality and commercial RCA at 180 days at

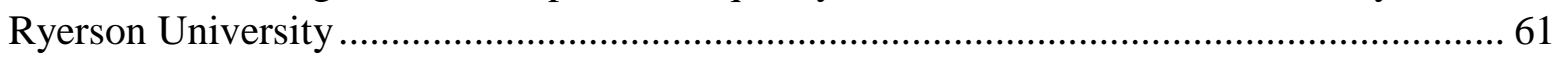

Figure 41: The scaling resistance of concrete containing $100 \%$ RCA of preserved quality or

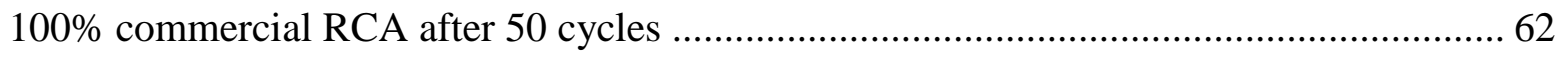

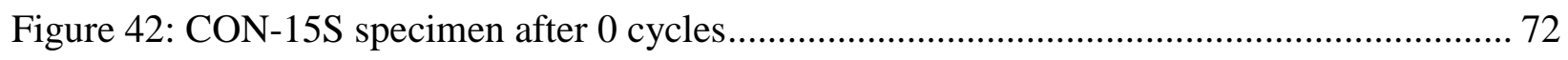

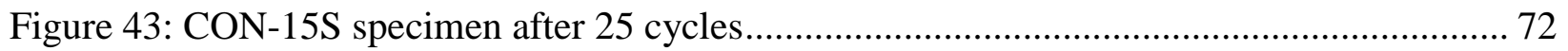

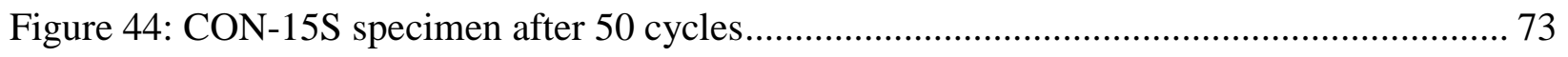

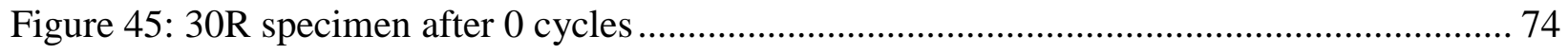

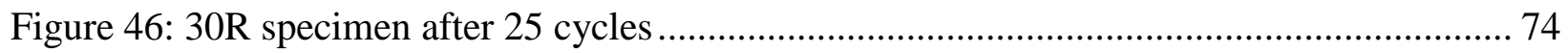

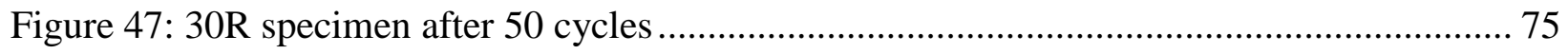




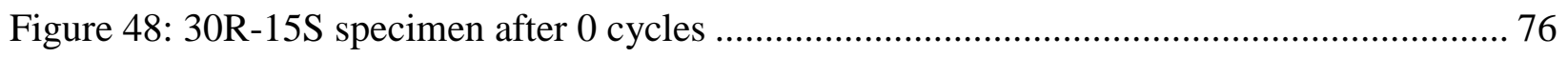

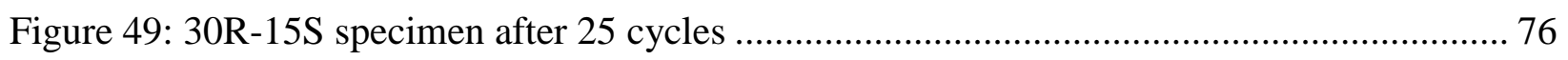

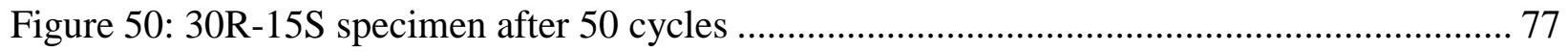

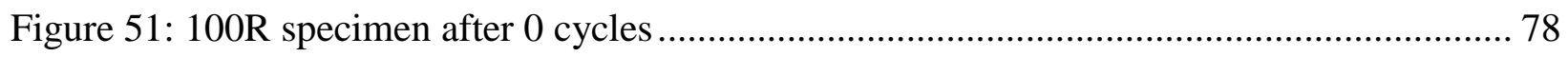

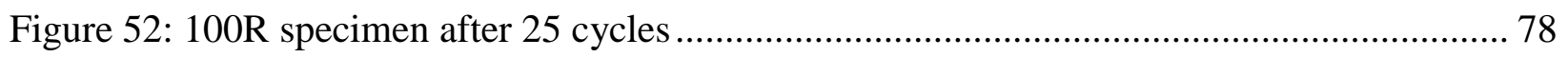

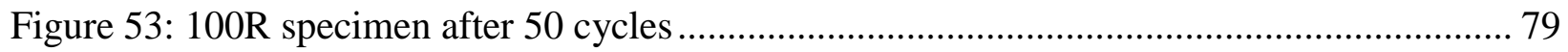

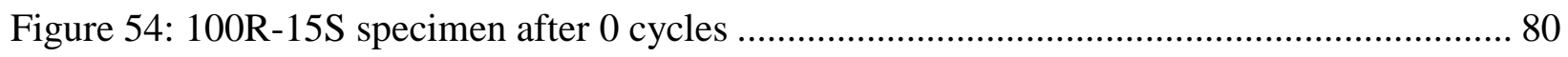

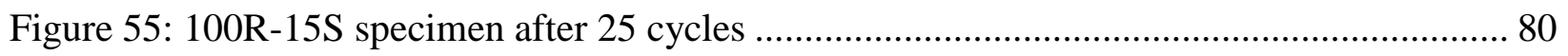

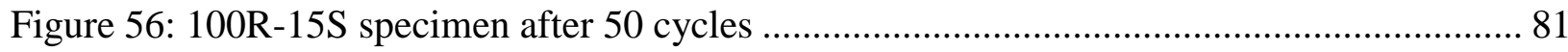

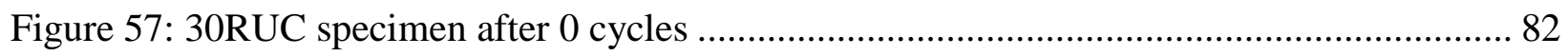

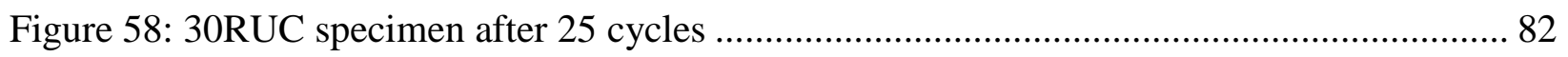

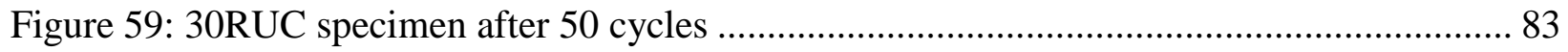

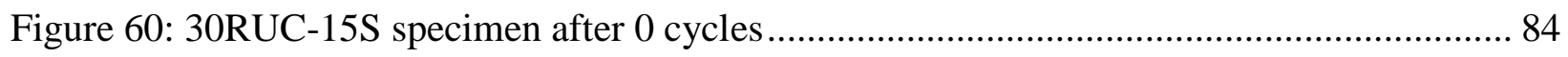

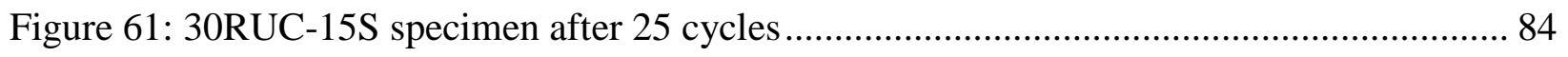

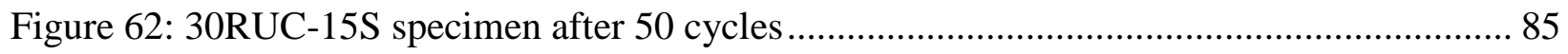

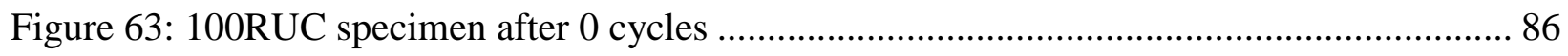

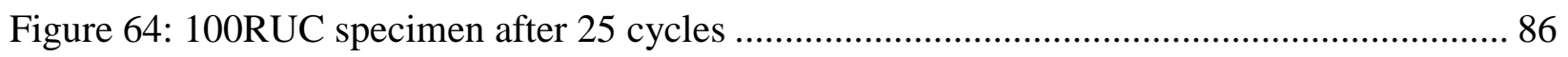

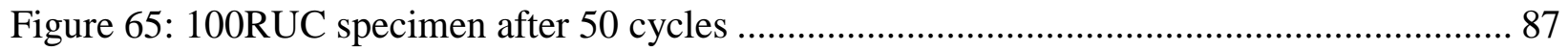

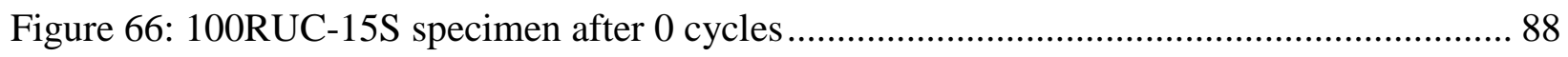

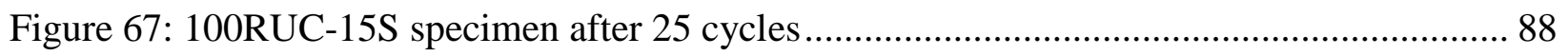

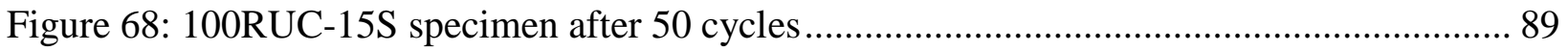




\section{List of Appendices}

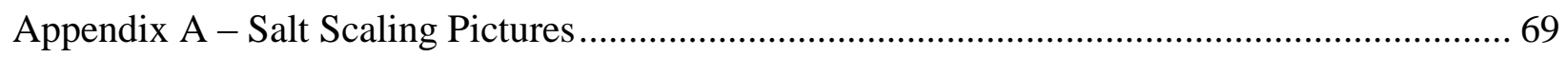

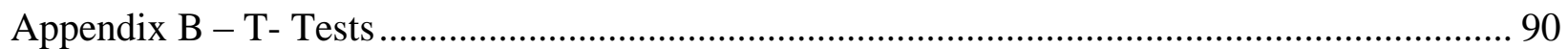




\section{Introduction}

The depletion of natural virgin aggregate sources is a critical topic in today's construction industry. These natural resources cannot be replenished. To build infrastructure around the world many natural raw materials are used and are not replaced. In the modern world, concrete is used in many facets of infrastructure such as buildings, roads, bridges and tunnels. When the life expectancy of these types of infrastructure is over or they need to be replaced these concrete structures are demolished and the waste is sent to landfills. Additionally, when there is leftover fresh concrete from the construction of a new structure to replace the old one it is sent back to the batch plants and washed out and left to harden. The concrete waste remains unused and pile up in landfills occupying valuable space.

Creating a use for this waste concrete could prove as an environmentally friendly and sustainable solution. Recycling the concrete as aggregate for future concrete mixes has recently become an option for commercial concrete suppliers around the world, particularly in Europe as well as North America. Recycled concrete aggregate (RCA) has gained popularity as it is a sustainable resource and does not deplete virgin aggregate (VA) sources. RCA is known as hardened concrete that has been crushed and sieved into aggregate. Two forms of RCA exist; reclaimed and returned to plant. Reclaimed concrete aggregate is a result of the demolition of already built infrastructure. The rubble from the demolition is then crushed and sieved to meet standard gradation. Returned-toplant concrete involves fresh concrete that was been returned to the batch plant. The returned concrete is discharged from the transit mixer using water and left to harden. The hardened concrete is crushed and sieved to meet gradation standards. 
The use of RCA has garnered different opinions. The unpredictability and uncertainty of where the RCA originated and what the RCA was exposed to previously has been a concern many have raised (Gokce et al., 2004). However, over the years RCA seen use in granular backfill, subgrade material and use in sidewalk (Butler et al., 2012). The sustainability and economic benefits of RCA has allowed many to continue research on the various properties of RCA.

The residual mortar surrounding the original aggregate is one of the main factors that affect properties such as density, porosity and absorption of RCA (McNeil and Kang, 2013). The addition of RCA has shown changes to the fresh properties of concrete. The high absorption rate or RCA have resulted in a lower workability (Rahman \& Hamdam, 2009). The use of RCA in concrete has also resulted in changes in mechanical properties. It has seen reduced strength (Corinaldesi, 2011) as well as an increase in drying shrinkage (Domingo et al., 2009).

Currently, the use of RCA has its limitations. Through proper research RCA can be used in the appropriate field applications. This is could involve using a low percentage of RCA as replacement, use in only an indoor application, use in a forgiving climate or use in a non-structural application.

\subsection{Research significance}

The study of RCA in Canada has become increasingly popular but very few have investigated preserving the original qualities of returned-to-plant concrete. Additionally, comparing the RCA with preserved quality to commercially available RCA may prove to be significant in changing the 
way returned-to-plant is handled. Increasing the volume of RCA used as replacement in concrete applications will alleviate the space taken up in landfills by concrete waste. Furthermore, increasing the volume of RCA used as replacement would enhance sustainability and reduce costs involved in acquiring virgin aggregate (VA), and its processing and transportation.

\subsection{Research Objectives and Scope}

This study aims to promote the use of RCA in concrete for different field applications. Additionally, this study proposes to increase the volume of RCA used as a coarse aggregate replacement. Specifically, this study aims to incorporate RCA in concrete of different class exposures and varying strengths.

The study looks at changing the way returned-to-plant is handled and turned in RCA. The main objective of this study is to investigate RCA with preserved quality under many facets including aggregate properties. Additionally, the study will investigate the fresh and mechanical properties as well as the durability of concrete incorporating RCA with preserved quality and compare it to commercially available RCA. To obtain RCA of preserved quality, a protocol for handing and processing the returned concrete is adopted and will be presented in this thesis.

Concrete incorporating a varying percentage of RCA as replacement was cast using primarily three mix designs. Concrete was cast to conform to two different class exposures, C2 and F1 as well a low strength (15 MPa) concretes. These specimens were tested to ensure the hardened concrete mechanical properties such as compressive strength and drying shrinkage requirement were met. 
Specimens were also tested for splitting tensile strength and permeability. Further, durability against salt scaling was done using the standard salt scaling test.

The testing and research performed in this study aim to produce concrete incorporating RCA that is able to meet certain class exposure and durability requirements. It also aims at showing that RCA quality can be preserved to a large extent if the handling of returned concrete and the processing of RCA is carried out under some quality control guidance. The results from this study will promote future research towards controlling returned-to-plant concrete before it is crushed into RCA as well as the use of RCA in a higher volume as a replacement for VA in large-scale concrete applications. 


\section{Literature Review}

\subsection{Recycled Concrete Aggregate}

In a constantly evolving society there stems a need to develop and improve the current infrastructure. In order to build new infrastructure, building materials such as concrete will be needed. The raw materials needed for the aggregates and cements come from natural resources that do not get replaced. In the addition the energy needed to acquire these raw materials is very costly. The previous infrastructure such as old roads and buildings that is demolished is often considered worthless and disposed of as demolition waste (McNeil and Kang, 2013).

The use of RCA is able to reduce the rate of depletion of our natural aggregate.

Construction is often associated with many environmental issues, including the depletion of raw materials, consumption of energy and the creation of waste. The use of RCA is considered to be a more sustainable option. (Oikonomou, 2005)

One form of recycled concrete aggregate is returned-to-plant concrete. This involves fresh concrete that has been returned to the batching plant, discharged from the transit mixer and left to harden. The hardened concrete is the crushed and sieved to produce RCA. RCA has seen use all around the world, particularly in North America and Europe. In 1994, Holland used 78,000 tons of RCA and reported that the use of $20 \%$ of coarse RCA resulted in no differentiation of the fresh or hardened properties (Oikonomou, 2005). 
Although research in RCA has steadily increased, it has been limited in the type of application. RCA has been limited to use in mainly non-cement based applications, such as unbound road base and backfill (Tam, Gao \& Tam, 2005). RCA has also been used in low strength applications such as unshrinkable-fill (U-fill). U-fill is a controlled low-strength material (CLSM) commonly used for backfilling utility cuts (Kolahdoozan et al., 2014).). In a study performed by Kolahdoozan et al. (2014), RCA was used as a coarse aggregate replacement in a U-fill field application. At a 70\% replacement, they found considerable segregation due to the high volume of coarse aggregate. A mix of 55\% RCA and $45 \%$ natural sand produced results comparable to U-fill mixtures using natural gravel and sand and did not show any signs of segregation.

One way RCA is different from virgin aggregate is the presence of residual or adhered mortar that surround the original stone. When the RCA is used as coarse aggregate in a new concrete mixture it is introduced to new paste or mortar. The hardened properties of the concrete become affect by both the adhered mortar from the original mix as well as the new paste. Figure 1 depicts concrete incorporating RCA. 


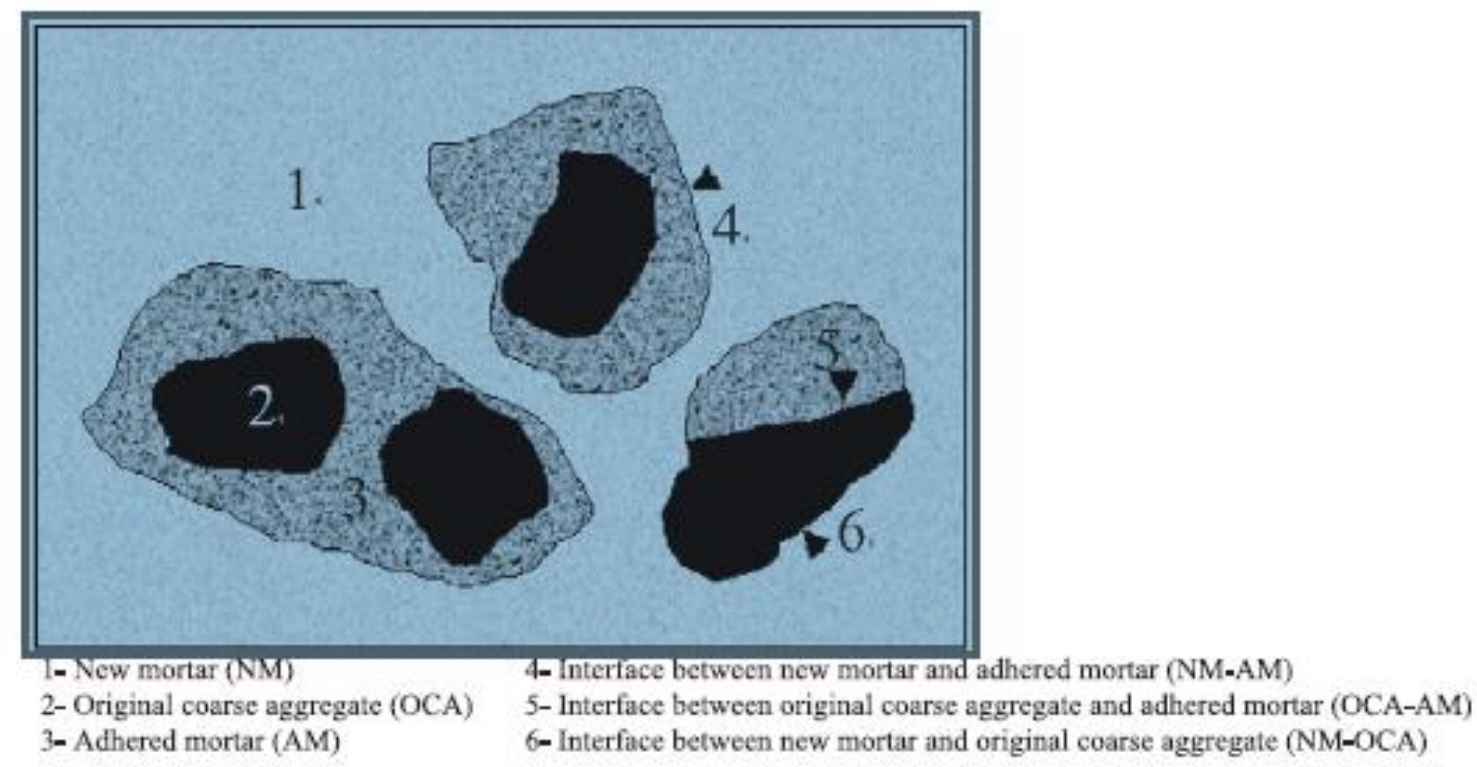

Figure 1: Concrete containing RCA (Gokce et al., 2003)

\subsection{Physical Properties of RCA}

RCA and virgin aggregate differ in many categories. The physical properties of RCA such as shape, texture, specific gravity, bulk density, pore volume and absorption are generally worse than those of virgin aggregate. Due to the intense processing that RCA goes through, it tends to be very angular and rough. In addition, RCA has a lower specific gravity and bulk density while having a higher pore volume and absorption when compared to virgin aggregate. This is due to the presence of the adhered mortar and its porous nature (Sagoe- Crentsil et al., 2001). A summary of the physical properties of virgin aggregate and RCA can be seen in Table 1. 
Table 1: Physical properties of virgin aggregate and RCA $(E C C O, 1999)$

\begin{tabular}{lll}
\hline Physical property & Virgin Aggregate & RCA \\
\hline Shape and texture & $\begin{array}{l}\text { Well rounded, smooth } \\
\text { (gravels) to angular and } \\
\text { rough (crushed rock) }\end{array}$ & $\begin{array}{l}\text { Angular with rough } \\
\text { surface }\end{array}$ \\
\hline Specific gravity (SSD) & $2.4-2.9$ & $2.1-2.5$ \\
\hline $\begin{array}{l}\text { Bulk density } \\
\text { (compacted) }\left(\mathrm{kg} / \mathrm{m}^{3}\right)\end{array}$ & $1450-1750$ & $1200-1425$ \\
\hline Absorption $(\%)$ & $0.5-4$ & $3-12$ \\
\hline Pore volume $(\%)$ & $0.5-2$ & $5-16.5$ \\
\hline
\end{tabular}

The mechanical properties of virgin aggregate and RCA are also very different. RCA tends to have a higher aggregate abrasion value, crushing value and impact value. All three of these tests indicate RCA having an overall weaker structure, which is a result of the adhered mortar (Sagoe- Crentsil et al., 2001). The mechanical properties of RCA are largely dependent on the quality of the residual mortar of the original mixture (Chakradhara et al., 2011)

\subsection{Hardened Properties of Concrete containing RCA}

Generally, there is a decline in the hardened properties of concrete incorporating RCA when the percentage of RCA increases. The compressive strength of RCA concrete tends to be lower than that of virgin aggregate concrete. It can be decreased up to $25 \%$ depending on the quality of RCA (Hansen, 1992). A study presented by Kwan et al. (2012) indicated that there exists a trend between the amount of RCA used as replacement coarse aggregate and compressive strength. The $100 \mathrm{x}$ $100 \times 100$ mm cube specimens used 15\%,30\%, 60\% and 80\% RCA. Their results, which can be seen in Figure 2, indicated that the increase the percentage of RCA used as replacement led to a 
decrease in compressive strength. They suggested that the decrease in compressive strength was due to the poor quality of adhered mortar.

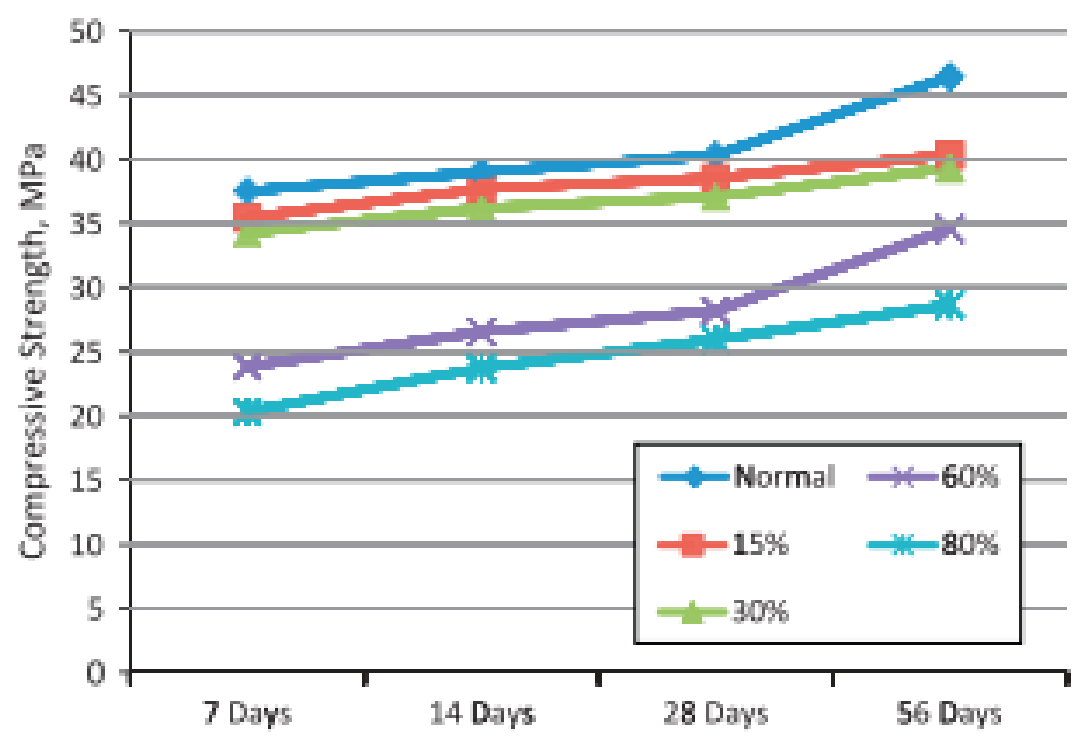

Figure 2: The average compression strength of concrete containing a various percent of RCA (Kwan et al. 2012)

Additionally, they indicated that when RCA undergoes the crushing process zones of weakness in the RCA are created. Nelson (2012) also supported this trend and their results can be seen in Figure 3. 


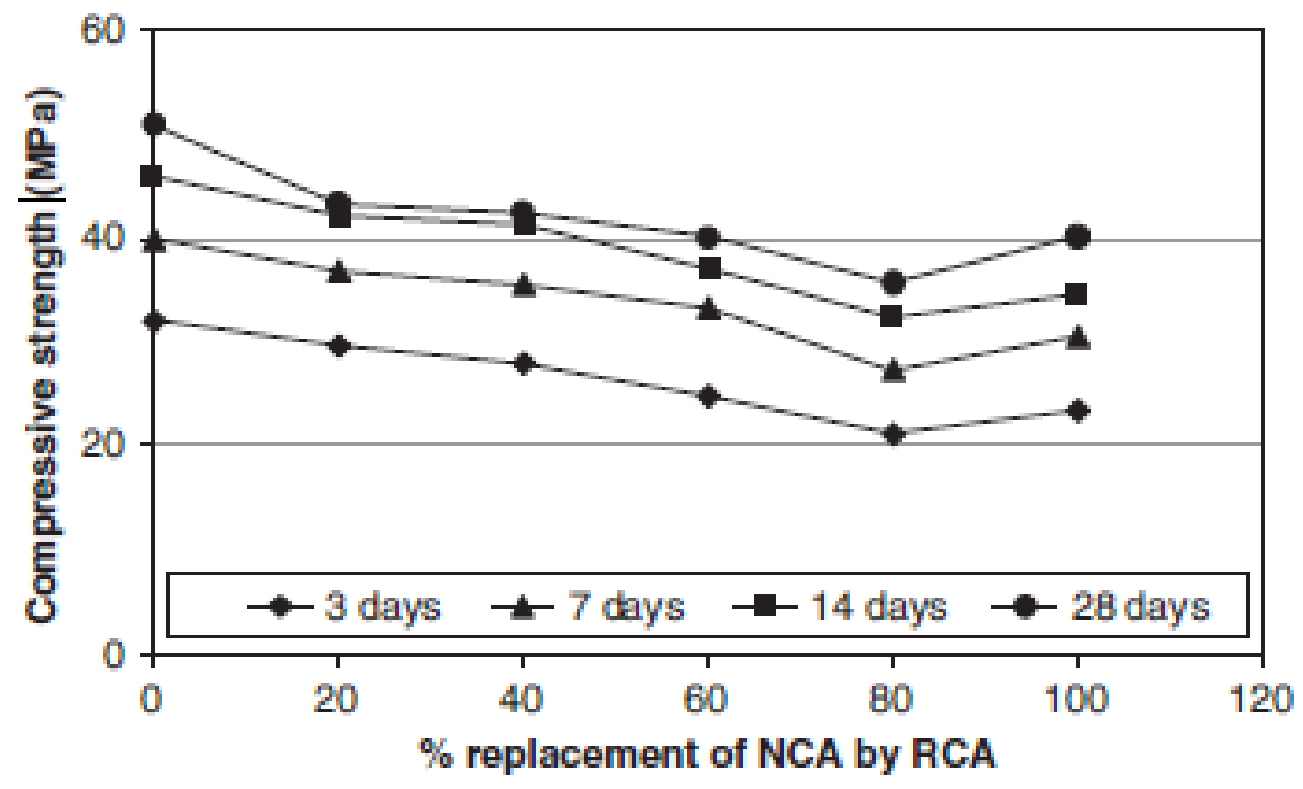

Figure 3: The Effect of RCA on compressive strength (Nelson, 2004)

A study performed by Salau et al. (2014) investigated concrete at a water/cement ration of 0.52 containing RCA at $25 \%, 50 \%$ and $100 \%$ replacement. They confirmed that the increase in RCA replacement led to a decrease in compressive strength. Their compressive strength results in 150 x 150 x $150 \mathrm{~mm}$ cube specimens can be seen in Figure 4. Salau et al. (2014) attributed the decrease in compressive strength to the adhered mortar, low specific gravity and high water absorption of RCA. Additionally, it is stated that the strength of concrete containing RCA is governed by the weaker interface between the adhered mortar and the original stone and between the adhered mortar and the new mortar. 


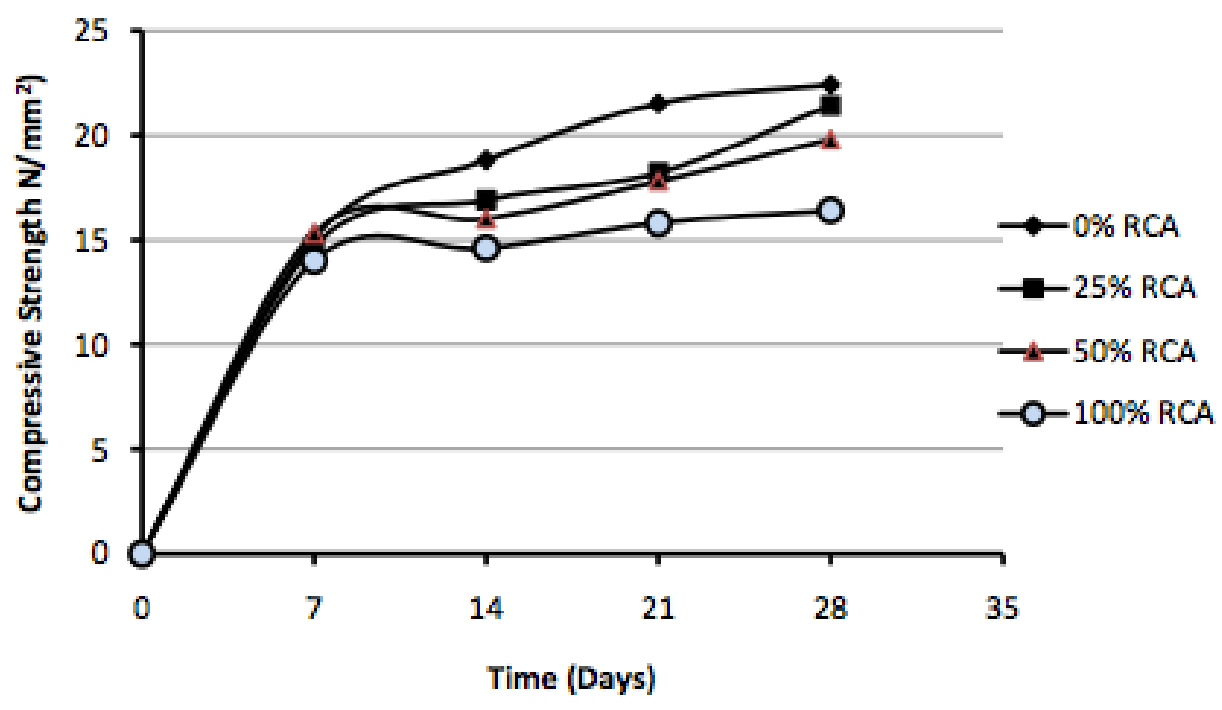

Figure 4: The compressive strength over time of concrete incorporating RCA (Salau et al., 2014)

There are some cases in which RCA concrete can have a similar or higher compressive strength when compared to virgin aggregate concrete. Padmini et al. (2009) stated that if the RCA is obtained from concrete with a lower water to cement ratio than that of the new concrete it can achieve comparable or sometimes higher compressive strengths compared to virgin aggregate concrete.

Several studies have indicated that splitting tensile strength is less affected by RCA content than compressive strength. (Mcneil \& Kang, 2013). Exteberria et al. (2007) states that while the adhered mortar in RCA creates a weakened spot for compressive failure, in limited quantities it can improve tensile strength by creating a smoother transition between mortar and aggregate. Yang et al. (2008) stated that one way to improve the tensile strength of concrete incorporating RCA is to choose a RCA source that has a lower water/cement ratio and higher overall strength. A study performed by Qasrawi and Marie (2013) used $100 \times 100$ x $500 \mathrm{~mm}$ prisms to investigate tensile 
strength of concrete incorporating RCA at a various replacement levels. Their study indicated that the use of RCA resulted in reduction in tensile strength. They further stated that higher strength concrete suffered more tensile strength reduction. Their results can be seen in Figure 5.

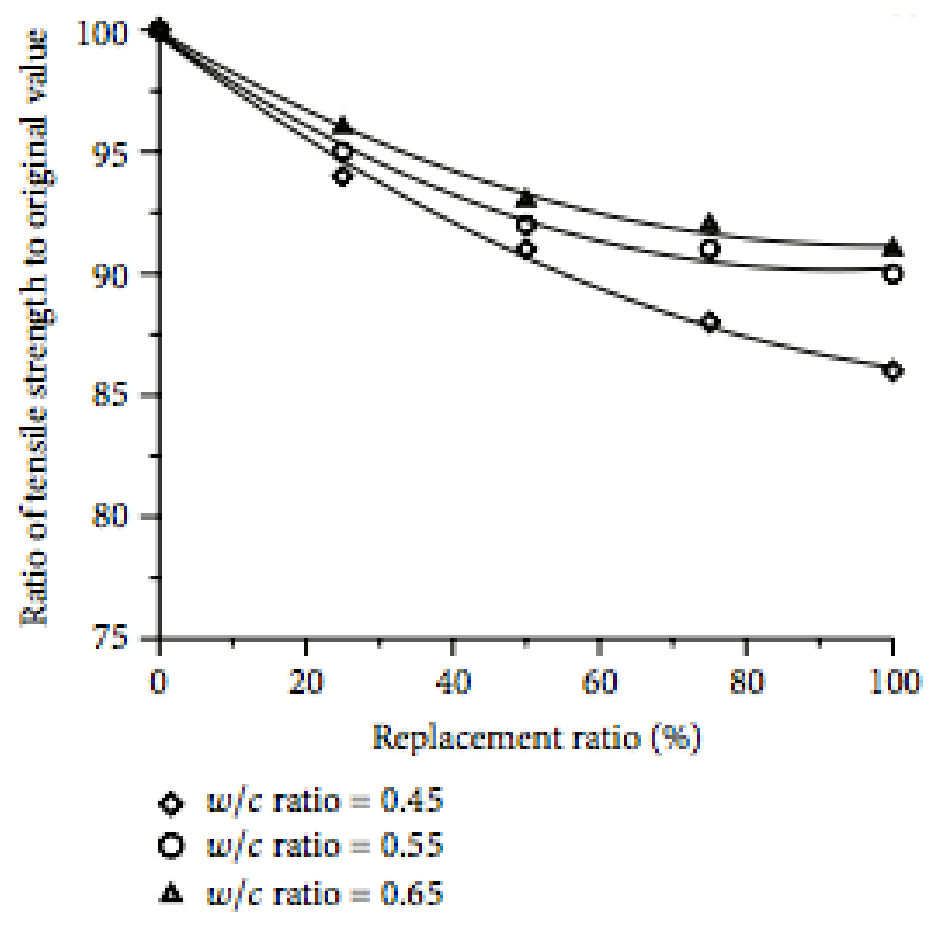

Figure 5: The relationship between $R C A$ replacement and the reduction in 28 day tensile strength (Qasrawi \& Marie, 2013)

Many factors contribute to shrinkage, including cement type and quantity, water/cement ratio, aggregate type and quantity, size of the specimen and the relative humidity of the environment (Boucherit et al., 2014). Drying shrinkage is a result of the loss of moisture from the concrete. This moisture loss can be attributed to the decrease in the internal relative humidity of the concrete. The shrinkage cause tensile stresses that propagate into cracks and deformation (Mu et al., 2011). The aggregate serves as a restraint on the shrinkage of the cement paste (Fujiwara, 2008). Capillary pores and gel pores have the greatest impact on shrinkage (Guo et al., 2013). 
Many studies have reported that RCA concrete experiences greater shrinkage than natural aggregate concrete (Guo et al., 2013). A study performed by Guo et al. (2013) using 100 x 100 x $515 \mathrm{~mm}$ specimens and in accordance with Chinese standard GB/T 50082-2009 indicated that increasing the percent replacement of RCA also increases the drying shrinkage. The results can be seen in Figure 6.

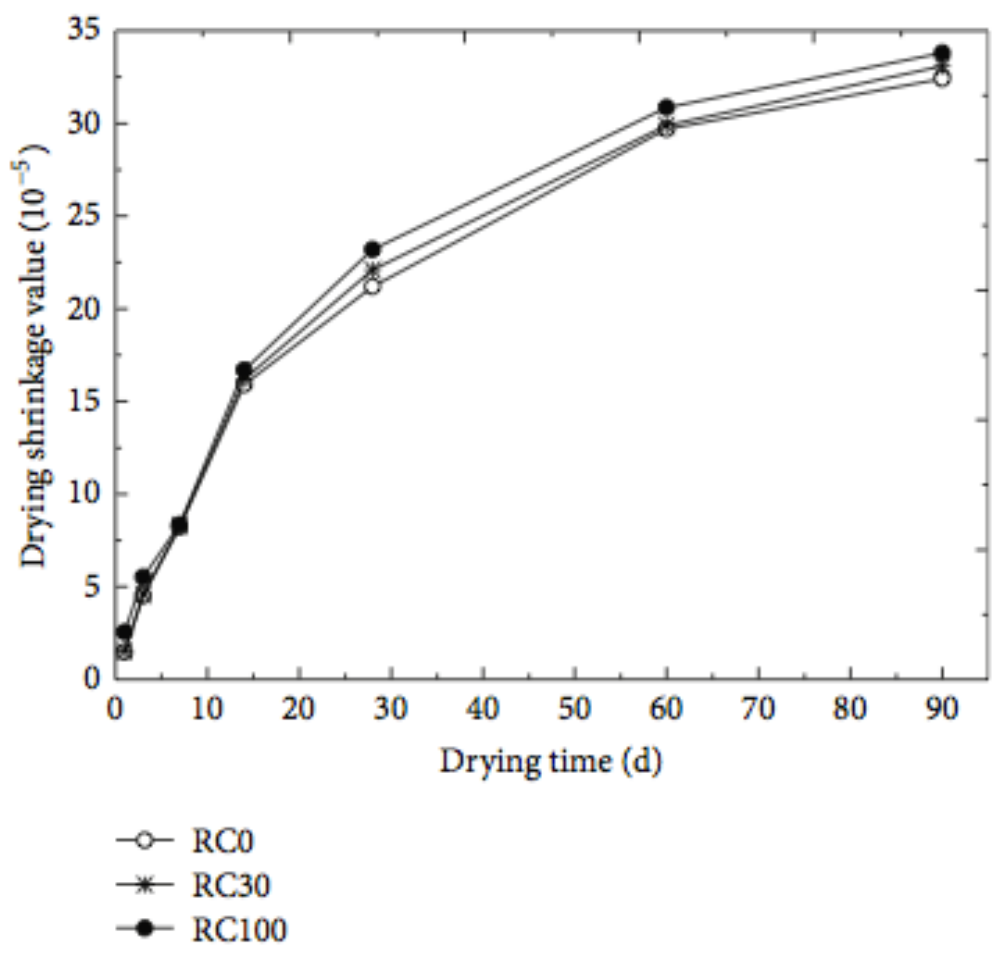

Figure 6: The influence of RCA replacement on drying shrinkage (Guo et al., 2013)

They suggested that porosity and in particular, pore type, have a significant impact on shrinkage. They discovered that the addition of RCA also increased the porosity of the capillary pores. Figure 7 illustrates influence of RCA on the porosity. Additionally, Guo et al. (2013) concluded that the RCA specimens contained more pores of sizes $2.5 \mathrm{~nm}$ to $50 \mathrm{~nm}$ and $50 \mathrm{~nm}$ to $100 \mathrm{~nm}$, which are considered to have the greatest impact on shrinkage. 


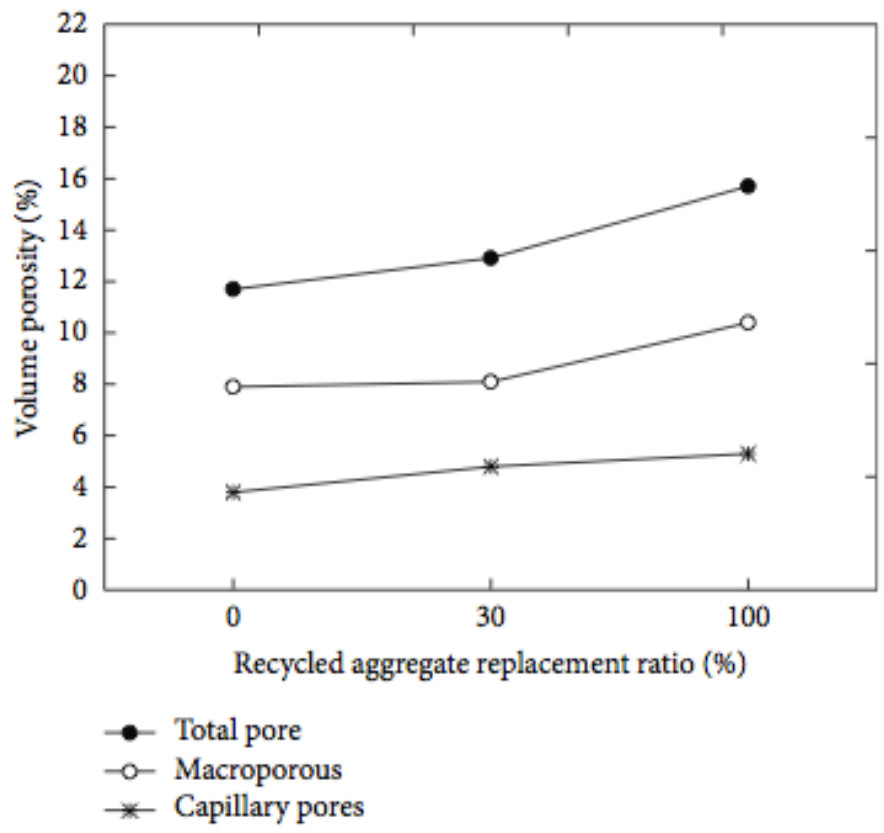

Figure 7: The influence of RCA replacement on the porosity of recycle aggregate concrete (Guo et al., 2013)

The incorporation of RCA has been known to also increase drying shrinkage. This is widely attributed to the adhered mortar surrounding the original stone. A study performed at Missouri University (2014) indicated as increase in shrinkage as a result of the increase in RCA replacement. Using $75 \times 75 \times 285$ prism specimens in accordance with ASTM C157, the study revealed that the $100 \%$ RCA specimens at a 0.40 water/cm ratio experienced $0.06 \%$ shrinkage after 200 days. The results can be seen in Figure 8. 


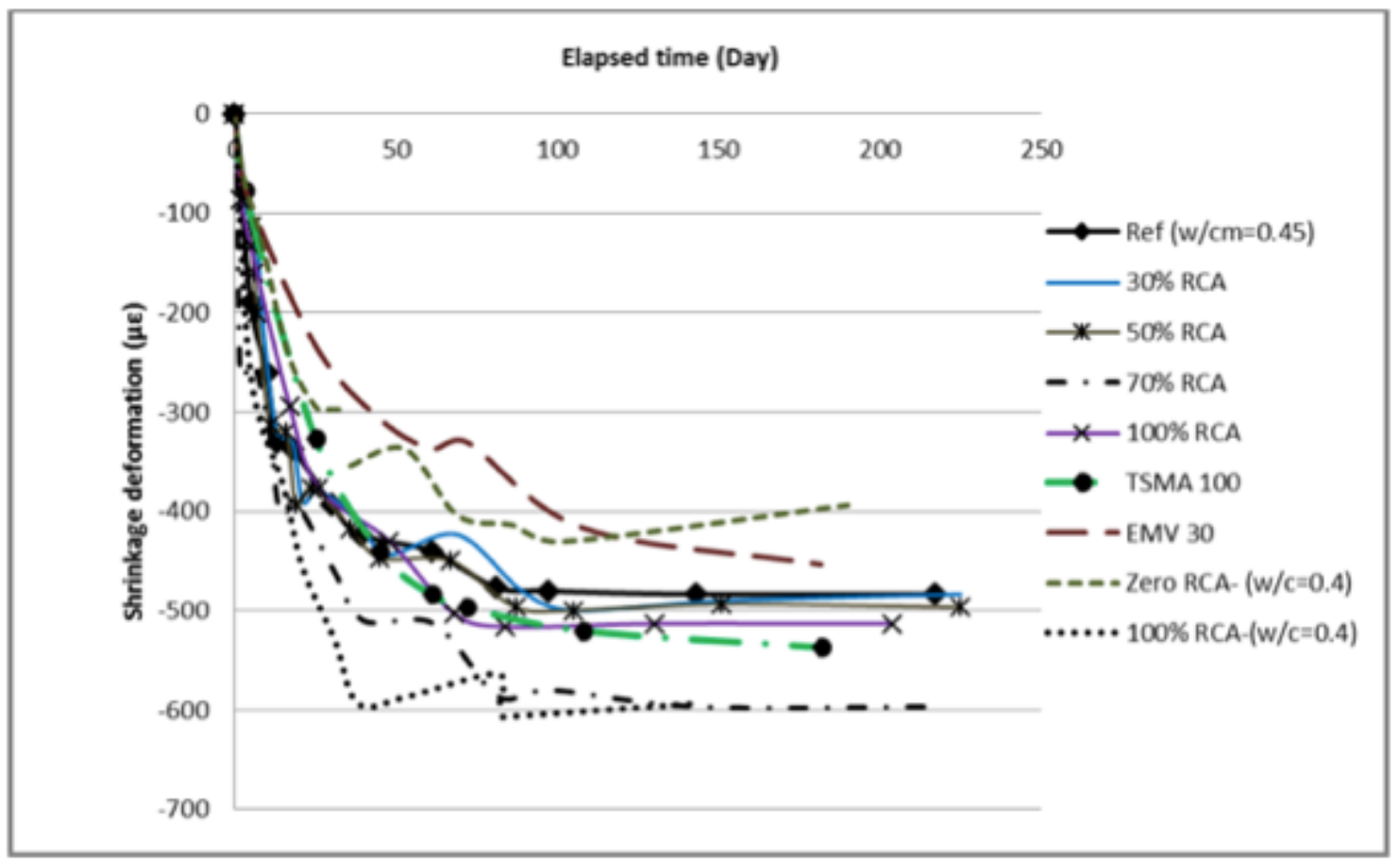

Figure 8: The shrinkage of specimens with a variety of RCA replacement (Missouri University, 2014)

A study performed according to ASTM C157 by Faithifazal et al. (2011) using 100 x 100 x 285 mm specimens produced results that indicated an increase in RCA replacement also increased drying shrinkage using a conventional mixing method after 250 days. The results are illustrated in Figures 9 and 10. 


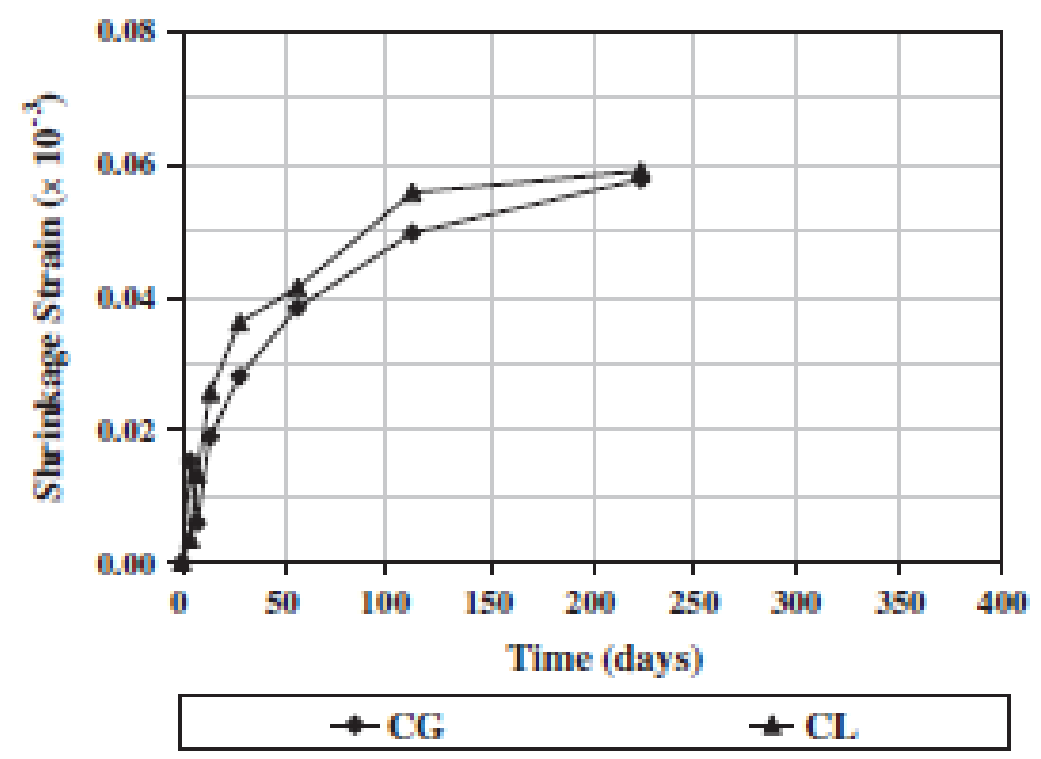

CG: Concrete containing $100 \%$ gravel using conventional mixing procedure CL: Concrete containing $100 \%$ limestone using conventional mixing procedure

Figure 9: The drying shrinkage of concrete containing limestone and gravel (Faithifazal et al., 2001)

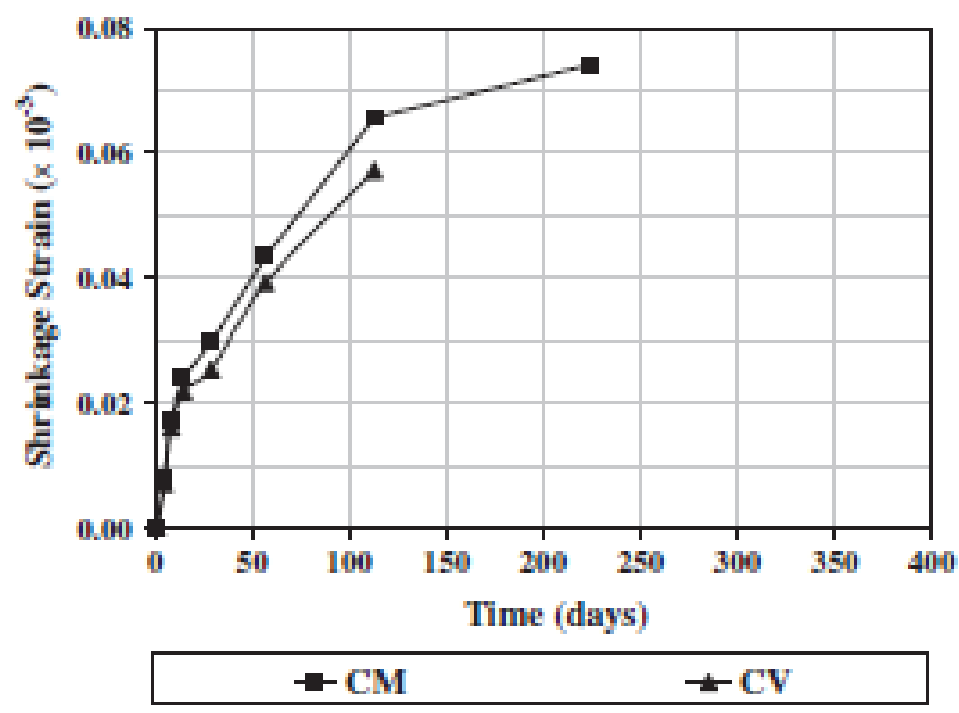

CM: Concrete containing 100\% RCA from a Montreal, Canada CV: Concrete containing 100\% RCA from a Vancouver, Canada

Figure 10: The drying shrinkage of concrete containing RCA (Faithifazal et al., 2001) 
A study performed by Salau et al. (2014) using 100 x 100 x $400 \mathrm{~mm}$ specimens confirmed that the incorporation of RCA in concrete increases drying shrinkage. Their results, displayed in Figure 11 , indicate a $36 \%$ increase in drying shrinkage with a RCA replacement of $25 \%$. Salau et al. (2014) attributed the increase in drying shrinkage to the stiffness or compressibility of the RCA. The lack of stiffness allows the concrete containing RCA to shrink more. The study also concluded that RCA itself shrinks due to the adhered mortar and that the quality of aggregate ultimately determines potential for strength and resistance to shrinkage. It should be noted that the temperature ranged from 27 to $32{ }^{\circ} \mathrm{C}$ while the relative humidity ranged from 85 to $96 \%$ during the entirety of the test.

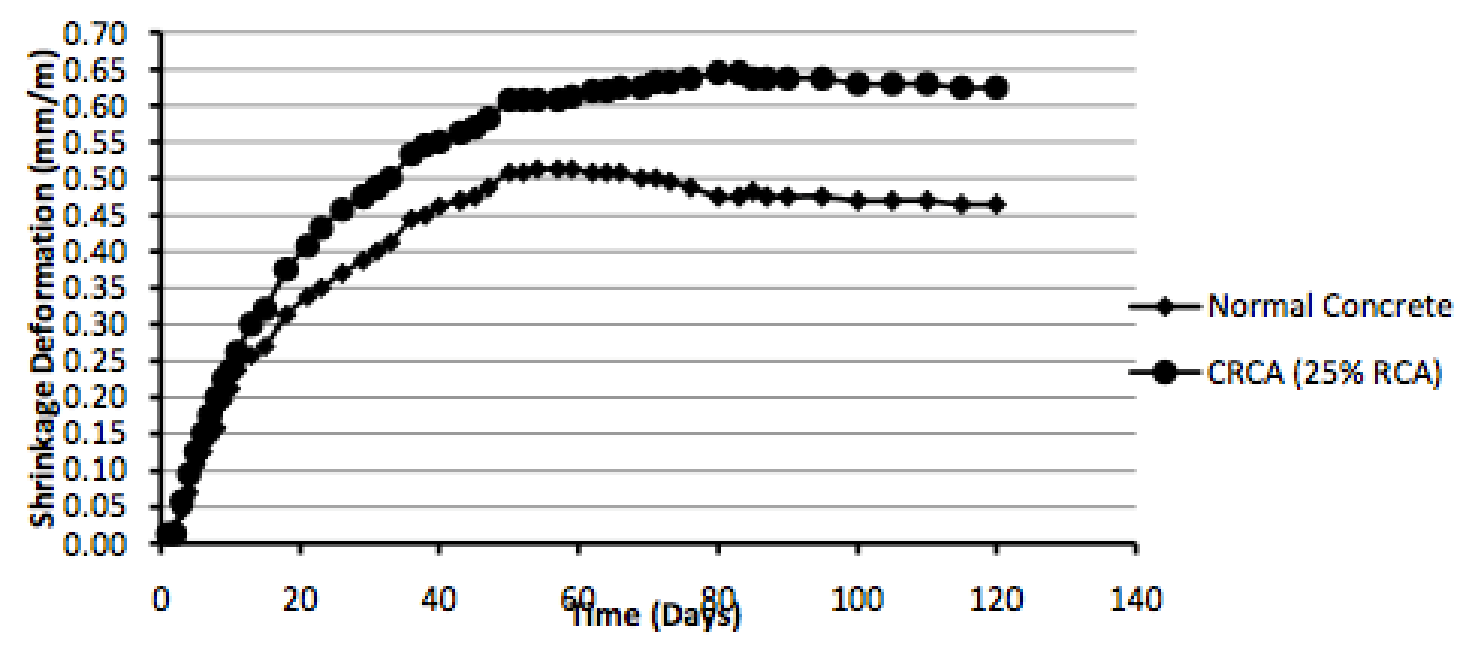

Figure 11: The drying shrinkage of concrete with 25\% RCA (Salau et al., 2014)

The use of a shrinkage reducing admixture (SRA) has shown to reduce shrinkage in concrete containing RCA (Sucic, 2013). Results from a study performed by Sucic (2013) is illustrated in 
Figure 12 and indicates that SRA was able to significantly reduce shrinkage in concrete specimens containing $100 \%$ RCA. He discovered that using the max dosage recommended by the supplier was able to reduce the shrinkage of $100 \%$ RCA and $30 \%$ slag specimens to a level comparable to that of the virgin aggregate specimens.

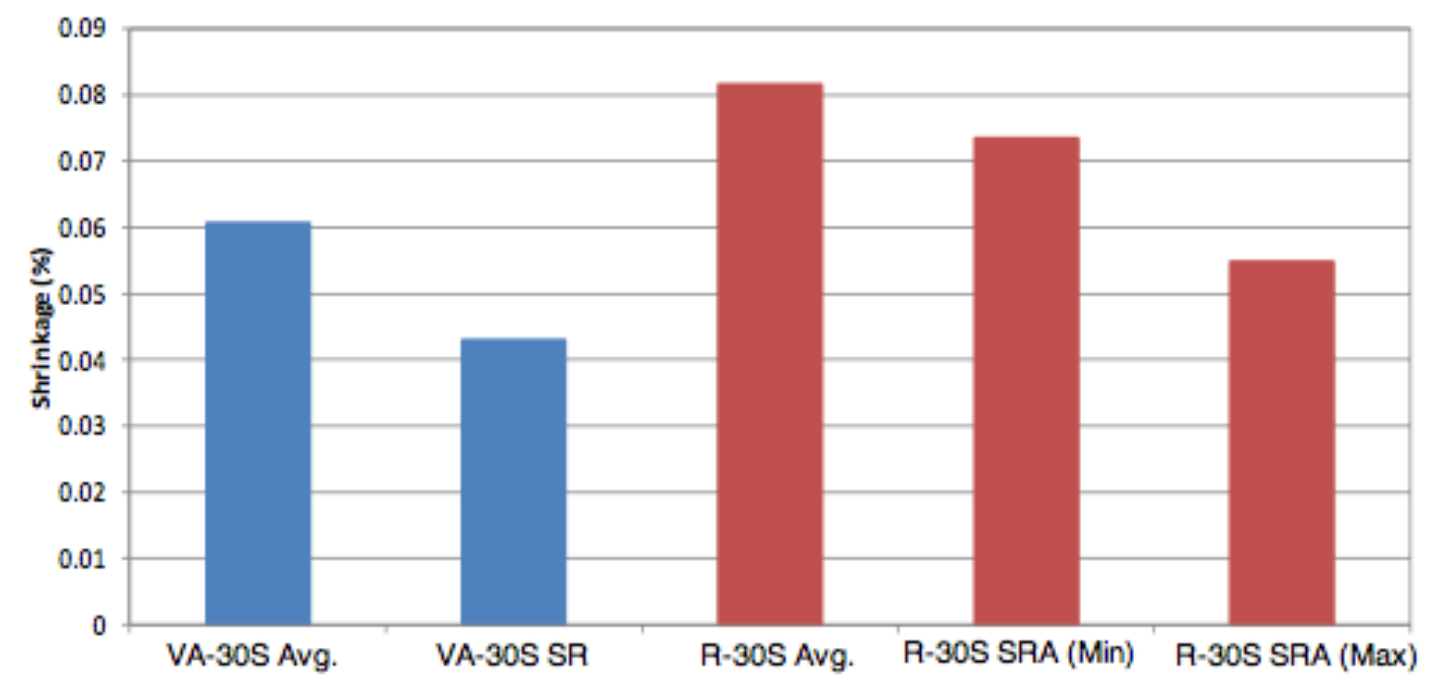

Figure 12: The drying shrinkage of virgin aggregate (VA) and RCA concrete containing SRA at 180 days (Sucic, 2013)

Bissonnette et al. (1999) suggested that if specimens contain the same water to cement ratio, the specimen having a higher total volume of water experienced higher shrinkage. This was supported by other researchers, such as Zhang et al. (2014) who stated that specimens with a higher volume of water per cubic metre would result in a higher drying shrinkage, even in specimens containing the same w/cm ratio. Anderson et al. (2009) reported 20-50\% higher drying shrinkage when compared to VA concrete. A summary of the effect of RCA on the hardened properties of concrete can be seen on Table 2 . 
Table 2: The effect of RCA on hardened properties of concrete (Safiuddin et.al, 2012)

\begin{tabular}{lc}
\hline Property & Range of changes \\
\hline Dry density & $5-15 \%$ less \\
\hline Compressive strength & $0-30 \%$ less \\
\hline Splitting tensile strength & $0-10 \%$ less \\
\hline Flexural strength & $0-10 \%$ less \\
\hline Bond strength & $9-19 \%$ less \\
\hline Modulus of elasticity & $10-45 \%$ less \\
\hline Porosity & $10-30 \%$ more \\
\hline Permeability & $0-500 \%$ more \\
\hline Water absorption & $0-40 \%$ more \\
\hline Chloride penetration & $0-30 \%$ more \\
\hline Drying shrinkage & $20-50 \%$ more \\
\hline Creep & $30-60 \%$ more \\
\hline Thermal expansion & $10-30 \%$ more \\
\hline
\end{tabular}

\subsection{Fresh Properties of Concrete containing RCA}

Additionally, RCA also has an effect on the fresh properties of concrete. There is a decrease in workability when incorporating RCA. The greater angularity and surface roughness are contributing factors (Yrjanson, 1989). Additional water would be needed to obtain the same workability as concrete made with virgin aggregate. The high absorptive property of RCA can lead to a rapid loss of workability. There is generally less bleeding in concrete incorporating RCA. This is a result of the increase in fines when the old adhered mortar is chipped away during the mixing process (Safiuddin et al., 2012). RCA is associated with higher absorptive properties due to the presence of the residual mortar attached to the primary stone. When dry RCA is used in mix designs without correcting for absorption, it can lower the effective water cement ratio, resulting in a higher compressive strength (Domingo-Cabo, et al., 2009. The influence of RCA on the fresh 
concrete properties is predicated its greater angularity, surface roughness, absorption and porosity (Safiuddin et al., 2012).

Hardened concrete made from virgin aggregate contains a plane of weakness known as the interfacial transition zone (ITZ). This zone contains a slightly higher water to cement ratio that the rest of the concrete (Scrivener et al., 2004). In concrete incorporating RCA, there are two zones of weakness. The first ITZ is between the primary aggregate and the residual mortar. The second ITZ if formed between the RCA and the fresh paste (Ryu, 2002). The ITZ is known to be more porous than the rest of the matrix. This can be due to two processes. A thin film of water created on the surface of aggregate, approximately $10 \mu \mathrm{m}$, where the cement particles are not present. Secondly, the aggregate particle acts as a wall that disperse the cement particles away. This is known as the wall effect (Cui et al., 2014). Since the ITZ is a plane of weakness it is significant in determining the overall preformance of the concrete. The mechanical properties of concrete produced using RCA is closley depenent on the quality of the conrete matrix and the interfacial bond between the RCA the fresh paste.

The two stage mixing approach (TSMA) proposed by Tam Gao \& Tam (2005) was aimed at improving the quality of recycle aggregate concrete. This is done by dividing the mixing process into two stages, splitting the mixing water as well. The procedure can be seen in Table 3 . The TSMA has been used to improve the ITZ between RCA and the new cement paste in fresh concrete. The TSMA uses the porous property of RCA to fill up some pores and crack to create a denser concrete matrix during the initial mixing process (Kong et al. 2010). 
Table 3: The two-stage mixing approach (TSMA) mixing procedure (Tam Gao \& Tam, 2005)

\begin{tabular}{llc}
\hline Step & Materials & $\begin{array}{c}\text { Mix duration } \\
\text { (seconds) }\end{array}$ \\
\hline 1 & Coarse and fine aggregate & 60 \\
\hline 2 & First half of the mixing water & 60 \\
\hline 3 & Cementing material & 30 \\
\hline 4 & Second half of the mix water & 120 \\
\hline
\end{tabular}

\subsection{Durability of Concrete Containing RCA}

Concrete incorporating RCA is widely known to have durability issues due to its porous nature. Impurities within coarse RCA lead to the loss of concrete resistance to aggressive environments (Poon et al., 2004). These impurities increase porosity and the risk to chemical attack (Ann et al., 2008). The high porous nature of RCA does not make it a good candidate when selecting coarse aggregate for concrete exposed to freeze thaw or harsh climates. A deterioration of any unsound particle within the RCA by constant freeze-thaw cycles would allow water to go into the surrounding cement paste and cause frost damage (Zaharieva, Buyle-Bodin \& Wirquin, 2004). Hwang et al. (2012) also noted the susceptibility of RCA concrete. The 100\% RCA replacement concrete specimens obtained severe frost damage before the completion of 200 cycles. They also discovered that the specimens incorporative 100\% RCA and 60\% GGBFS obtained a mass change of approximately $9 \%$ while the $100 \%$ RCA specimens obtained a mass change of approximately 17\%. The results can be seen in Figure 13. 


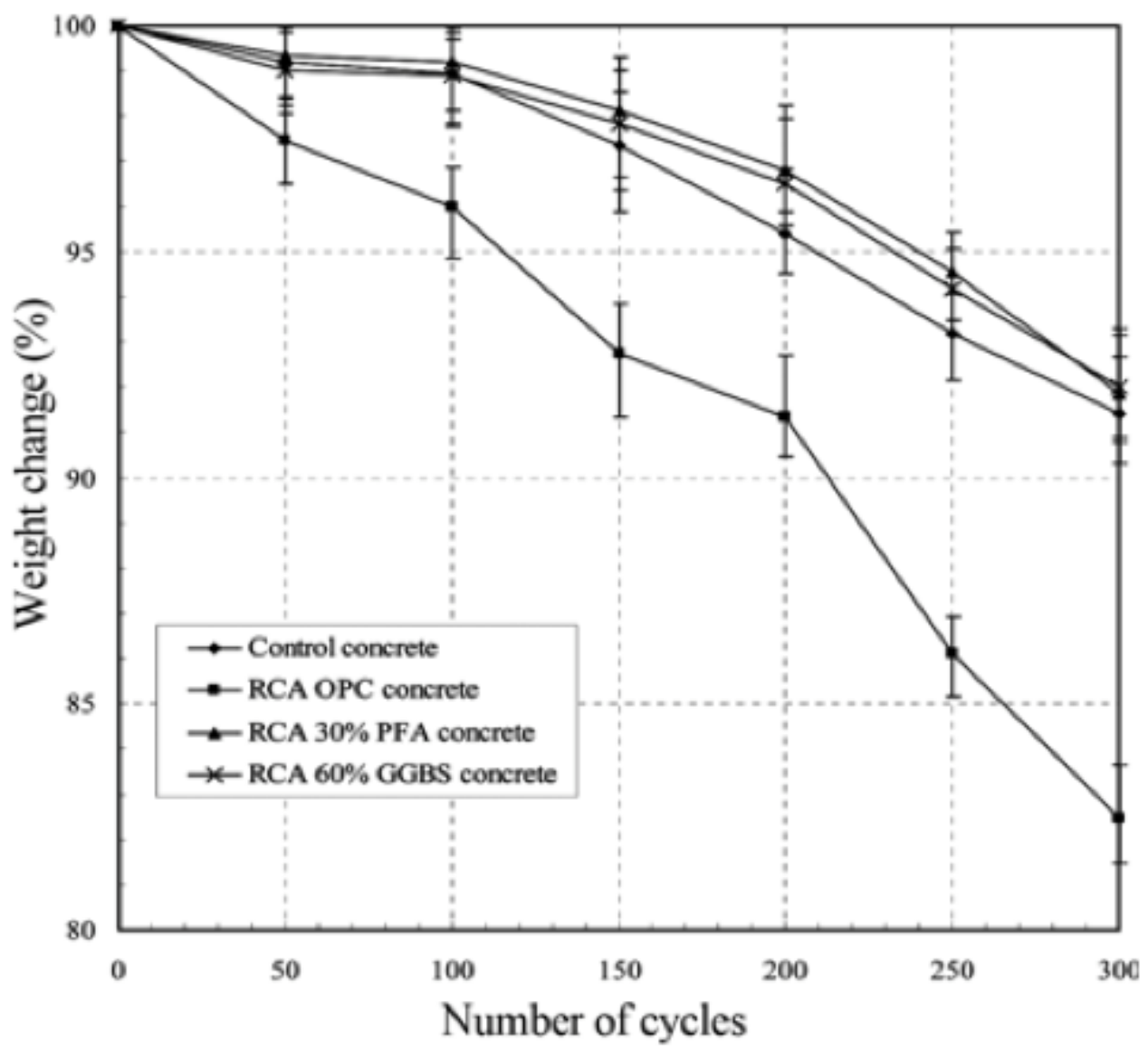

Figure 13: The mass change of specimens incorporating 100\% RCA for 300 freeze-thaw cycles (Hwang et al., 2012)

In a study performed by Huda \& Alam (2015), resulted showed that with an increase in RCA replacement there is also an increase in length change. The results can be seen in Figure 14. Although there was an increase in length change with the increase in RCA replacement, all specimens were able to satisfy durability performance using the durability factor in accordance with ASTM C666. 


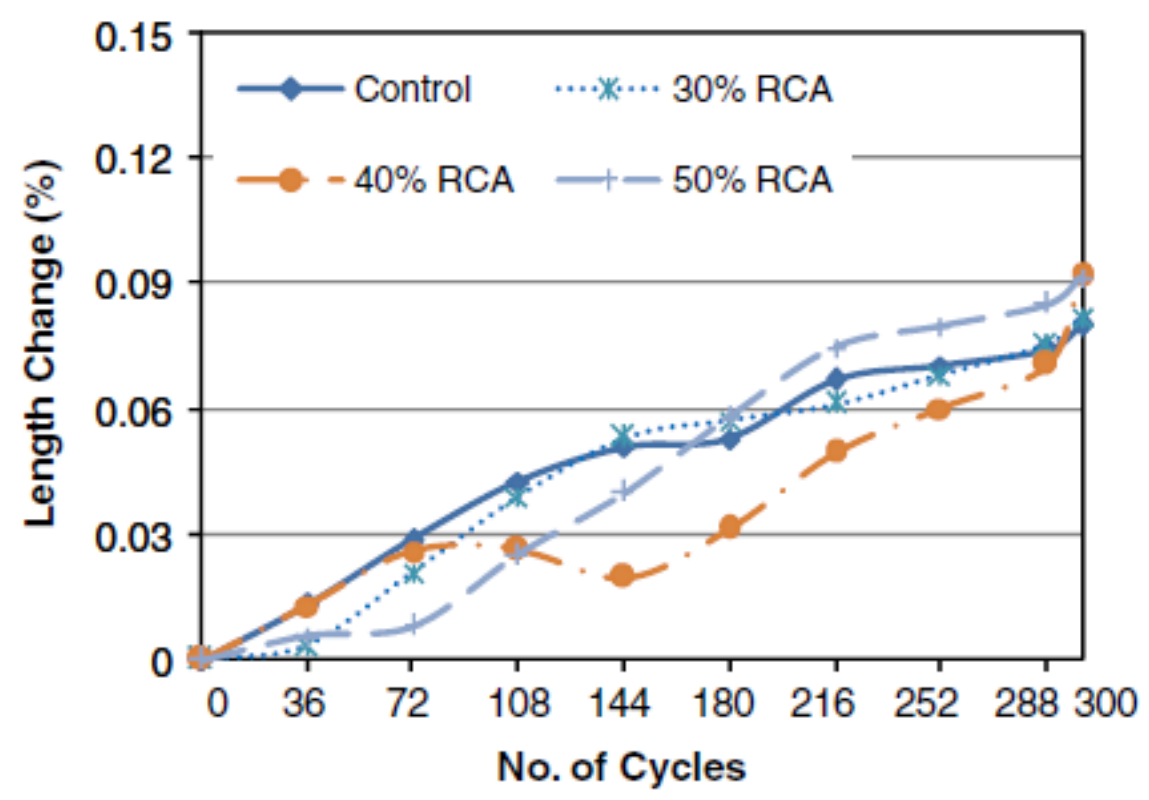

Figure 14: The length change of concrete specimens due to freezing and thawing (Huda \& Alam, 2015)

However, several studies have suggested that RCA concrete displays adequate resistance to freezethaw cycles (Safiuddin et al., 2012). Gokce et al. (2004) suggested that the durability of RCA concrete is dependent on the source of the original concrete. They found that RCA concrete made air entrained recycled aggregate performed better than RCA concrete made with non-air entrained recycled concrete. Yamato et al. (1998) reported a small reduction in resistance when incorporating RCA up to $30 \%$.

A study performed by Jain et al. (2012) investigate scaling resistance of concrete containing Type C fly ash and incorporating RCA up to a $100 \%$ replacement. These specimens were exposed to a $4 \% \mathrm{CaCl}_{2}$ solution for 50 freeze-thaw cycles. Jain et al. (2012) concluded that the specimens containing RCA achieved a satisfactory performance and experienced scaling equivalent to the 
control specimen. They attributed the RCA resistance to scaling to an efficient air void system. It should be noted that for this study, specimens were under freezing condition for 12-14 hours instead of the standard 16-18 hours set by ASTM C672. Bouzoubaa et al. (2008) suggested that finishing the surface of the specimen by brushing according to ASTM C672 has an effect on early scaling. They stated that if the brushing was done too early or much later after bleeding has stopped it can damage the air-void network and microstructural characteristics of the specimen. Bleed water can be entrapped beneath the surface of the specimen if the brushing was performed too early (Hooton \& Vassilev, 2012). Wu et al. (2015) suggests that the main factor in deterioration in concrete due to salt scaling is spalling and cracking. In their study, they confirmed the formation of Friedel's salt, which results from the reactions between $\mathrm{NaCl}$ or $\mathrm{CaCl}_{2}$ and calcium aluminate hydrates. The salt scaling resistance of concrete is often evaluated using visual inspection and given a visual rating. This rating is highly subjective, especially when the test surface is not severely deteriorated (Pigeon \& Pleau, 1995).

Several studies have also reported durability issues regarding rapid chloride permeability testing (RCPT). Tu et al. (2006) reported similar chloride penetration results in high performance concrete with and without RCA. Alternatively, Correal-Higuera et al. (2011) reported a decrease in 100\% RCA concrete to resist chloride penetration by $30 \%$ when compared to virgin aggregate concrete. RCA concrete tend to have higher drying shrinkage than VA concrete. (Safiuddin et al., 2012). The use of GGBFS has led to a decrease in permeability. The smaller particles associated with supplementary cementing materials refines pore space (Berndt, 2009). Hwang et al. (2012) confirmed that RCA concrete obtained higher levels of chloride penetration. They also reported 
that the use of $60 \%$ GGBFS reduced the rate of chloride penetration to a level equivalent to the control concrete after 91 days. A table of chloride ion penetrability based on charges passed as proposed by ASTM C1202 can be found on Table 4.

Table 4: The chloride ion penetrability based on charge passed (ASTM C1202)

\begin{tabular}{ll}
\hline Charge Passed (coulombs) & Chloride ion penetrability \\
\hline $\mathbf{4 0 0 0}$ & High \\
\hline $\mathbf{2 0 0 0 - 4 0 0 0}$ & Moderate \\
\hline $\mathbf{1 0 0 0 - 2 0 0 0}$ & Low \\
\hline $\mathbf{1 0 0 - 1 0 0 0}$ & Very low \\
\hline$<\mathbf{1 0 0}$ & Negligible \\
\hline
\end{tabular}




\section{Materials and Experimental Methods}

\subsection{Materials}

\subsubsection{Aggregates}

\subsubsection{Coarse Aggregate}

Two forms of RCA were used in this study and were denoted as RCA with preserved quality and commerical RCA. The RCA with preserved quality shown in Figures 15 and 16 and was produced from only returned-to-plant concrete and followed a protocol that aimed at maintaining or preserving the quality of the orginial concrete.

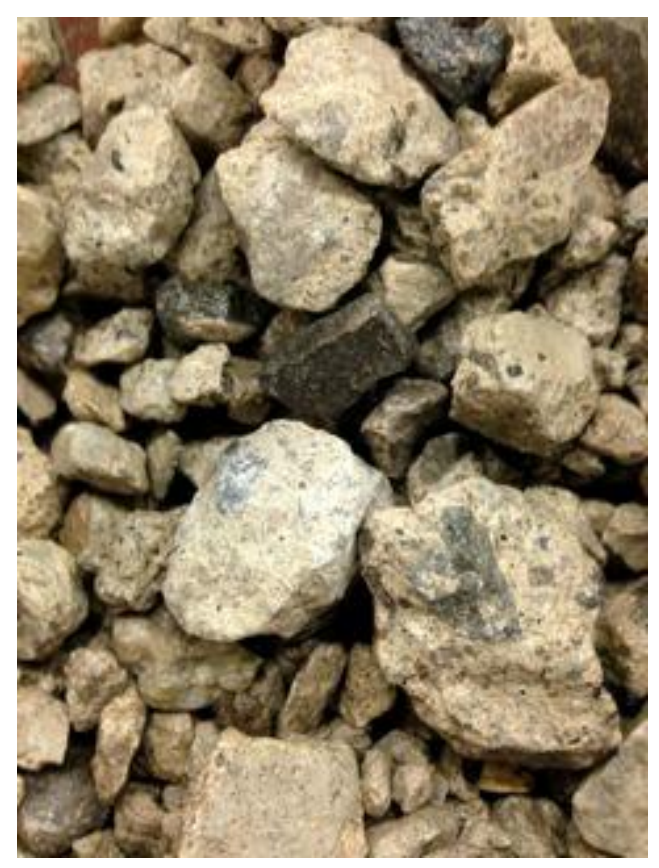

Figure 15: Sample of RCA with preserved quality produced in this study 


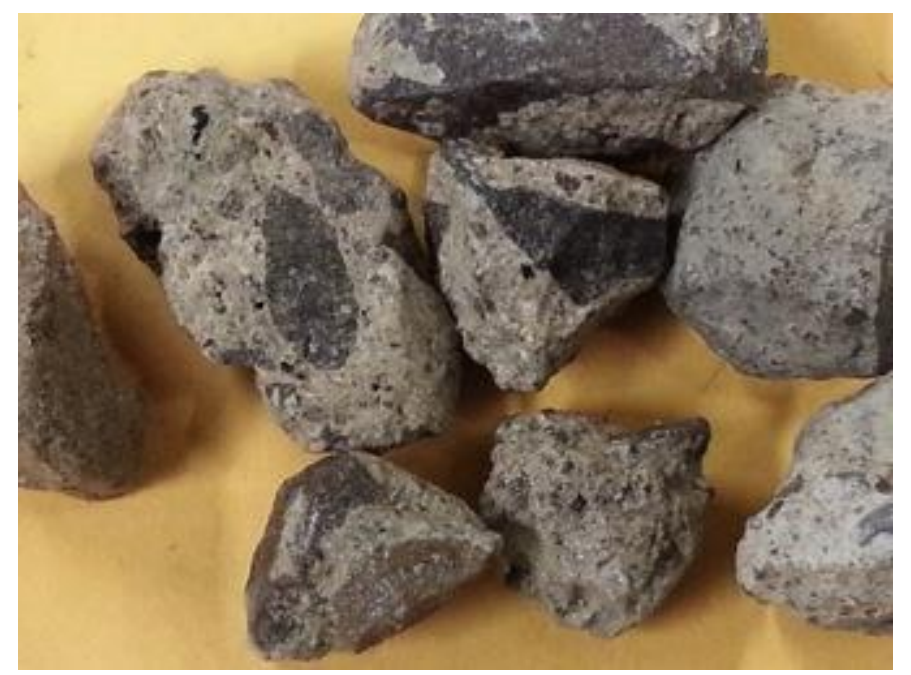

Figure 16: A Close-up of the preserved-quality RCA produced in this study

Previous studies, such as Sucic (2013) targeted controlling the mix design properties during the mixing process, to produce concrete of adequate quality. Contrary to the previous studies, this study aims to control RCA during production/processing. The protocol of producing the preservedquality RCA focused on: (a) separating the returned concrete based on its grade; i.e, strength (25 $\mathrm{MPa}$ and higher); and (b) controlling the addition of water while discharging the returned concrete from the transit mixer. The other form of RCA used in this study is denoted as commercial RCA and was used for comparison purposes and was also returned-to plant. The commercial RCA contains less than $1 \%$ deleterious material. The deleterious material includes gypsum board, wood, asphalt, ceramics or organics

The Dolostone coarse aggregate was used as a control specimen for this study. It was quarried in Hamilton, Ontario and is used in commercial concrete in Ontario and considered as high quality concrete aggregate 


\subsubsection{Fine Aggregate}

All trial mixes were cast using natural sand (NS) as fine aggregate. This fine aggregate is considered high quality concrete sand and was quarried in Caledon, Ontario and is used in commercial concrete in Ontario.

All aggregates gradation were according to CSA A23.1-2009 with $20 \mathrm{~mm}$ nominal size. The gradations can be seen in Figures 17 and 18. Aggregate properties can be seen in Table 5.

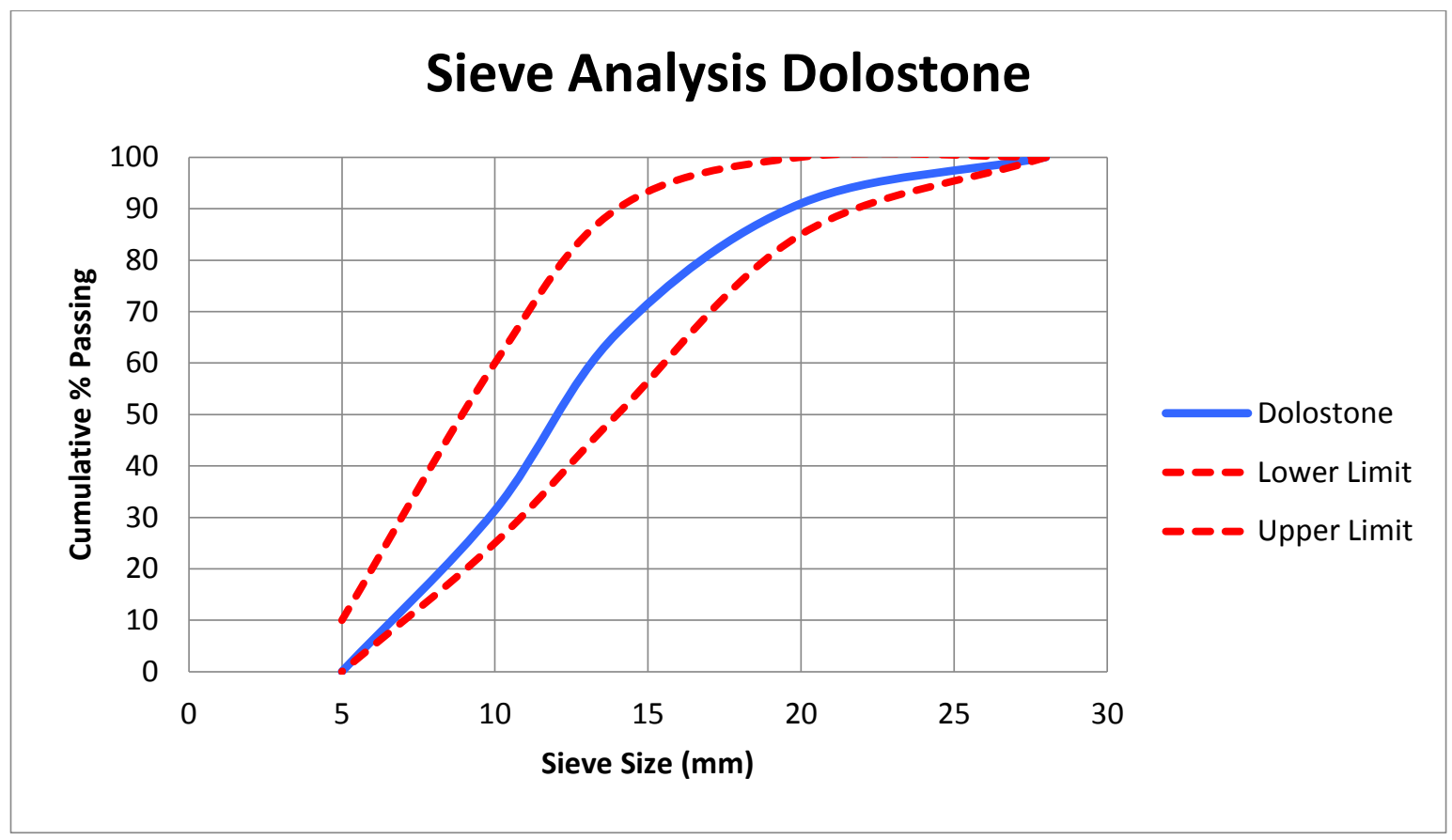

Figure 17: Gradation of the Dolostone aggregate 


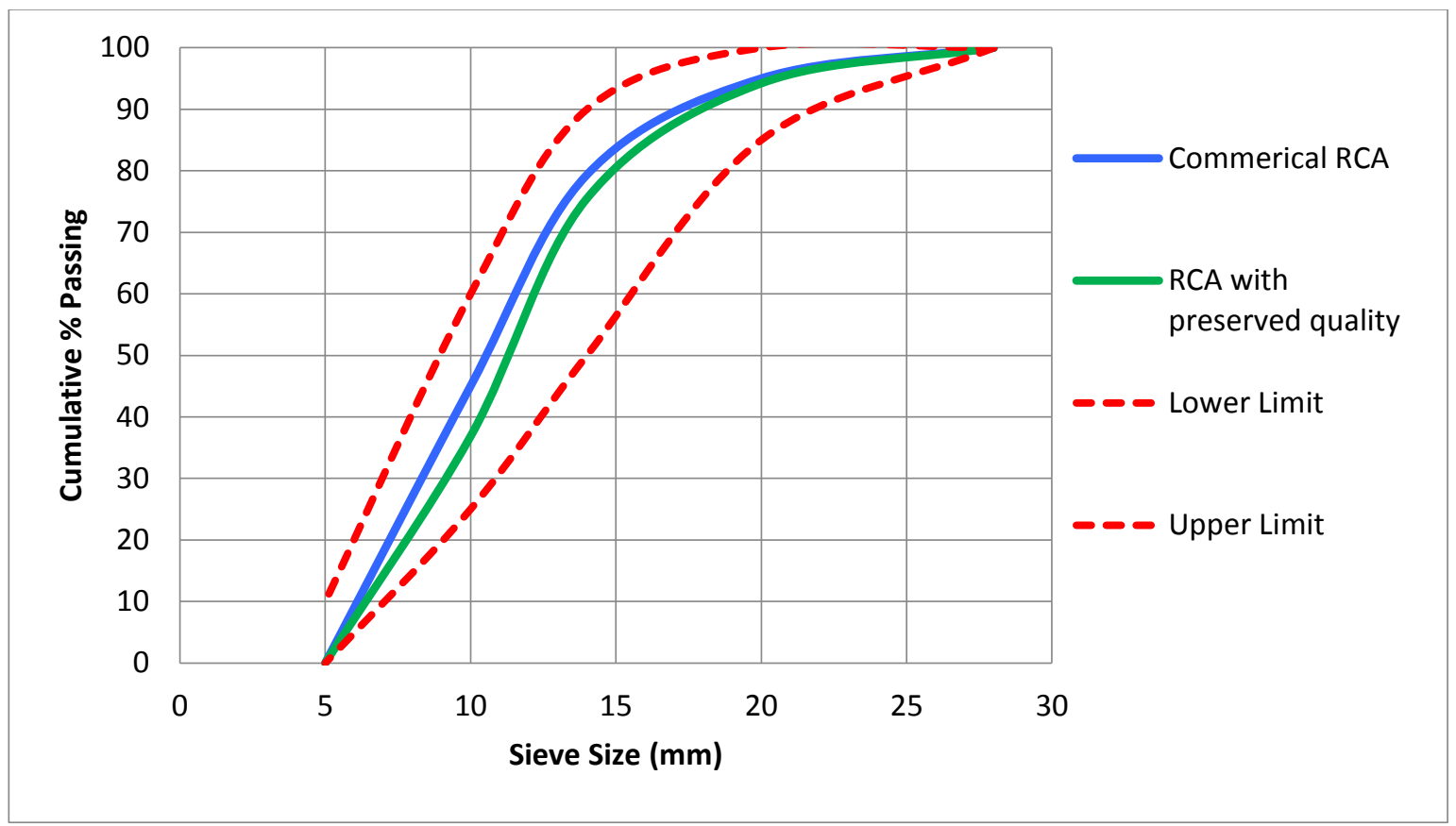

Figure 18: Gradation of the coarse commercial RCA and RCA with preserved quality

Table 5: Properties of the coarse and fine aggregate

\section{Coarse Aggregate}

RCA with

\begin{tabular}{|c|c|c|c|c|}
\hline & Dolostone & $\begin{array}{c}\text { RCA with } \\
\text { preserved } \\
\text { quality }\end{array}$ & $\begin{array}{c}\text { Commercial } \\
\text { RCA }\end{array}$ & Natural sand \\
\hline Absorption (\%) & 0.92 & 4.88 & 5.32 & 1.01 \\
\hline Bulk relative density $\left(\mathrm{kg} / \mathrm{m}^{3}\right)$ & 2720 & 2320 & 2310 & 2693 \\
\hline Dry-rodded density $\left(\mathrm{kg} / \mathrm{m}^{3}\right)$ & 1653 & 1418 & 1413 & -- \\
\hline Micro-deval loss (\%) & -- & 18.8 & 23.2 & -- \\
\hline
\end{tabular}
preserved quality

\begin{tabular}{|c|c|c|c|c|}
\hline & Dolostone & $\begin{array}{c}\text { RCA with } \\
\text { preserved } \\
\text { quality }\end{array}$ & $\begin{array}{c}\text { Commercial } \\
\text { RCA }\end{array}$ & Natural sand \\
\hline Absorption (\%) & 0.92 & 4.88 & 5.32 & 1.01 \\
\hline Bulk relative density $\left(\mathrm{kg} / \mathrm{m}^{3}\right)$ & 2720 & 2320 & 2310 & 2693 \\
\hline Dry-rodded density $\left(\mathrm{kg} / \mathrm{m}^{3}\right)$ & 1653 & 1418 & 1413 & -- \\
\hline Micro-deval loss (\%) & -- & 18.8 & 23.2 & -- \\
\hline
\end{tabular}

\section{Fine}

Aggregate 
Aggregate bulk densities were determined using CSA A32.2-6A for fine aggregate and CSA A23.2-12A for coarse aggregate. Micro-deval testing was performed according to Ministry of Transportation Ontario (MTO) LS-618 while dry-rodded density testing was performed according to CSA A23.2-10A.

\subsubsection{Cementing Materials}

All mixes were produced using general use (Type GU) Portland cement. Standard procedure was followed in accordance with all ready mix suppliers. Ground Granulated Blast Furnace Slag (GGBFS) was used as a supplementary cementing material to replace a percentage of cement. A $30 \%$ GGBFS replacement was used for all mixes with the exception of any C2 mix intended for use in salt scaling testing. A $15 \%$ GGBFS replacement was used for salt scaling specimens. A chemical analysis of the cementing materials can be found in Table 6 .

Table 6: Chemical analysis of the cementing materials

\begin{tabular}{lcccccccc}
\hline $\begin{array}{l}\text { Cementing } \\
\text { Material }\end{array}$ & $\begin{array}{c}\mathrm{CaO} \\
(\%)\end{array}$ & $\begin{array}{c}\mathrm{SiO}_{2} \\
(\%)\end{array}$ & $\begin{array}{c}\mathrm{Al}_{2} \mathrm{O}_{3} \\
(\%)\end{array}$ & $\begin{array}{c}\mathrm{Fe}_{2} \mathrm{O}_{3} \\
(\%)\end{array}$ & $\begin{array}{c}\mathrm{MgO} \\
(\%)\end{array}$ & $\begin{array}{c}\mathrm{SO}_{3} \\
(\%)\end{array}$ & $\begin{array}{c}\mathrm{TiO}_{2} \\
(\%)\end{array}$ & $\begin{array}{c}\mathrm{P}_{2} \mathrm{O}_{5} \\
(\%)\end{array}$ \\
\hline $\begin{array}{l}\text { Portland Cement } \\
(\mathrm{GU})\end{array}$ & 62.61 & 19.33 & 5.25 & 2.42 & 2.35 & 4.03 & 0.28 & 0.13 \\
\hline GGBFS & 39.9 & 36.9 & 7.82 & 0.68 & 11.2 & 0.45 & 0.41 & - \\
\hline
\end{tabular}




\subsubsection{Chemical Admixtures}

BASF Micro-Air was used as an air-entraining admixture (AEA) and implemented in all mixes in accordance with ASTM C260. As this is a Canadian study, AEA is needed when producing concrete exposed to the climate. BASF Pozzolith $100 \mathrm{XR}$ was used as a water reducing admixture (WRA) in all mixes.

\subsection{Trial Mixes}

The various trial mixes are displayed on Table 8. These mixes are separated into three classifications based on exposure; $\mathrm{C} 2, \mathrm{~F} 1$ and $15 \mathrm{MPa}$. Table 7 displays the mixture identification for all mixes.

\section{Table 7: Mixture identification table}

\begin{tabular}{ll}
\hline Variable & Definition \\
\hline CON & Control specimen (Virgin Dolostone) \\
\hline 30R, 50R* or 100R & $\begin{array}{l}30,50 \text { or } 100 \% \text { RCA with preserved quality } \\
\text { replacement by volume }\end{array}$ \\
\hline 30RUC, 50RUC* or 100RUC & 30,50 or $100 \%$ Commercial RCA replacement \\
& by volume \\
\hline 15S or 30S & 15 or $30 \%$ GGBFS replacement by volume of \\
& cement \\
\hline C2 & Specimens tested for salt scaling \\
& $\begin{array}{l}\text { Exposure class C2: } \\
\text { reinforced concrete exposed to chlorides and } \\
\text { freezing and thawing }\end{array}$ \\
\hline F1 & $\begin{array}{l}\text { Exposure class F1: Concrete exposed to } \\
\text { freezing and thawing in a saturated condition } \\
\text { but not to chlorides }\end{array}$ \\
\hline
\end{tabular}

*All C2 specimens were tested for salt scaling with the exception of 50R and 50RUC 
Table 8: Trial mixture proportions

\begin{tabular}{|c|c|c|c|c|c|c|c|c|c|}
\hline Mix & $\begin{array}{l}\text { Cement } \\
\left(\mathrm{Kg} / \mathrm{m}^{3}\right)\end{array}$ & $\begin{array}{l}\text { GGBFS } \\
\left(\mathrm{Kg} / \mathrm{m}^{3}\right)\end{array}$ & $\begin{array}{c}\mathrm{VA} \\
\left(\mathrm{Kg} / \mathrm{m}^{3}\right)\end{array}$ & $\begin{array}{c}\mathrm{RCA} \\
\left(\mathrm{Kg} / \mathrm{m}^{3}\right)\end{array}$ & $\begin{array}{l}\text { CRCA } \\
\left(\mathrm{Kg} / \mathrm{m}^{3}\right)\end{array}$ & $\begin{array}{l}\text { Natural } \\
\text { Sand } \\
\left(\mathrm{Kg} / \mathrm{m}^{3}\right)\end{array}$ & $\begin{array}{c}\text { Water } \\
\left(\mathrm{Kg} / \mathrm{m}^{3}\right)\end{array}$ & $\begin{array}{l}\mathrm{w} / \mathrm{cm} \\
\text { ratio }\end{array}$ & $\begin{array}{l}\text { Air } \\
(\%)\end{array}$ \\
\hline $15-\mathrm{CON}$ & 250 & - & 1058 & - & - & 836 & 155 & 0.62 & 5.0 \\
\hline $15-30 \mathrm{R}$ & 250 & - & 688 & 295 & - & 865 & 155 & 0.62 & 5.2 \\
\hline 15-100R & 250 & - & - & 877 & & 866 & 155 & 0.62 & 5.8 \\
\hline $\begin{array}{l}15-\mathrm{CON}- \\
30 \mathrm{~S}\end{array}$ & 175 & 75 & 1058 & - & - & 832 & 155 & 0.62 & 5.2 \\
\hline $15-30 R-30 S$ & 175 & 75 & 688 & 295 & - & 861 & 155 & 0.62 & 4.6 \\
\hline $\begin{array}{l}15-100 \mathrm{R}- \\
30 \mathrm{~S}\end{array}$ & 175 & 75 & - & 877 & - & 862 & 155 & 0.62 & 6.0 \\
\hline $\mathrm{C} 2-\mathrm{CON}$ & 335 & - & 1058 & - & - & 737 & 151 & 0.45 & 5.2 \\
\hline C2-30R & 335 & - & 688 & 295 & & 766 & 151 & 0.45 & 5.6 \\
\hline $\mathrm{C} 2-50 \mathrm{R}$ & 335 & - & 507 & 507 & - & 752 & 151 & 0.45 & 6.6 \\
\hline C2-100R & 335 & - & - & 908 & - & 731 & 151 & 0.45 & 5.8 \\
\hline $\begin{array}{l}\mathrm{C} 2-\mathrm{CON}- \\
30 \mathrm{~S}\end{array}$ & 235 & 100 & 1058 & - & - & 731 & 151 & 0.45 & 6.2 \\
\hline C2-30R-30S & 235 & 100 & 688 & 295 & - & 760 & 151 & 0.45 & 6.0 \\
\hline $\begin{array}{l}\text { C2-100R- } \\
30 \mathrm{~S}\end{array}$ & 235 & 100 & - & 908 & - & 725 & 151 & 0.45 & 6.6 \\
\hline C2-30RUC & 335 & - & 696 & - & 298 & 754 & 151 & 0.45 & 6.4 \\
\hline C2-50RUC & 335 & - & 508 & - & 508 & 746 & 151 & 0.45 & 6.2 \\
\hline C2-100RUC & 335 & - & - & - & 911 & 722 & 151 & 0.45 & 7.2 \\
\hline $\begin{array}{l}\text { C2-30RUC- } \\
30 \mathrm{~S}\end{array}$ & 235 & 100 & 696 & - & 298 & 748 & 151 & 0.45 & 6.0 \\
\hline $\begin{array}{l}\text { C2- } \\
\text { 100RUC- } \\
30 \mathrm{~S}\end{array}$ & 235 & 100 & - & - & 911 & 716 & 151 & 0.45 & 6.2 \\
\hline F1-CON & 332 & - & 1058 & - & - & 687 & 166 & 0.5 & 5.8 \\
\hline F1-30R & 332 & - & 688 & 295 & - & 715 & 166 & 0.5 & 6.0 \\
\hline F1-100R & 332 & - & - & 908 & - & 681 & 166 & 0.5 & 6.0 \\
\hline $\begin{array}{l}\text { F1-CON- } \\
30 \mathrm{~S}\end{array}$ & 232 & 100 & 1058 & - & - & 681 & 166 & 0.5 & 5.4 \\
\hline F1-30R-30S & 232 & 100 & 688 & 295 & - & 708 & 166 & 0.5 & 5.4 \\
\hline
\end{tabular}




\begin{tabular}{lccccccccc}
\hline $\begin{array}{l}\text { F1-100R- } \\
\text { 30S }\end{array}$ & 232 & 100 & - & 908 & - & 675 & 166 & 0.5 & 6.8 \\
\hline $\begin{array}{l}\text { C2-CON- } \\
\text { 15S-SS }\end{array}$ & 285 & 50.3 & 1058 & - & - & 734 & 151 & 0.45 & 5.6 \\
\hline $\begin{array}{l}\text { C2-30R- } \\
\text { 15S-SS }\end{array}$ & 285 & 50.3 & 688 & 295 & - & 762 & 151 & 0.45 & 5.6 \\
\hline $\begin{array}{l}\text { C2-100R- } \\
\text { 15S-SS }\end{array}$ & 285 & 50.3 & - & 908 & - & 728 & 151 & 0.45 & 6.2 \\
$\begin{array}{l}\text { C2-30RUC- } \\
\text { 15S-SS }\end{array}$ & 285 & 50.3 & 696 & - & 298 & 752 & 151 & 0.45 & 6.6 \\
$\begin{array}{l}\text { C2-100RUC- } \\
\text { 15S-SS }\end{array}$ & 285 & 50.3 & - & - & 911 & 718 & 151 & 0.45 & 7.0 \\
\hline
\end{tabular}

Table 9 displays a list of all trial mixes and the tests they were exposed to.

Table 9: List of mixes and testing program

\begin{tabular}{|c|c|c|c|c|c|c|}
\hline \multirow[b]{2}{*}{ Mix } & \multicolumn{6}{|c|}{ Test } \\
\hline & $\begin{array}{c}\text { Slump } \\
\text { Retention }\end{array}$ & $\begin{array}{c}\text { Compressive } \\
\text { Strength }\end{array}$ & $\begin{array}{l}\text { Splitting } \\
\text { Tensile } \\
\text { Strength }\end{array}$ & $\begin{array}{c}\text { Drying } \\
\text { Shrinkage }\end{array}$ & $\begin{array}{c}\text { Salt } \\
\text { Scaling }\end{array}$ & RCPT \\
\hline $15-\mathrm{CON}$ & $\checkmark$ & $\checkmark$ & $\mathrm{X}$ & $\mathrm{X}$ & $X$ & $\mathrm{X}$ \\
\hline $15-30 \mathrm{R}$ & $\checkmark$ & $\checkmark$ & $\mathrm{X}$ & $\mathrm{X}$ & $\mathrm{X}$ & $\mathrm{X}$ \\
\hline $15-100 \mathrm{R}$ & $\checkmark$ & $\sqrt{ }$ & $X$ & $\mathrm{X}$ & $\mathrm{X}$ & $X$ \\
\hline $\begin{array}{l}15-\mathrm{CON}- \\
30 \mathrm{~S}\end{array}$ & $\checkmark$ & $\checkmark$ & $X$ & $\mathrm{X}$ & $\mathrm{X}$ & $\mathrm{X}$ \\
\hline 15-30R-30S & $\checkmark$ & $\checkmark$ & $X$ & $\mathrm{X}$ & $\mathrm{X}$ & $\mathrm{X}$ \\
\hline $\begin{array}{l}15-100 R- \\
30 S\end{array}$ & $\checkmark$ & $\checkmark$ & $\mathrm{X}$ & $\mathrm{X}$ & $\mathrm{X}$ & $\mathrm{X}$ \\
\hline $\mathrm{C} 2-\mathrm{CON}$ & $\checkmark$ & $\checkmark$ & $\checkmark$ & $\checkmark$ & $\sqrt{ }$ & $\sqrt{ }$ \\
\hline C2-30R & $\checkmark$ & $\checkmark$ & $\checkmark$ & $\checkmark$ & $\checkmark$ & $\checkmark$ \\
\hline $\mathrm{C} 2-50 \mathrm{R}$ & $X$ & $\mathrm{X}$ & $\mathrm{X}$ & $\checkmark$ & $\mathrm{X}$ & $\mathrm{X}$ \\
\hline C2-100R & $\checkmark$ & $\checkmark$ & $\checkmark$ & $\checkmark$ & $\checkmark$ & $\checkmark$ \\
\hline
\end{tabular}




\begin{tabular}{|c|c|c|c|c|c|c|}
\hline $\begin{array}{l}\mathrm{C} 2-\mathrm{CON}- \\
30 \mathrm{~S}\end{array}$ & $\sqrt{ }$ & $\checkmark$ & $\sqrt{ }$ & $\checkmark$ & $\mathrm{X}$ & $\checkmark$ \\
\hline C2-30R-30S & $\sqrt{ }$ & $\checkmark$ & $\sqrt{ }$ & $\checkmark$ & $X$ & $\checkmark$ \\
\hline $\begin{array}{l}\text { C2-100R- } \\
30 S\end{array}$ & $\checkmark$ & $\checkmark$ & $\checkmark$ & $\checkmark$ & $\mathrm{X}$ & $\checkmark$ \\
\hline C2-30RUC & $\checkmark$ & $\checkmark$ & $\checkmark$ & $\mathrm{X}$ & $\checkmark$ & $\checkmark$ \\
\hline C2-50RUC & $\mathrm{X}$ & $X$ & $\mathrm{X}$ & $\checkmark$ & $\mathrm{X}$ & $X$ \\
\hline C2-100RUC & $\checkmark$ & $\checkmark$ & $\checkmark$ & $\checkmark$ & $\checkmark$ & $\checkmark$ \\
\hline $\begin{array}{l}\text { C2-30RUC- } \\
30 \mathrm{~S}\end{array}$ & $\checkmark$ & $\checkmark$ & $\sqrt{ }$ & $\mathrm{X}$ & $\mathrm{X}$ & $\checkmark$ \\
\hline $\begin{array}{l}\text { C2- } \\
\text { 100RUC- } \\
30 \mathrm{~S}\end{array}$ & $\sqrt{ }$ & $\checkmark$ & $\sqrt{ }$ & $\mathrm{X}$ & $\mathrm{X}$ & $\checkmark$ \\
\hline F1-CON & $\sqrt{ }$ & $\checkmark$ & $\mathrm{X}$ & $\mathrm{X}$ & $\mathrm{X}$ & $X$ \\
\hline F1-30R & $\checkmark$ & $\checkmark$ & $X$ & $\mathrm{X}$ & $\mathrm{X}$ & $\mathrm{X}$ \\
\hline F1-100R & $\sqrt{ }$ & $\checkmark$ & $X$ & $\mathrm{X}$ & $\mathrm{X}$ & $\mathrm{X}$ \\
\hline $\begin{array}{l}\text { F1-CON- } \\
30 \mathrm{~S}\end{array}$ & $\checkmark$ & $\checkmark$ & $\mathrm{X}$ & $\mathrm{X}$ & $\mathrm{X}$ & $\mathrm{X}$ \\
\hline F1-30R-30S & $\checkmark$ & $\checkmark$ & $\mathrm{X}$ & $\mathrm{X}$ & $\mathrm{X}$ & $X$ \\
\hline $\begin{array}{l}\text { F1-100R- } \\
30 \mathrm{~S}\end{array}$ & $\sqrt{ }$ & $\checkmark$ & $\mathrm{X}$ & $X$ & $\mathrm{X}$ & $\mathrm{X}$ \\
\hline $\begin{array}{l}\text { C2-CON- } \\
15 S-S S\end{array}$ & $\mathrm{X}$ & $\mathrm{X}$ & $\mathrm{X}$ & $\mathrm{X}$ & $\checkmark$ & $\mathrm{X}$ \\
\hline $\begin{array}{l}\text { C2-30R- } \\
15 S-S S\end{array}$ & $\mathrm{X}$ & $\mathrm{X}$ & $\mathrm{X}$ & $\mathrm{X}$ & $\checkmark$ & $X$ \\
\hline $\begin{array}{l}\text { C2-100R- } \\
15 \mathrm{~S}-\mathrm{SS}\end{array}$ & $\mathrm{X}$ & $\mathrm{X}$ & $\mathrm{X}$ & $\mathrm{X}$ & $\checkmark$ & $\mathrm{X}$ \\
\hline $\begin{array}{l}\text { C2-30RUC- } \\
15 \mathrm{~S}-\mathrm{SS}\end{array}$ & $\mathrm{X}$ & $\mathrm{X}$ & $\mathrm{X}$ & $\mathrm{X}$ & $\checkmark$ & $\mathrm{X}$ \\
\hline $\begin{array}{l}\text { C2-100RUC- } \\
15 S-S S\end{array}$ & $\mathrm{X}$ & $\mathrm{X}$ & $\mathrm{X}$ & $\mathrm{X}$ & $\checkmark$ & $X$ \\
\hline
\end{tabular}




\subsection{Testing Procedure}

\subsubsection{Batching and Fresh Properties}

The batching procedure followed was in accordance with the two-stage mixing approach (TSMA) (Tam, Gao \& Tam, 2005) in combination with Sucic (2013). First the fine aggregate was added to the drum. The AEA was then added to the fine aggregate as per the instructions of the supplier. The coarse aggregate was then added, followed by half of the mixing water. All cementing materials, including GGBFS if needed were added and mixed to allow for an initial aggregate coating. The remaining water was then added and mixed. After a resting period, the WRA was added and mixed to complete the mixing procedure. The mixing procedure can be found on Table 10.

Table 10: Mixing procedure

\begin{tabular}{ccc}
\hline Step & Materials & $\begin{array}{c}\text { Mix duration } \\
\text { (seconds) }\end{array}$ \\
\hline 1 & $\begin{array}{c}\text { Coarse and fine aggregate } \\
\text { (including AEA) }\end{array}$ & 60 \\
\hline 2 & Rest & 60 \\
\hline 3 & First half of the mixing water & 60 \\
\hline 4 & Rest & 60 \\
\hline 5 & $\begin{array}{c}\text { Cementing material (including } \\
\text { GGBFS if needed) }\end{array}$ & 30 \\
\hline 6 & $\begin{array}{c}\text { Second half of the mix water } \\
\text { (including WRA) }\end{array}$ & 120 \\
\hline 7 & Rest & 120 \\
\hline 8 & Mix & 120 \\
\hline 9 & Rest & \\
\hline
\end{tabular}

Following the batching process, the concrete was tested for slump and slump retention. The slump retention was tested at 15 -minute intervals for a total of 45 minutes. 


\subsubsection{Compressive Strength Testing}

The compressive strength tests were performed according to ASTM C39. Each mix was tested for compressive strength using $100 \times 200 \mathrm{~mm}$ cylinders at 7 and 28 days. Figure 19 illustrates a specimen under compressive strength testing. All results were recorded and presented as an average of three test specimens. Additionally, results were presented as an average of two test specimens, depending on the variation of the third specimen. Compressive strength testing was performed on all three classes of concrete: C2, F1 and $15 \mathrm{MPa}$. In order to be classified under one of these three categories the specimen had to successfully meet the compressive strength requirements. Prior to testing, all specimens were ground to provide a flat surface that allowed for the ends to be in plane with $0.050 \mathrm{~mm}$. The top and bottom surfaces of the specimen were wiped clean and the axis of the specimen was placed in the testing area to align with the center of the bearing block. A load of $0.25 \pm 0.05 \mathrm{MPa} / \mathrm{s}$ was applied at a constant rate. The incorporation of $30 \%$ GGBFS was used to investigate any level of effect.

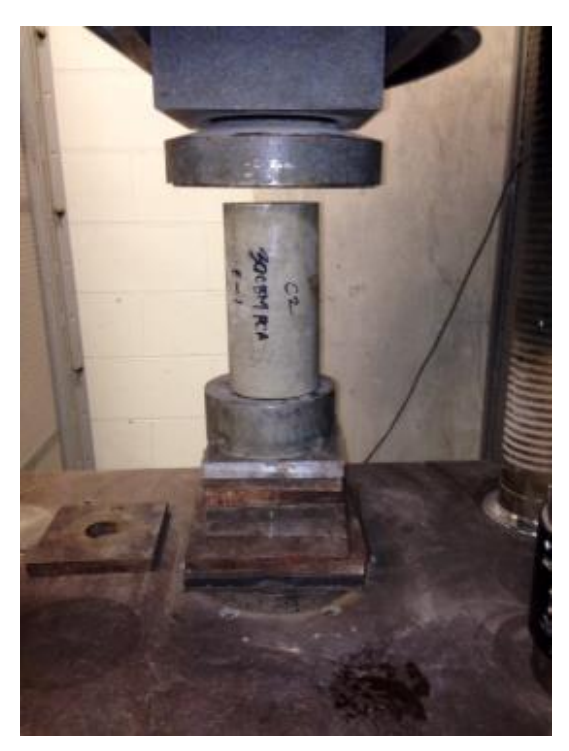

Figure 19: Concrete specimen under compressive strength testing 


\subsubsection{Splitting Tensile Strength Testing}

Splitting tensile tests were performed in accordance with ASTM C496 using 100 x $200 \mathrm{~mm}$ concrete cylinders. Testing was performed on specimens at 28 days. All results were recorded and presented as an average of three test specimens. Only C2 specimens were tested from splitting tensile strength to provide a comparison between tensile strength of concrete with virgin aggregate and that with RCA. Specimens were placed under the bearing block as shown in Figure 20. The specimen was placed in the testing area to align with the center of the bearing block. A continuous load of 0.7 to $1.4 \mathrm{MPa} / \mathrm{min}$ was applied to each specimen. The incorporation of $30 \%$ GGBFS was used to investigate any level of effect.

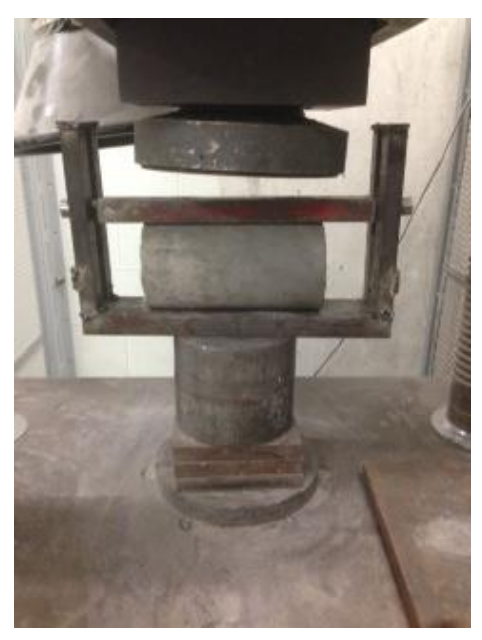

Figure 20: Concrete specimen under splitting tensile testing

\subsubsection{Drying Shrinkage Testing}

Drying shrinkage testing was performed according to ASTM C157 using 75 x 75 x $285 \mathrm{~mm}$ concrete prisms. After the specimens were demoulded they were left to cure in lime-saturated water for 7 days. After 7 days the specimens were exposed to drying conditions, $50 \pm 4 \%$ relative humidity and temperature of $23 \pm 2^{\circ} \mathrm{C}$ for 180 days. All readings reference the initial reading taken 
on the seventh day before exposure to drying conditions. These readings were measured using a length comparator, seen in Figure 21 and reported as an average of three specimens. Specimens were immediately measured once taken from the drying conditions. All C2 specimens were tested for drying shrinkage. The C2 specimens were used as a means of comparing the both types of RCA included in this study; RCA with preserved quality and commercial RCA. Additionally, specimens were stored and tested in two different controlled testing facilities (labs) to verify the accuracy of the results. Additional mixtures containing GGBFS were to cast to evaluate any level of effect. All specimens were monitored in accordance with ASTM C157.

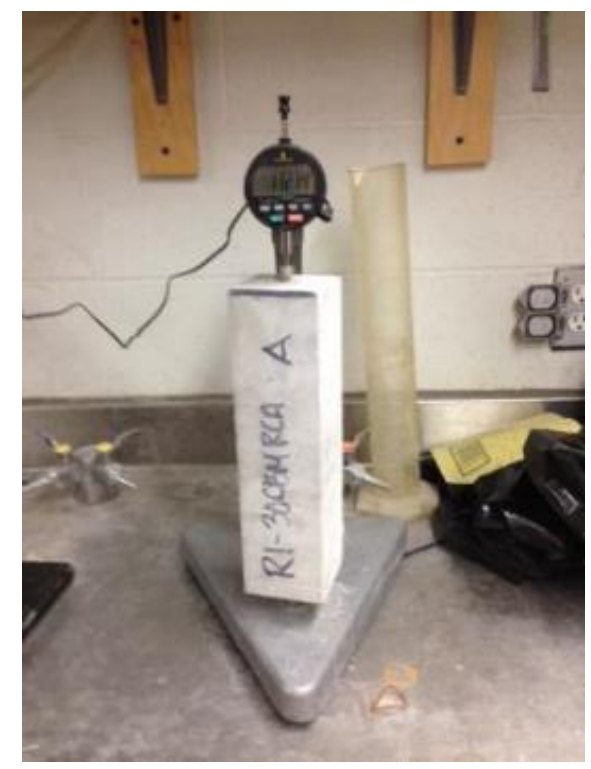

Figure 21: Drying shrinkage measurement of a concrete specimen using a length comparator

\subsubsection{Salt Scaling Testing}

Salt scaling testing was performed according to the Ministry of Transportation of Ontario (MTO) test method LS-412. Specimens were cast having dimensions of 300 x 300 x $75 \mathrm{~mm}$. After demoulding all specimens were conditioned for 28 days. The conditioning stage was separate into 
two phases, the first phase was 14 days of curing in moist storage followed by 14 days of drying in air storage at $23 \pm 2^{\circ} \mathrm{C}$ and relative humidity of $45-55 \%$. After curing the surface of the specimen was covered with approximately $6 \mathrm{~mm}$ of $3 \% \mathrm{NaCl}$ solution. The specimens, illustrated in Figure 22 were then exposed to 50 freeze thaw cycles, changing the $\mathrm{NaCl}$ solution every five cycles. Each cycle consisted of 16-18 hours in a freezing environment followed by storage at 23 $\pm 2{ }^{\circ} \mathrm{C}$ and relative humidity of $45-55 \%$ for 6-8 hours. After 5 cycles, the flaked off concrete was collected by washing the surface of the specimen with the $\mathrm{NaCl}$ solution. The washing continued until all lose particles were removed from the surface of the specimen.

C2 specimens were used to evaluate salt scaling. The RCA with preserved quality was compared to the commercially available RCA. Additionally, GGBFS was incorporated in companion mixtures to investigate its effects.

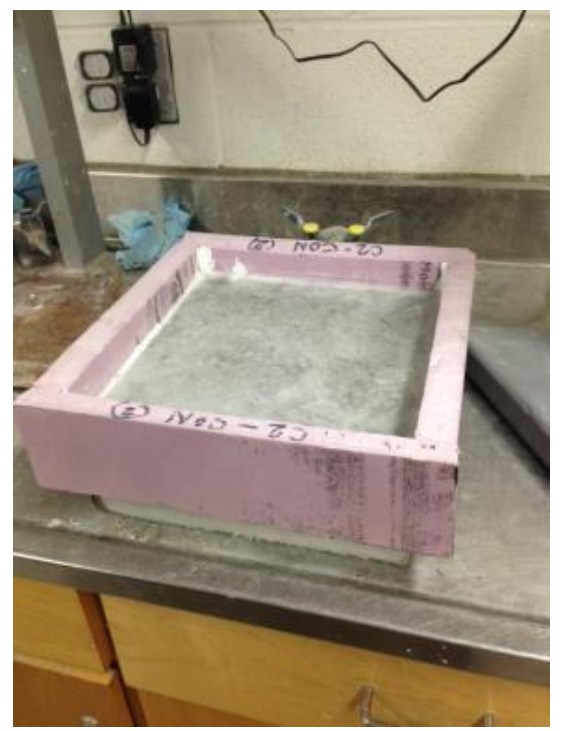

Figure 22: Salt scaling specimen 


\subsubsection{Rapid Chloride Permeability Testing (RCPT)}

Rapid chloride permeability testing was performed according to ASTM C1202. Testing was performed on specimens after 56 days of moist curing. Specimens with a diameter of $100 \mathrm{~mm}$ and thickness of $50 \mathrm{~mm} \pm 5 \mathrm{~mm}$ were cut from within the $100 \times 200 \mathrm{~mm}$ concrete cylinders. C2 specimens were chosen to undergo RCPT. Additionally, both the RCA with preserved quality and commercial RCA were tested in order to further compare the effect, if any, the type of RCA has on ion penetrability. . GGBFS was also used to investigate any level of effect.

Prior to testing, the specimens were placed into a vacuum desiccator and then submerged in deaerated water for $18 \pm 2$ hours. $\mathrm{A} 3 \% \mathrm{NaCl}$ and $0.3 \mathrm{~N} \mathrm{NaOH}$ solutions were prepared prior to testing and poured into the RCPT cells after the specimen was placed inside. The specimens were tested for total of 6 hours. 


\section{Results and Analysis}

\subsection{Slump and Slump Retention}

The fresh properties of each batch were determined using slump and slump retention tests. Additionally, air content was assessed to be in accordance with specific class exposures. The slump was monitored at 15 minute intervals for a total of 45 minutes. Slump retention was investigated to evaluate workability over time under simulated field conditions.

The $15 \mathrm{MPa}$ specimens with a w/cm ratio of 0.62 achieved a high initial slump. After 45 minutes all specimens continued to exhibit a very workable slump. Figure 23 illustrates the slump retention of the $15 \mathrm{MPa}$ specimens. The RCA specimens did not exhibit any considerable slump loss. The increase in fines from the adhered mortar of the RCA due to the continued rotation of the drum did not have a significant effect in reducing workability. Additionally, the absorptive property of the RCA had a minimal effect on reducing workability. 


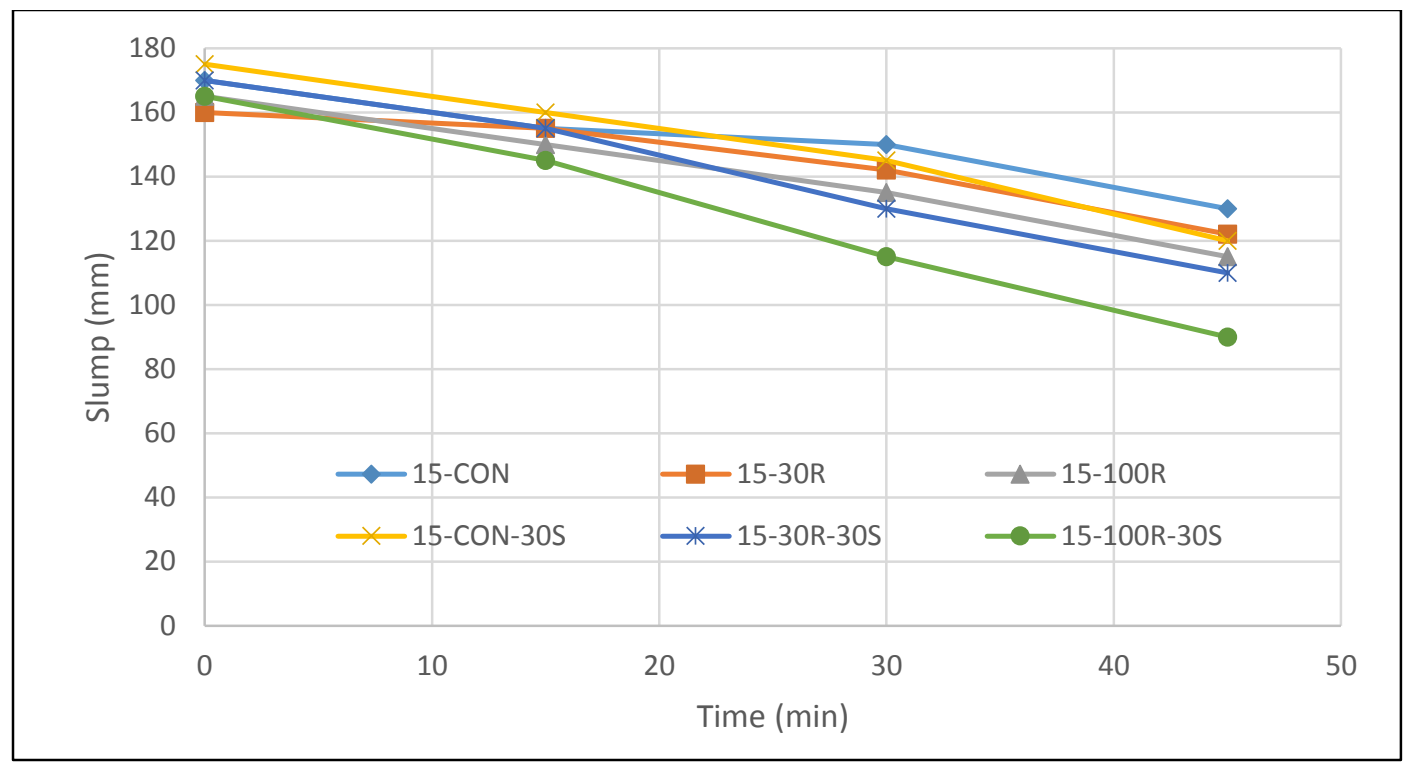

Figure 23: Slump retention of Class: $15 \mathrm{MPa}$ specimens containing $R C A$ with preserved quality

Figures 24 and 25 show the slump retention of the C2 specimens. These specimens contain a w/cm of 0.45 and achieved a workable slump. The specimens were able to meet the CSA A23.1 standard of $80 \mathrm{~mm}$. No additional water was held back or added to increase the slump. Specimens incorporating virgin aggregate attained a workable slump with minimal slump loss. All RCA specimens exhibited a slightly higher degree of slump loss, as shown with a steeper slope. This can be attributed to the lower w/cm compared to the $15 \mathrm{MPa}$ concrete as well was the absorptive property of the RCA. The specimens incorporating commercial RCA achieved a workable initial slump, however they exhibited a higher overall slump loss compared to the VA concrete or RCA concrete. 


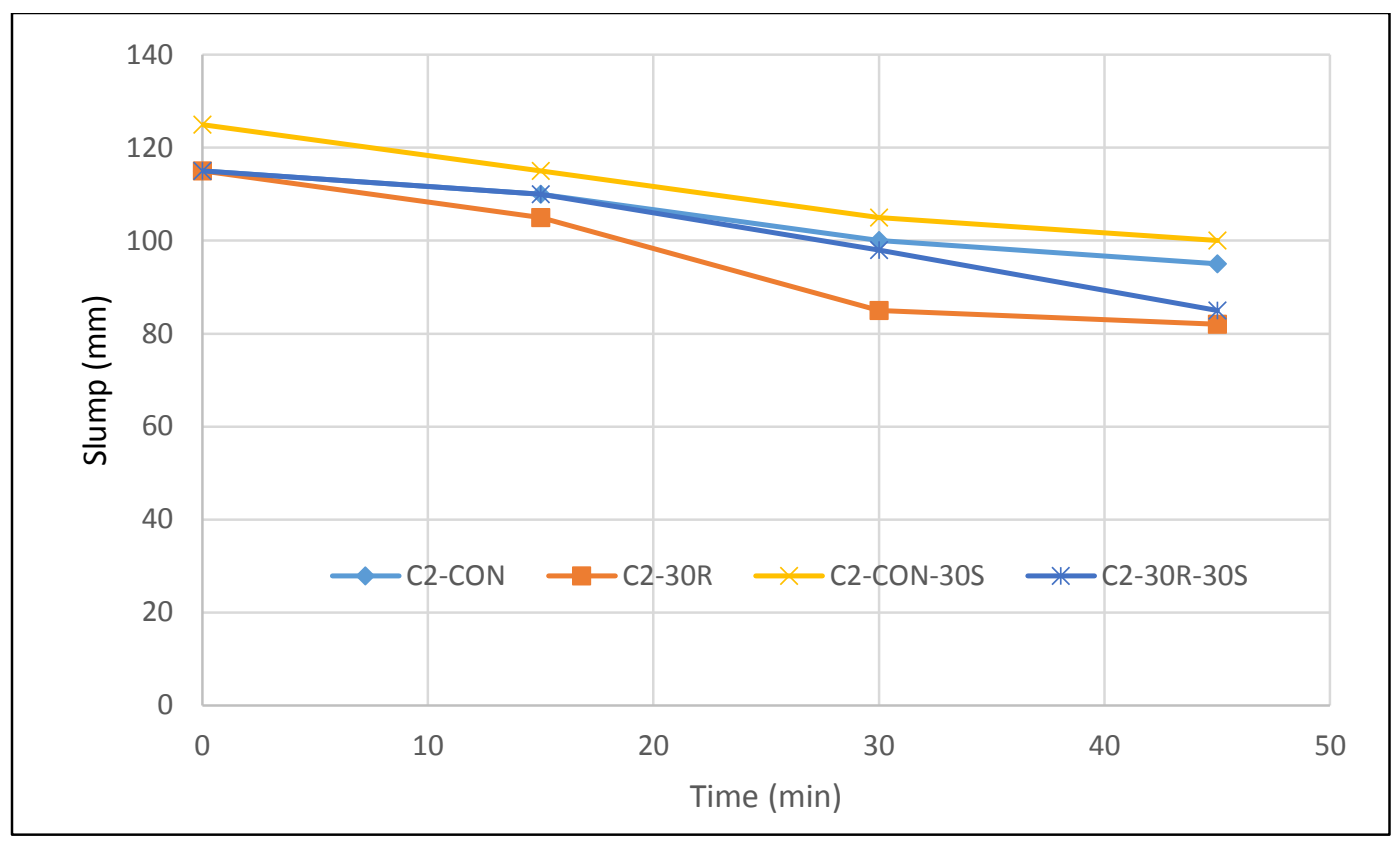

Figure 24: Slump retention of Class: C2 specimens

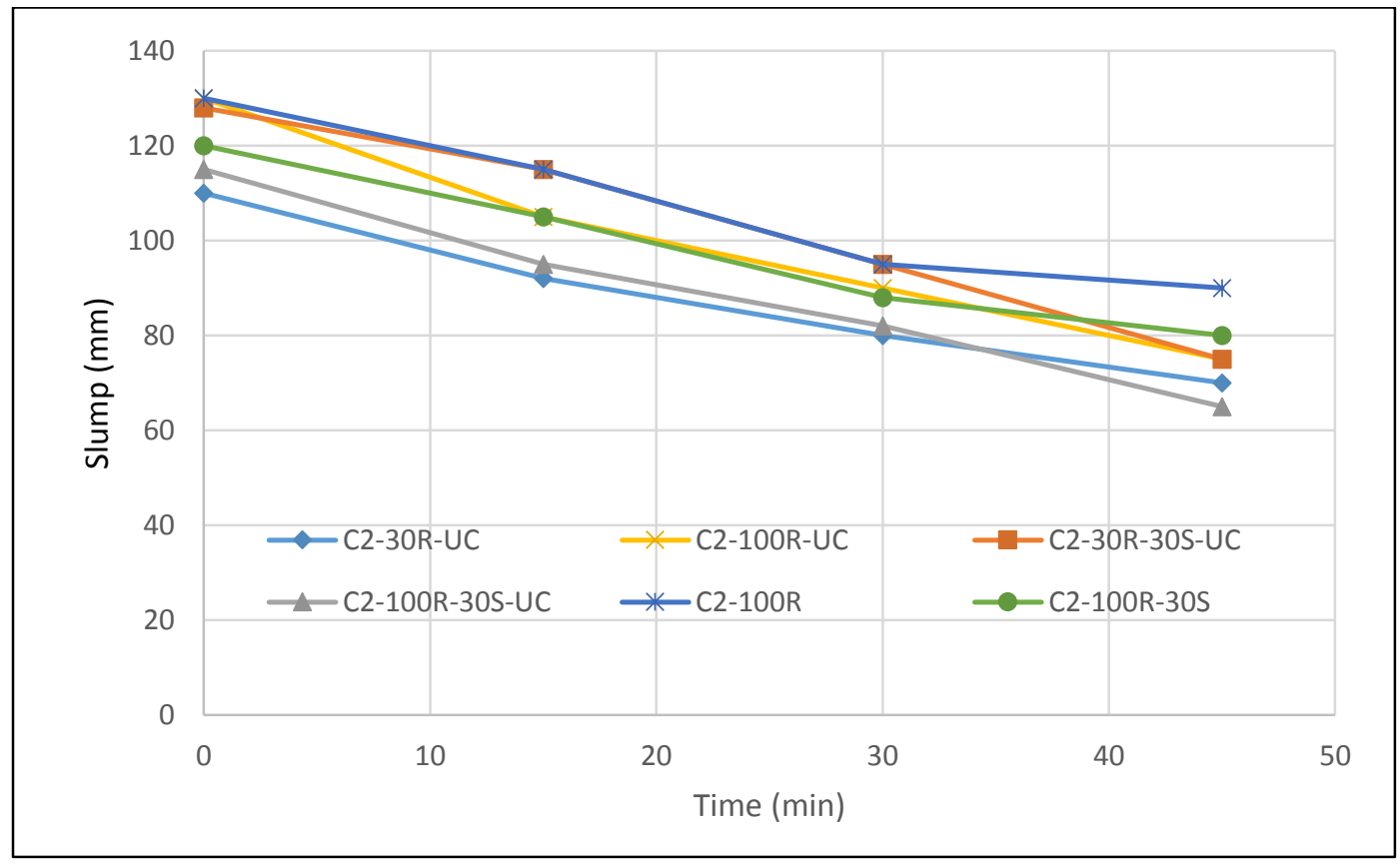

Figure 25: Slump retention of Class: C2 specimens 
Figure 26 illustrates the slump retention for F1 specimens. These specimens contained a w/cm ratio of 0.50 and achieved a very workable slump. The VA concrete specimens exhibited minimal slump loss while the RCA with preserved quality specimens displayed the most slump loss. However, the RCA specimens still left a workable slump after 45 minutes. No additional water was added or held back to increase the slump of any specimen.

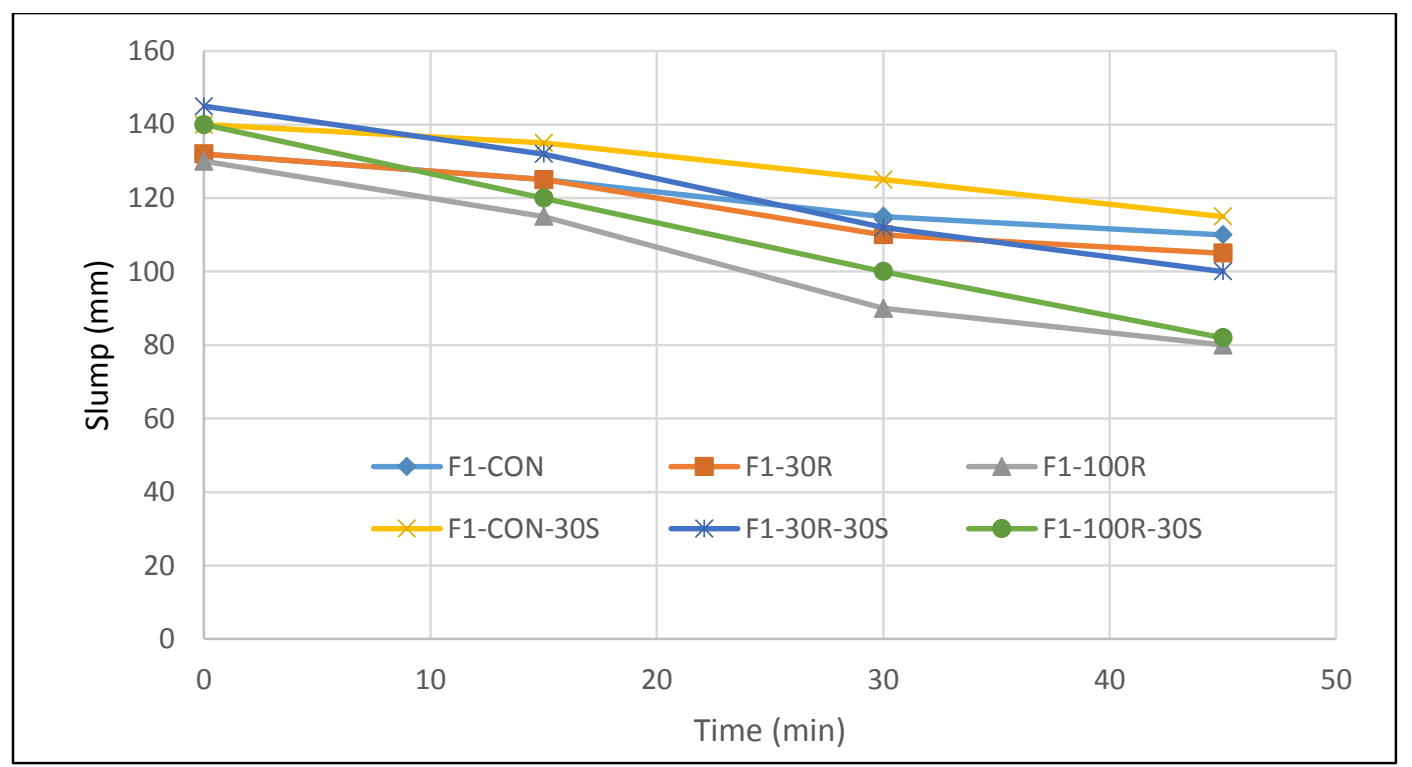

Figure 26: Slump retention of Class F1 Concrete

The slump retention procedure aims to mimic field applications. As the concrete is continually mixed in the transit mixer during travel the coarse aggregate is constantly being overturned and worked. The matrix of RCA is fairly weak and continuously being worked in drum of the transit mixer may increase the amount of fines introduced by the adhered mortar that was experience in the laboratory conditions. 


\subsection{Air content}

Three classes of concrete were casted during the study; $\mathrm{C} 2, \mathrm{~F} 1$ and $15 \mathrm{MPa}$. Air content testing was performed according to CSA A23.1 using the pressure method. All C2 and F1 mixtures met the 5-8\% air content specifications. The air content results of each mixture can be seen on Table 8. To ensure all mixtures adhered to the standard air content set by $\mathrm{C} 2$ and F1 class exposures air content was taken immediately following the mixing procedure. The fresh concrete was placed into the measure of the air meter, shown in Figure 27 in three equal layers and consolidated by uniformly rodding each layer 25 times over the cross-section. Once each layer was rodded, a mallet was used to strike the outside of the measure to remove any air bubbles. After consolidation, the rod was used to strike off the top surface and level the measure. The cover of the air meter was placed on and clamped down. All air above the concrete was expelled by injecting water through one of the petcocks until the water flowing from the other valve is free of air bubbles. Air was pumped into the air chamber until the air pressure reached the calibrated mark then released to obtain the air content percentage.

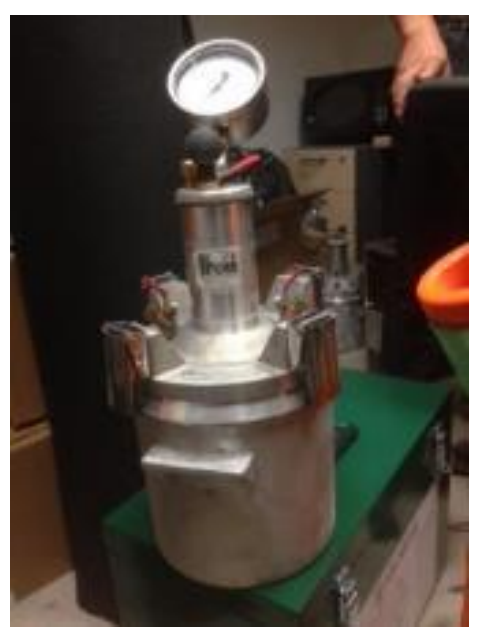

Figure 27: Air meter apparatus used in the study (Pressure Method) 


\subsection{Compressive Strength}

According to CSA A23.1 the minimum compressive strength requirement for C-2 specimens is 32 MPa at 28 days. Compressive strength tests were performed at 7 and 28 days as per ASTM C39. Figure 28 illustrates the compressive strength results of all C-2 specimens at 7 and 28 days all specimens incorporative RCA with preserved quality passes the CSA requirement.

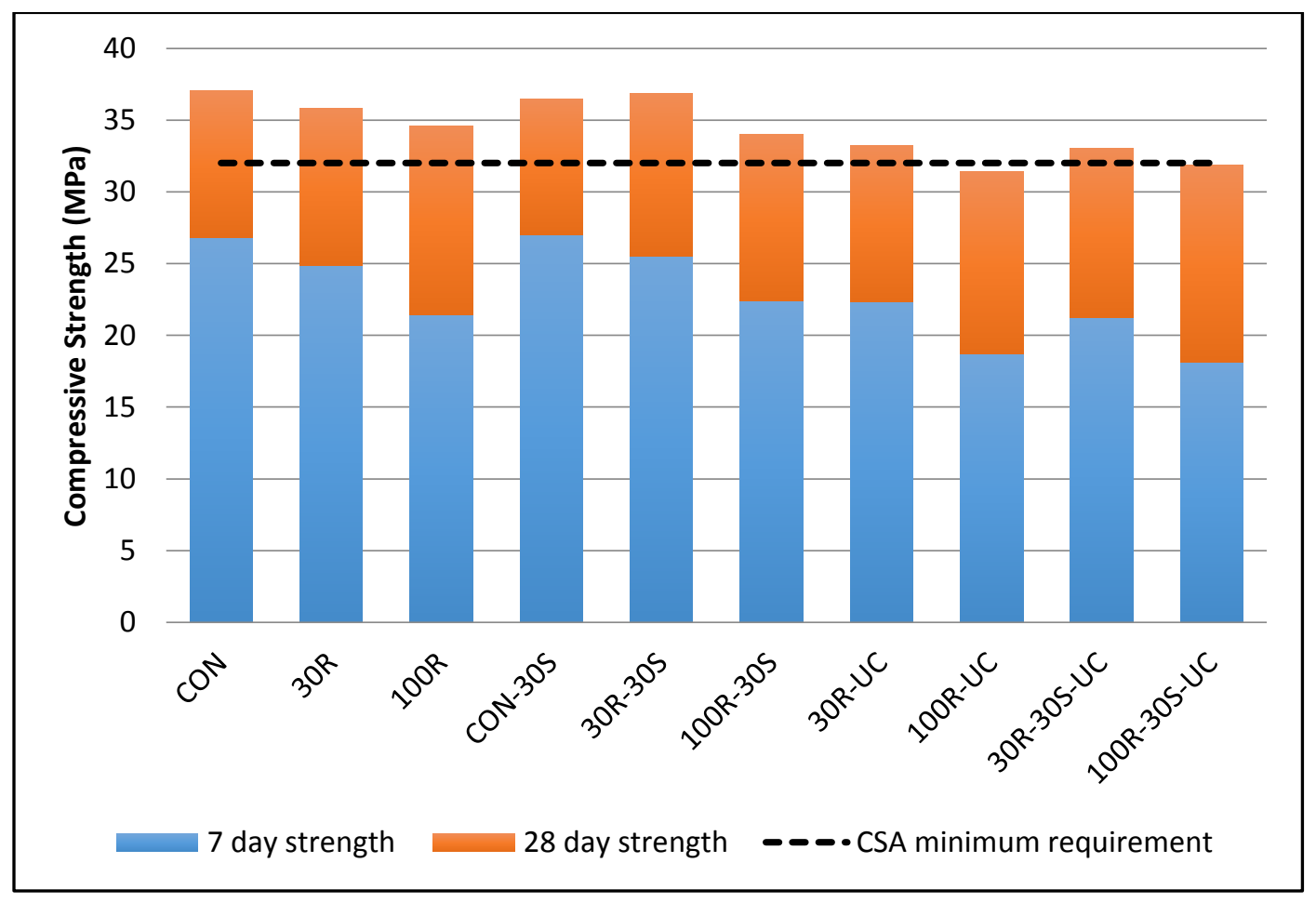

Figure 28: Compressive strength of C2 Concrete

The control specimens with virgin aggregates exhibited the highest compressive strength. Specimens incorporating commercial RCA exhibited the lowest compressive strength. A comparison between the commercial RCA and the RCA with preserved quality for class $\mathrm{C} 2$ specimens and was performed to showcase the difference in terms of compressive strength. Two 
specimens incorporating uncontrolled RCA, 100RUC and 100RUC-30S, fell just below the required strength. Their strengths were 31.43 and $31.87 \mathrm{MPa}$ respectively. There is an evident decrease in compressive strength with the increase in RCA was seen throughout all specimens. The decrease in compressive strength can be attributed to the low strength of the RCA or specifically the residual mortar surrounding the original aggregate in RCA. The use of commercial RCA further decreased the compressive strength. This can be attributed to expected lower quality of residual mortar surrounding the original aggregate. The use of GGBF slag showed no measurable effect on the compressive strength.

Figure 29 illustrates the compressive strength of the $15 \mathrm{MPa}$ concrete. All specimens were able to pass the $15 \mathrm{MPa}$ requirement. VA concrete specimens achieved the highest compressive strength while specimens with a $100 \%$ replacement of RCA with preserved quality exhibited the lowest compressive strength. The results indicated that an increase in the replacement of RCA correlated to a decrease in compressive strength. Specimens incorporating 30\% GGBFS showed a slight reduction in compressive strength at 7 days which was expected with the reduction of cement. 


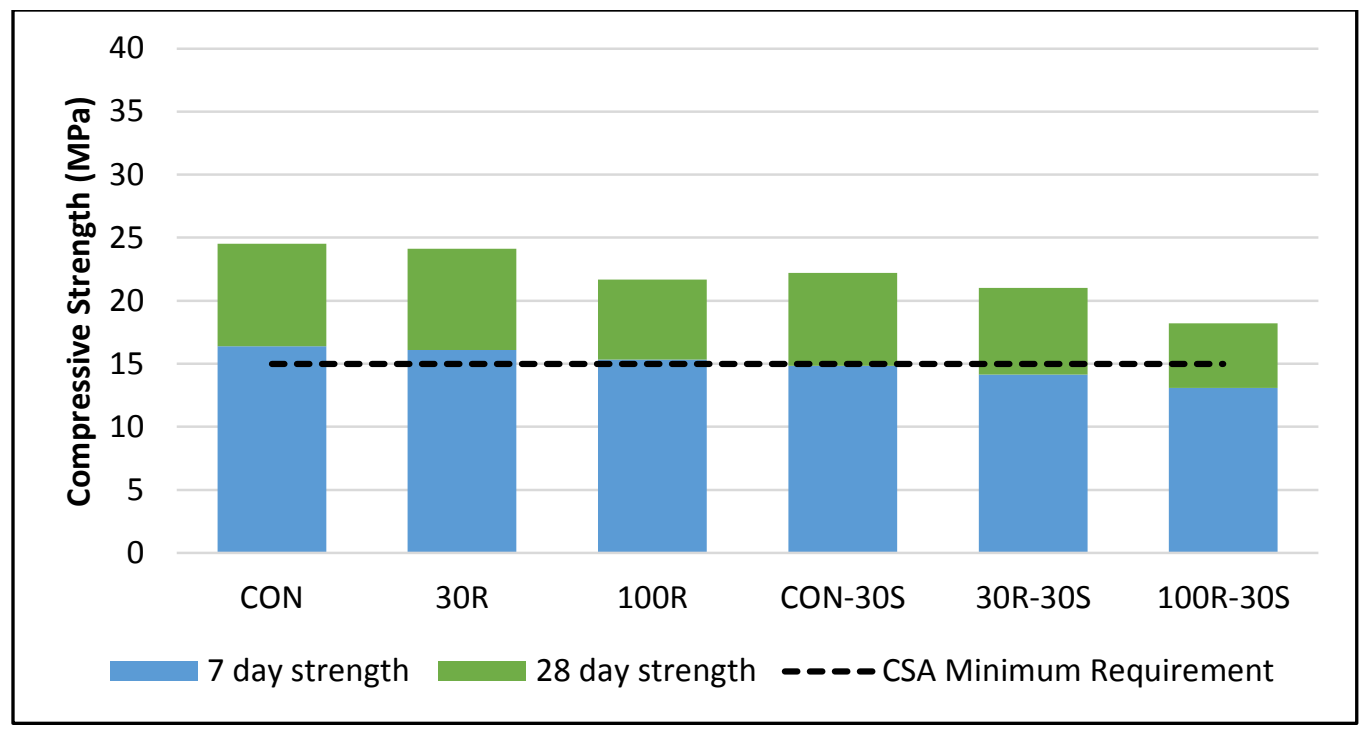

Figure 29: Compressive strength of $15 \mathrm{MPa}$ concrete

Figure 30 illustrates the compressive strength of F1 specimens. The results reinforce the previous conclusions. The increase in replacement of RCA correlated in decrease in compressive strength. Specimens containing 30\% GGBFS again exhibited a slight reduction in early compressive strength.

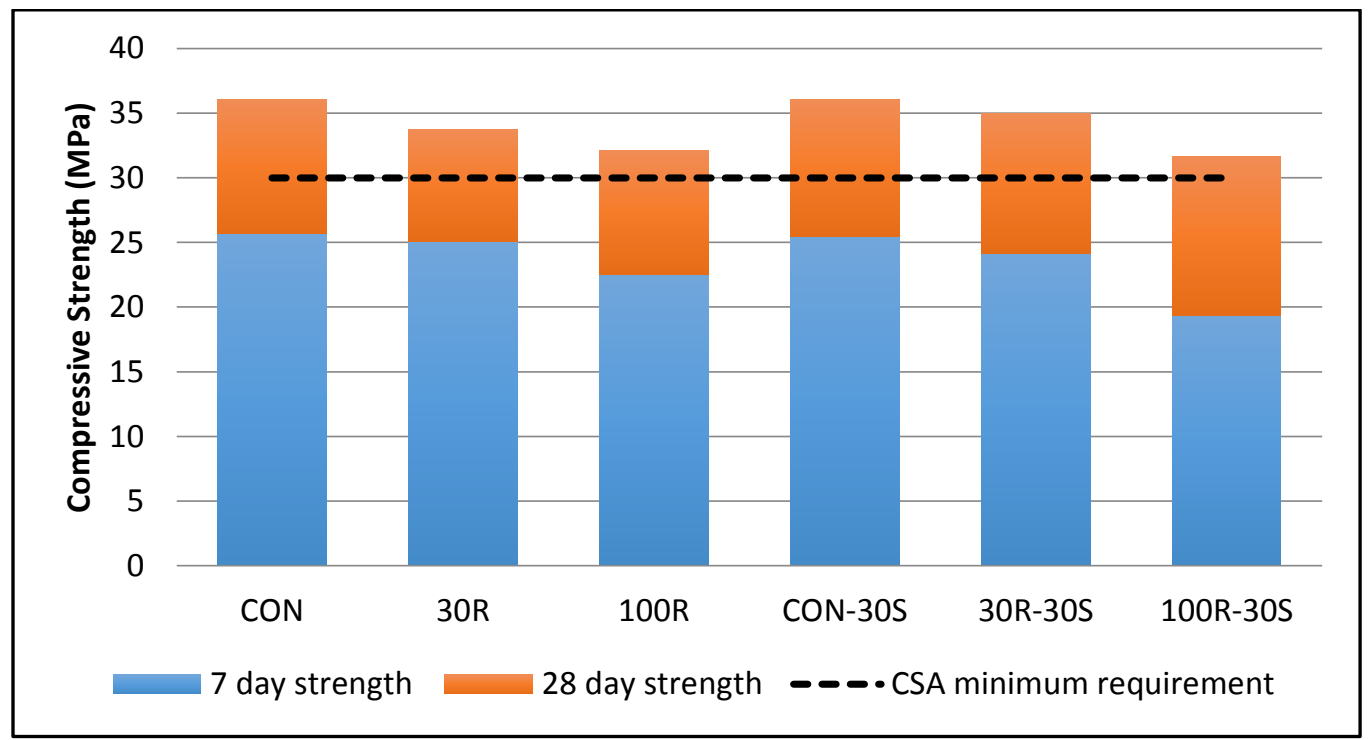

Figure 30: Compressive strength of F1 concrete 
A $100 \%$ replacement of RCA with preserved quality in the C2 specimens reduced compressive strength by approximately $9 \%$. In the F1 specimens there was a reduction of approximately $12.5 \%$ while in the $15 \mathrm{MPa}$ specimens there was a reduction in $14 \%$. The reduction in strength in the three classes of concrete was fairly similar. It seems that the reduction is higher in low strength concrete where the paste is weak and is not capable of compensating for the low strength of the RCA.

\subsection{Splitting Tensile Stress}

Splitting tensile testing was performed for all $\mathrm{C} 2$ specimens in order to compare the commercial RCA to the RCA with preserved quality. The splitting tensile strength for all $\mathrm{C} 2$ specimens after 28 days is shown in Figure 31. The VA concrete achieved the highest overall splitting tensile strength. Generally, there is a decrease in splitting tensile strength as the replacement of RCA is increased. This can be attributed to the higher porosity, lower density and lower overall strength of RCA. The results also indicated that the concrete incorporating the commercial RCA displayed a lower splitting tensile strength than the RCA with preserved quality concrete. This can be attributed to the commercial RCA being an overall weaker material compared to the RCA with preserved quality. Furthermore, the lower splitting tensile strength of the commercial RCA can be attributed to the volume and strength of the original adhered mortar surrounding the original stone. The introduction of $30 \%$ GGBFS had some effect on the splitting tensile strength of the specimens. The slight enhancement of tensile strength when slag was used can be attributed to the enhancement in ITZ when SCM, such as slag, is incorporated in the mix. The same can be said for mixtures with RCA, the "double ITZ" associated with the use of RCA could be one of the contributing factor to the reduced tensile strength for mixtures wit RCA. 


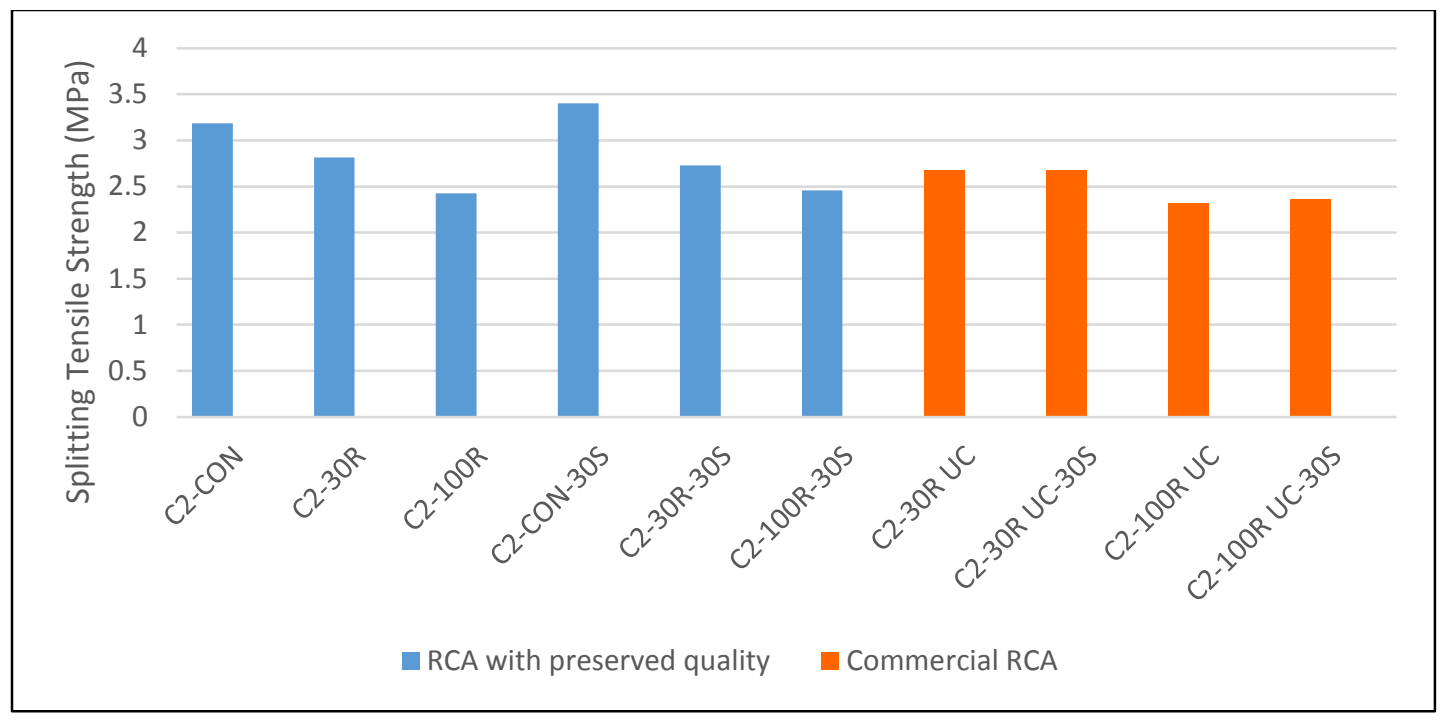

Figure 31: Splitting tensile strength of C2 concrete

\subsection{Drying Shrinkage}

The drying shrinkage of RCA is a critical topic of discussion. Drying shrinkage is highly affected by the w/cm ratio and volume of paste. The loss of capillary water cause tensile stresses in the hardened concrete that result in the formation of cracks.

All drying shrinkage specimens of the same class exposure were cast in the same time frame to reduce the influence of any interference to the laboratory conditions. Additionally, specimens of the same class exposure contained the same initial volume of water and cement. This was before any adjustments for aggregate absorption or moisture content was made. Figure 32 illustrates the drying shrinkage of $\mathrm{C} 2$ specimens. The results indicate that the VA concrete specimens experienced less drying shrinkage than the RCA concrete specimens. At 28 days, the specimens 
incorporating $100 \%$ replacement of RCA with preserved quality experienced $40 \%$ more shrinkage compared to the control VA concrete specimens. At 180 days, the specimens incorporating $100 \%$ replacement of RCA with preserved quality experienced $50 \%$ more shrinkage that the control VA concrete specimens. The addition of 30\% GGBFS did not present any significant conclusion in improving drying shrinkage. The results indicated that the RCA specimens experienced slightly lower shrinkage than expected.

However, other studies have also reported similar results. A study performed at Missouri University (2014) using $75 \times 75 \times 285 \mathrm{~mm}$ prisms according to ASTM C157 reported that the $100 \%$ RCA replacement specimens at a water/cm ratio of 0.40 experienced approximately $0.06 \%$ shrinkage after 200 days. A study performed by Fathifazl et al. (2011) in accordance with ASTM C157 using $100 \times 100 \times 285$ mm prisms reported a similar result. At 180 days the $100 \%$ RCA replacement specimens experienced approximately $0.07 \%$ shrinkage. It should be noted that the specimens in this case are slightly larger in thickness than the $75 \times 75 \times 285 \mathrm{~mm}$ specimens in this study. Samples of larger cross sections expanded at a lower rate. 


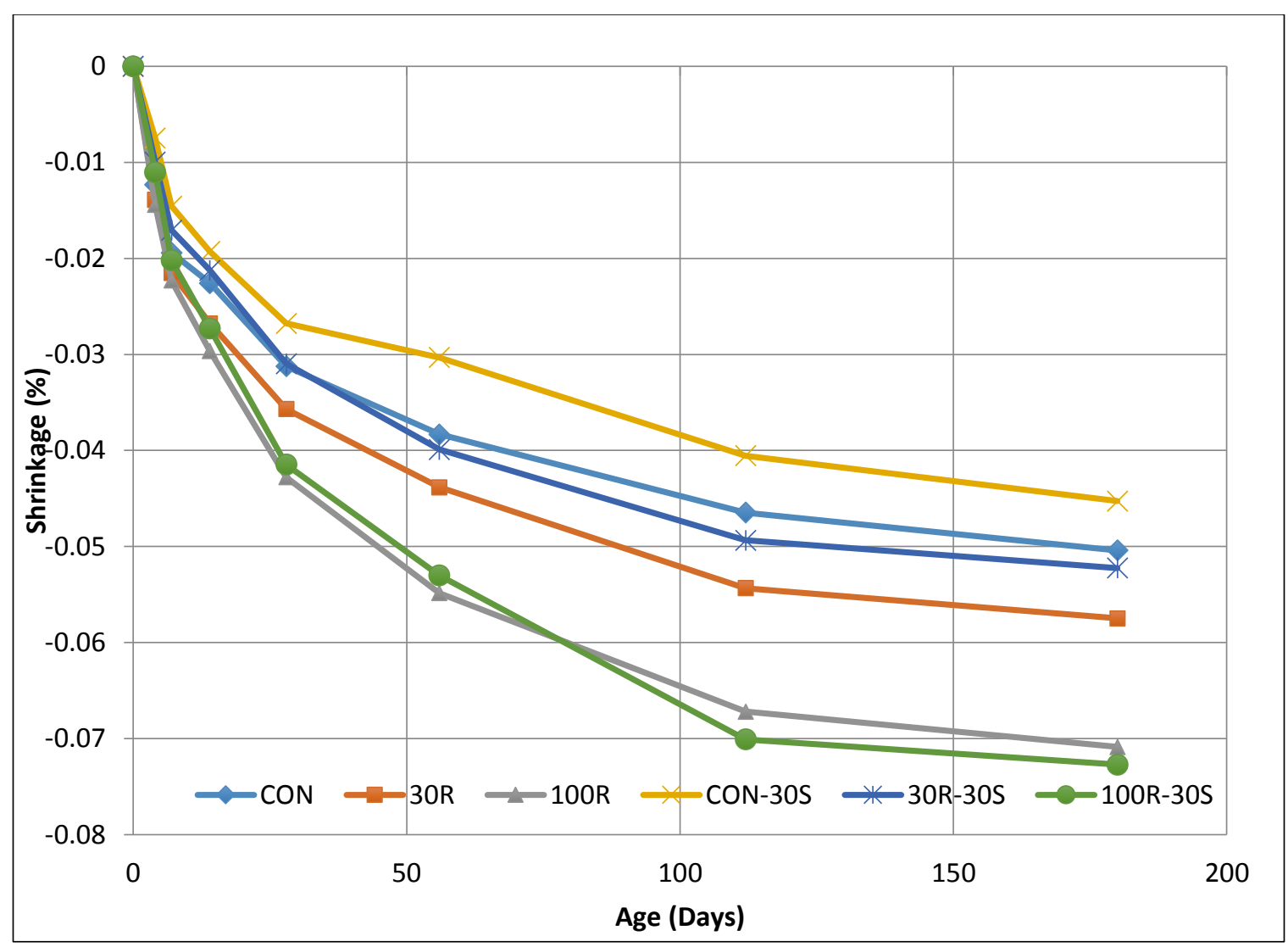

Figure 32: Drying shrinkage of C2 concrete

Additional specimens were cast as a comparison between concrete incorporating commercial RCA as well as RCA with preserved quality concrete. All specimens were cast at Ryerson University under laboratory conditions. A set of specimens were stored and test at Ryerson University while another set of specimens of the same batch were transported then stored and tested an external testing laboratory under laboratory conditions. This was done to verify the results in Figure 32 , as they appeared to be lower than what was expected, especially at earlier ages. All specimens were tested within the same time frame to ensure the RCA with preserved quality and commercial RCA specimens were exposed to the same humidity and temperature throughout the testing phase. The results are displayed in Figures 33 and 34. Similar results were attained from both the external 
testing facility and the Ryerson laboratory. At 28 days, the commercial RCA specimens exhibited more shrinkage than the specimens incorporating RCA with preserved quality in both facilities. The increase in drying shrinkage becomes more evident after 56 days. At 56 days, the Ryerson University specimens with a 100\% replacement commercial RCA experienced approximately $20 \%$ more drying shrinkage than the $100 \%$ replacement of RCA with preserved quality. This trend was also the case at the external facility. At 56 days the external facility specimens with a $100 \%$ replacement commercial RCA experienced approximately $12 \%$ more drying shrinkage than the $100 \%$ replacement of RCA with preserved quality. At 180 days the commercial RCA specimens continued to exhibit more drying shrinkage compared the RCA with preserved quality. The Ryerson University specimens exhibited a $12 \%$ increase while the external facility specimens exhibited a $10 \%$ increase. This result shows that the increase in the percentage replacement of RCA does not exponentially increase the drying shrinkage experienced.

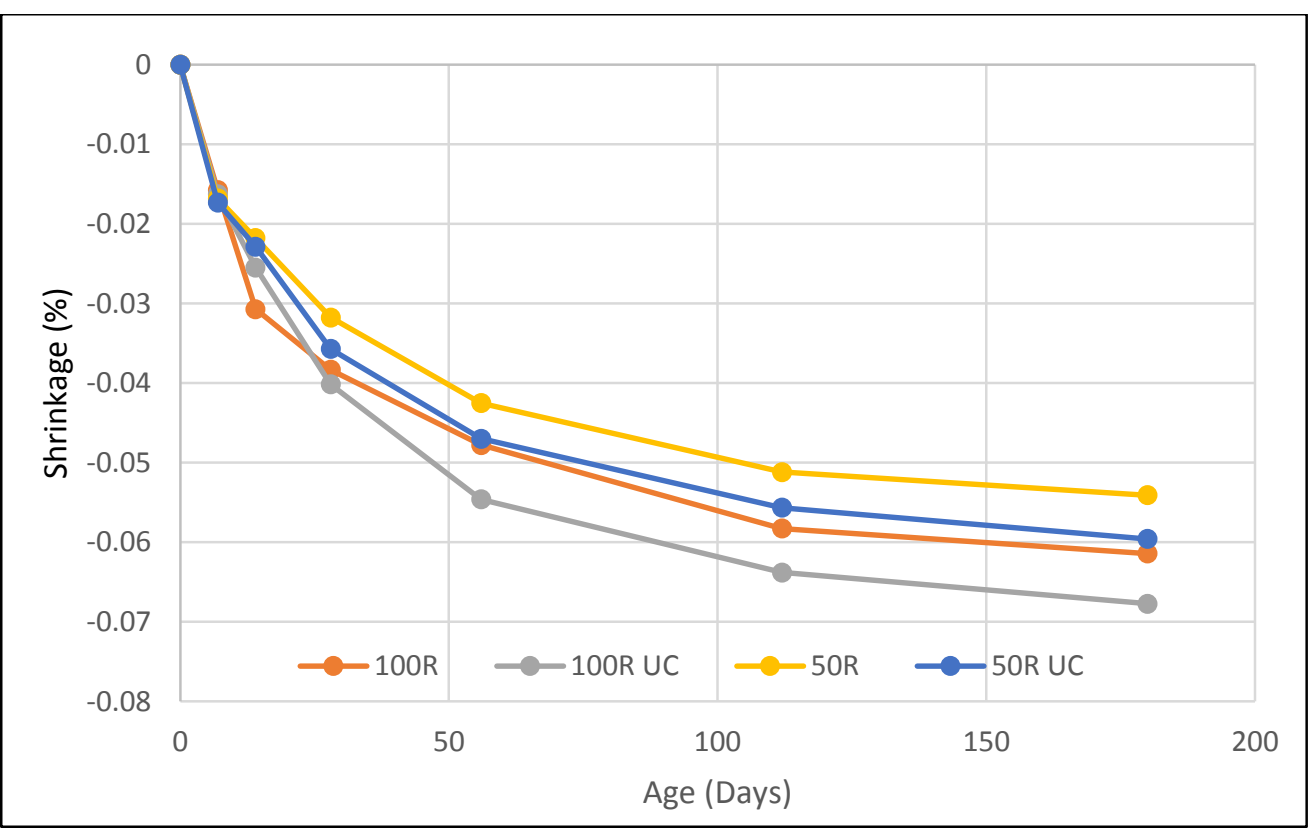

Figure 33: Drying shrinkage of C2 concrete tested at Ryerson University 


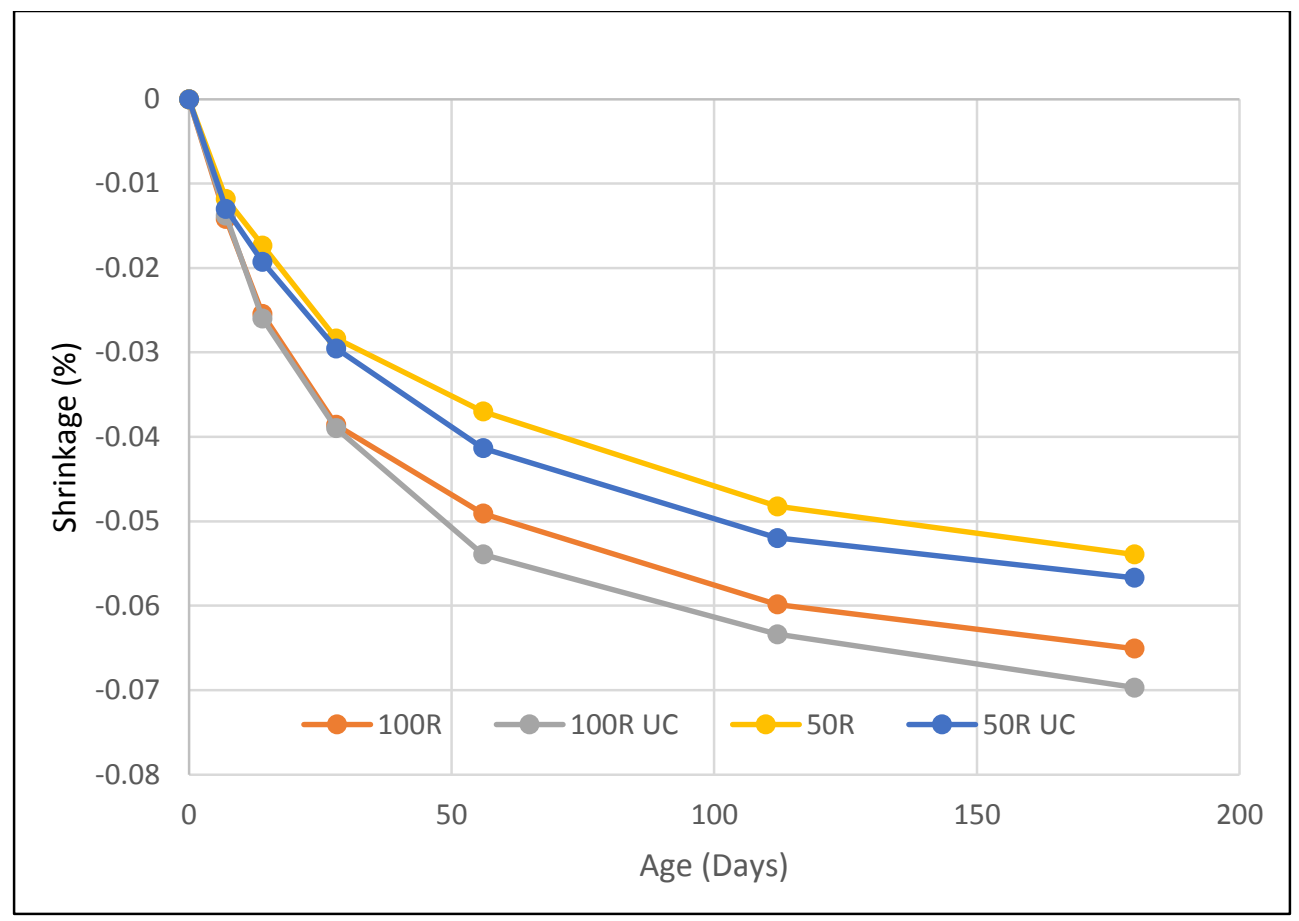

Figure 34: Drying shrinkage of C2 concrete tested at an external facility

\subsection{Salt Scaling Testing}

Salt scaling testing was only applied to the $\mathrm{C} 2$ specimens. Both the commercial RCA and the RCA with preserved quality were tested and compared to investigate any durability issues. The testing consisted of 50 freeze-thaw cycles. The Ontario Provincial Standard Specifications (OPSS) states that mass loss after 50 cycles should not exceed $0.8 \mathrm{~kg} / \mathrm{m}^{2}$. The results can be seen in figures 35 and 36. The data shows that all specimens did not exceed $0.8 \mathrm{~kg} / \mathrm{m}^{2}$ with the VA concrete specimens scaling the least. The results indicated that a 30\% replacement of RCA with preserved quality had a minimal effect on scaling, as the mass loss was comparable to that of the VA specimens. Conversely, the $30 \%$ replacement of commercial RCA exhibit much more scaling compared to the RCA with preserved quality of the same replacement percentage. 


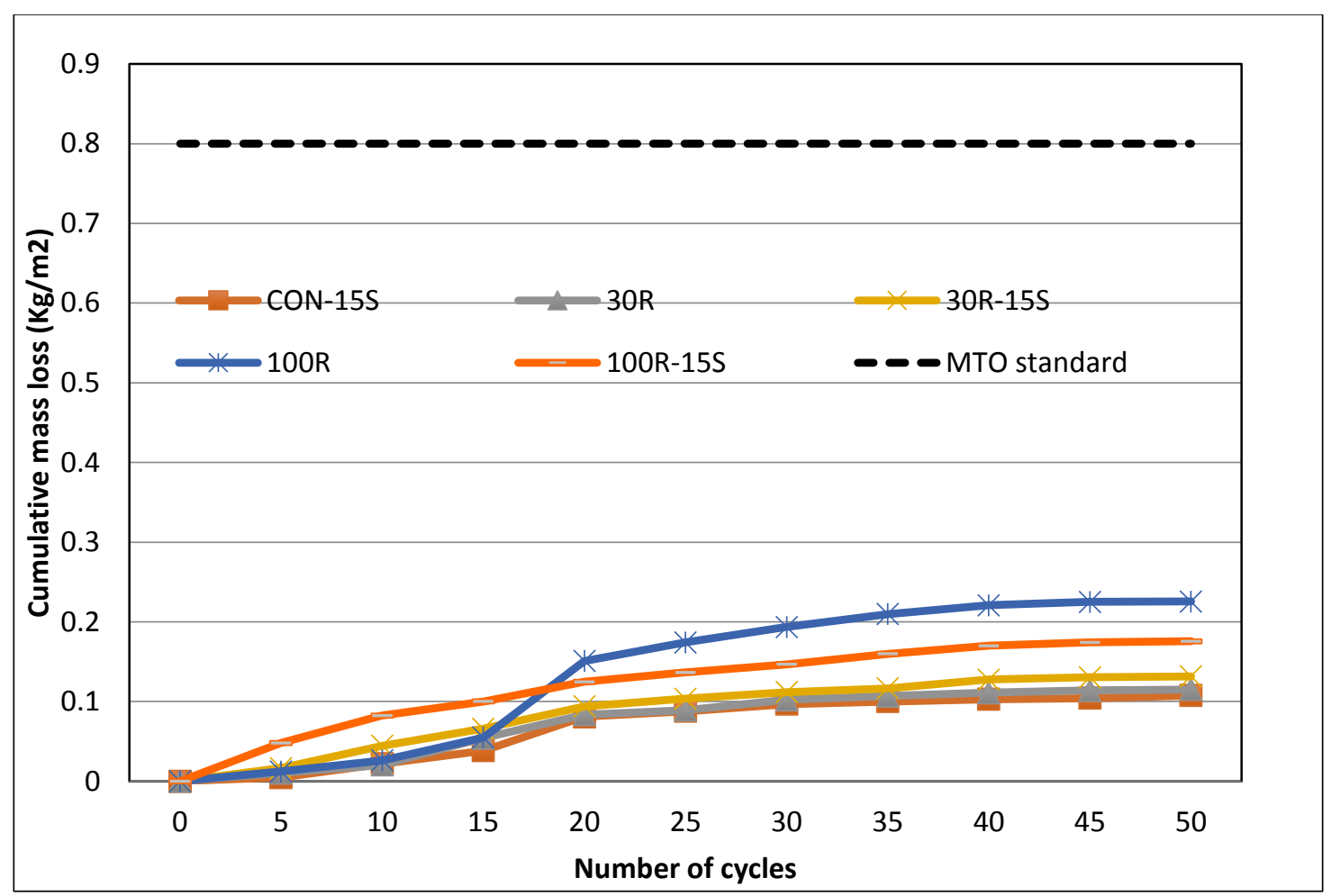

Figure 35: Salt scaling of C2 concrete containing RCA with preserved quality

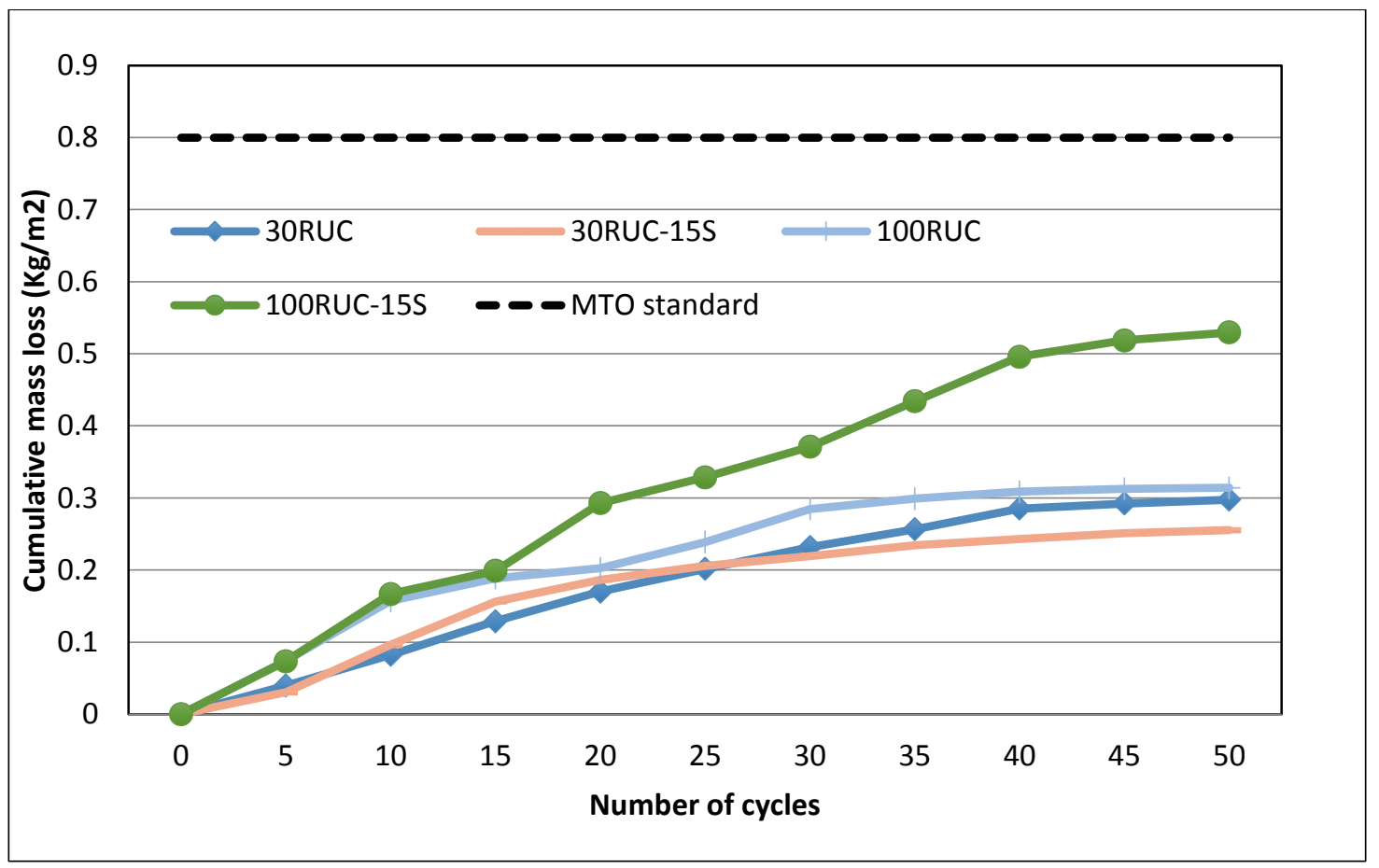

Figure 36: Salt scaling of C2 concrete containing commercial RCA 
Specimens incorporating 100\% replacement of commercial RCA achieved the highest mass loss after 50 cycles, reaching approximately $0.53 \mathrm{~kg} / \mathrm{m}^{2}$. This is approximately $195 \%$ more mass loss than the $100 \%$ replacement of the RCA with preserved quality. Scaling damage and mass loss was mainly due to aggregate pop-outs. This was particularly evident in the $100 \%$ commercial RCA specimen, which can be seen in Figure 37.

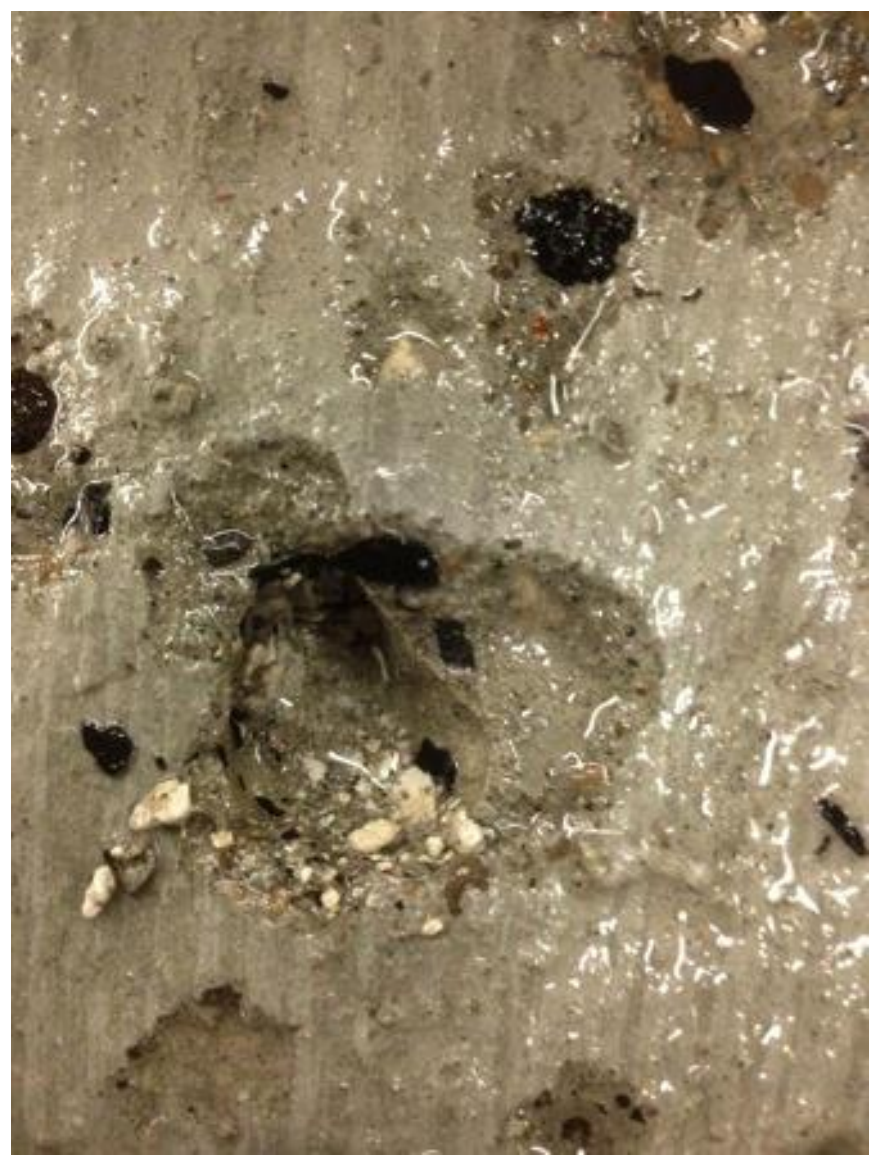

Figure 37: A close-up of salt scaling samples containing 100\% commercial RCA

Figure 38 illustrates a comparison of all C2 specimens after 50 cycles. The specimens incorporating RCA with preserved quality achieved less mass loss compared to the specimens incorporating commercial RCA. This may be indicative of the fact that the RCA with preserved 
quality was able to retain more of its original properties such as $\mathrm{w} / \mathrm{cm}$ ratio of the original mix. Additionally, the air-entrainment of the adhered mortar could have contributed to the decrease in mass loss. All salt scaling photos can be seen in Appendix A.

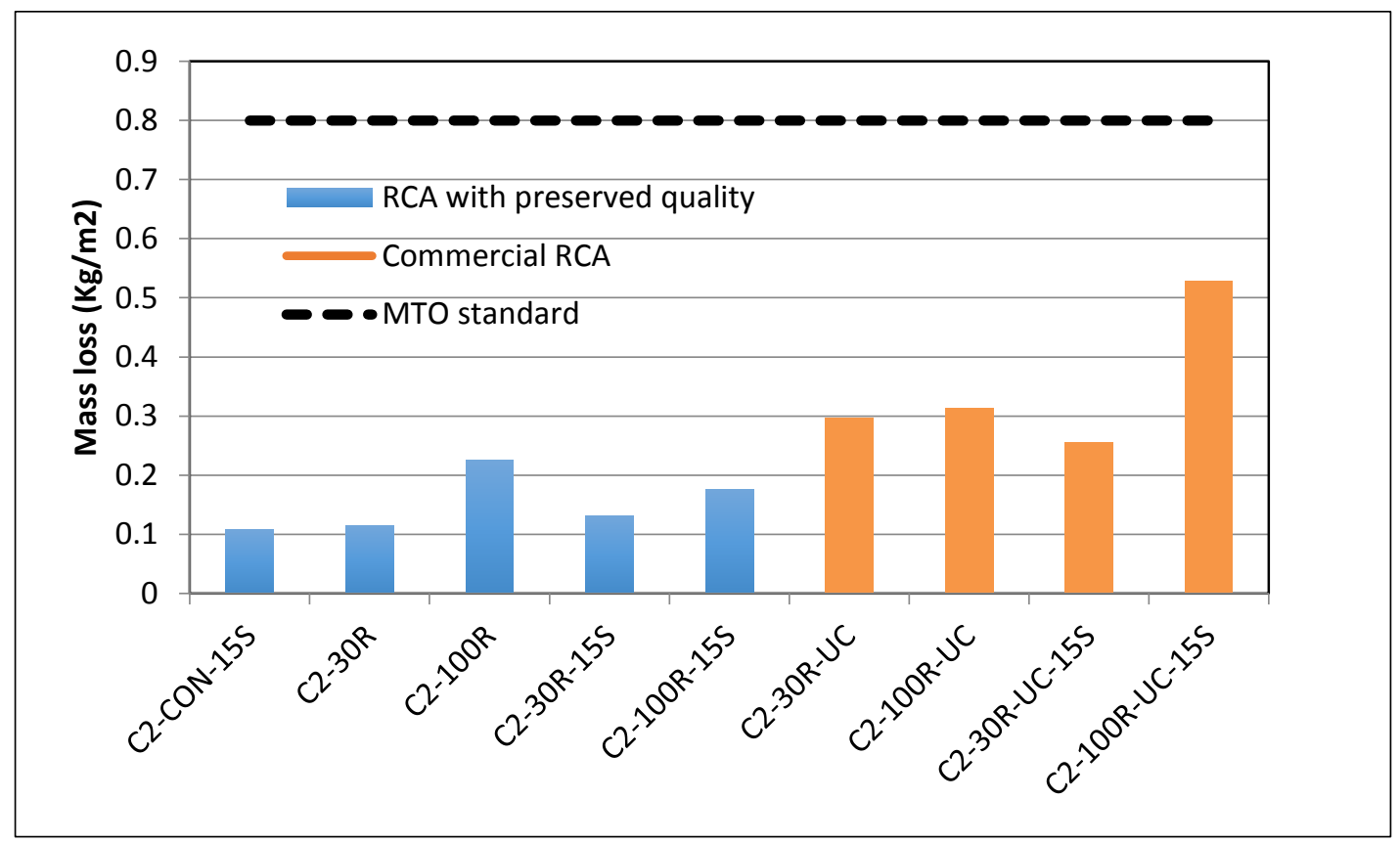

Figure 38: Mass loss of all C2 samples after 50 cycles of exposure to salt scaling test conditions

\subsection{Rapid Chloride Permeability Test}

Rapid chloride permeability testing was performed on all C2 specimens. The results illustrated in Figure 39 show that increasing the volume of RCA also increased the chloride penetration. The introduction of $30 \%$ GGBFS slightly decreased the chloride ingression. This was expected as the pozzolanic reaction of the slag produces more hydration products that enhance the pore structure of the paste. Specimens incorporating the commercial RCA experienced slightly more chloride 
ingression than the specimens containing RCA with preserved quality. The $100 \%$ replacement of the commercial RCA and RCA with preserved quality experience moderate/higher chloride ion ingression. This was expected due to increase in permeability from the adhered mortar attached to the RCA. The standard set by CSA for a 56-day specimen is 1500 coulombs. The only specimens that meet this specification were the specimens containing 30\% GGBFS as well as incorporating $30 \%$ RCA with preserved quality and the $30 \%$ commercial RCA

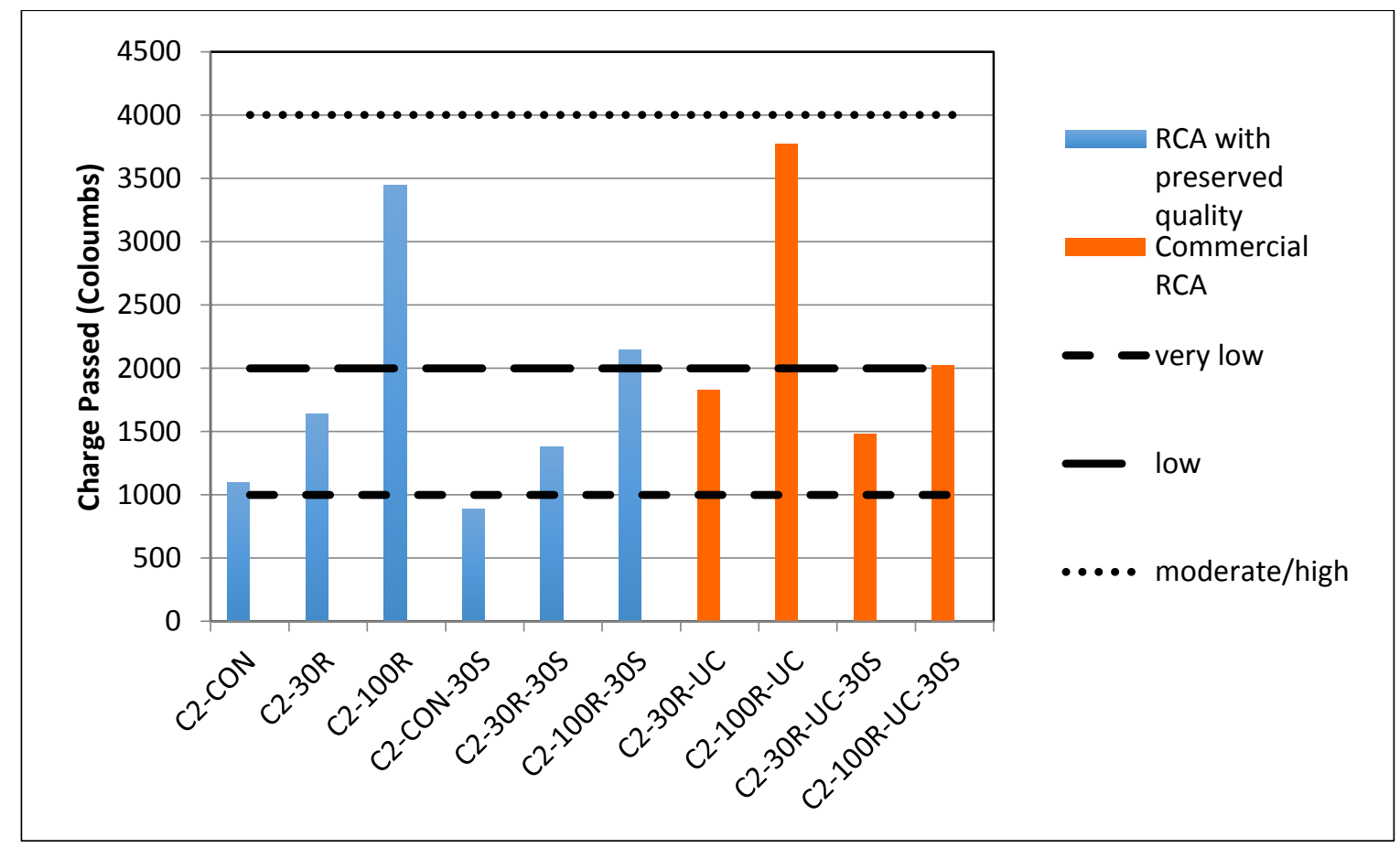

Figure 39: The rapid chloride permeability of samples at 56 days 


\section{Discussion}

One of the objectives of this study was to compare two types of RCA sources; RCA of preserved quality and commercial RCA. This commercial RCA was produced from mainly returned-to-plant concrete and produced commercially in Ontario on a high and consistent quality. Additionally, the commercial RCA used for this study did not include contaminant such as gypsum board, word, asphalt, ceramics or organics. However, it was not produced using a strict quality control protocol, such as that of the RCA with preserved quality. Across all categories of testing, the RCA of preserved quality was able to perform better compared to the commercial RCA. A comparison of the effects of using 100\% commercial RCA and 100\% RCA of preserved quality on Class C2 concrete can be seen in Table 11.

Table 11: A comparison of Class C2 concrete containing commercial RCA and RCA of preserved quality

\begin{tabular}{lccc}
\hline Test & $\begin{array}{c}\text { 100\% RCA with } \\
\text { preserved quality }\end{array}$ & $\begin{array}{c}100 \% \text { commercial } \\
\text { RCA }\end{array}$ & $\begin{array}{c}\text { Percent } \\
\text { increase/decrease } \\
(\%)\end{array}$ \\
\hline $\begin{array}{l}\text { Compressive } \\
\text { Strength }(\mathrm{MPa})\end{array}$ & 34.62 & 31.43 & 9 \\
\hline $\begin{array}{l}\text { Splitting tensile } \\
\text { strength (MPa) }\end{array}$ & 2.43 & 2.32 & 4.5 \\
\hline $\begin{array}{l}\text { Drying shrinkage } \\
(\%) \text { at } 180 \text { days }\end{array}$ & 0.061 & 0.068 & 12 \\
\hline Salt scaling $\left(\mathrm{Kg} / \mathrm{m}^{2}\right)$ & 0.22 & & 41 \\
\hline
\end{tabular}




\begin{tabular}{llll}
\hline RCPT (coloumbs) & 3446 & 3772 & 9.5
\end{tabular}

*All data represented in Table 10 are of specimens without GGBFS

The commercial RCA proved to have a lower overall strength compared to the RCA with preserved quality. In terms of compressive strength, the $100 \%$ commercial RCA replacement specimens did not satisfy the CSA requirement for $\mathrm{C} 2$ concrete. The reduction in strength can be attributed to the lower quality of adhered mortar in the commercial RCA.

The commercial RCA specimens experienced significantly more drying shrinkage compared to the RCA of preserved quality specimens. At a $100 \%$ replacement, the commercial RCA experienced approximately $12 \%$ more drying shrinkage. This can be attributed to the increase in fines due to lower quality adhered mortar in the commercial RCA, in addition to increasing the total porosity in the mix. Additionally, the increase in the total volume water added during mixing of the commercial RCA can attribute to the increase in drying shrinkage. Figure 40 displays a comparison of the shrinkage results of both RCA types obtained at Ryerson University. 


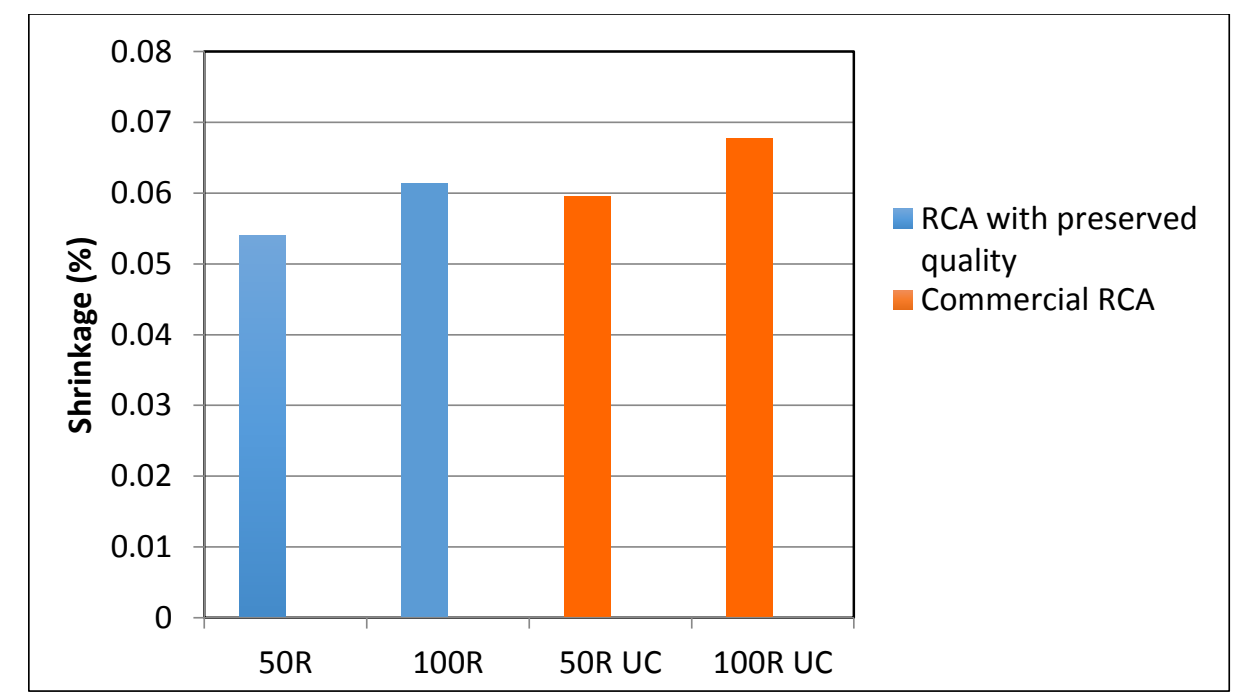

Figure 40: The shrinkage of RCA of preserved quality and commercial RCA at 180 days at Ryerson University

Figure 41 illustrates the scaling resistance of specimens incorporating 100\% RCA with preserved quality and $100 \%$ commercial RCA, with and without GGBFS. The mass loss results and visual inspection indicated that there was significantly more scaling in the specimens incorporating commercial RCA compared to the RCA with preserved quality specimens. This can be attributed to the protocol established to maintain the original properties of the RCA with preserved quality. Controlling the amount of water used in discharging the fresh concrete from the transit mixer maintains the original $\mathrm{w} / \mathrm{cm}$ ratio and does not weaken the overall matrix. Visual inspection of the specimens should be considered when evaluating concrete incorporating RCA. Although the scaling results of the specimens containing commercial RCA satisfy the allowable limit set by MTO the appearance after constant freeze-thaw cycles is less appealing and may be satisfactory to owners. The use of RCA of preserved quality is recommended in applications where appearance is of importance. 


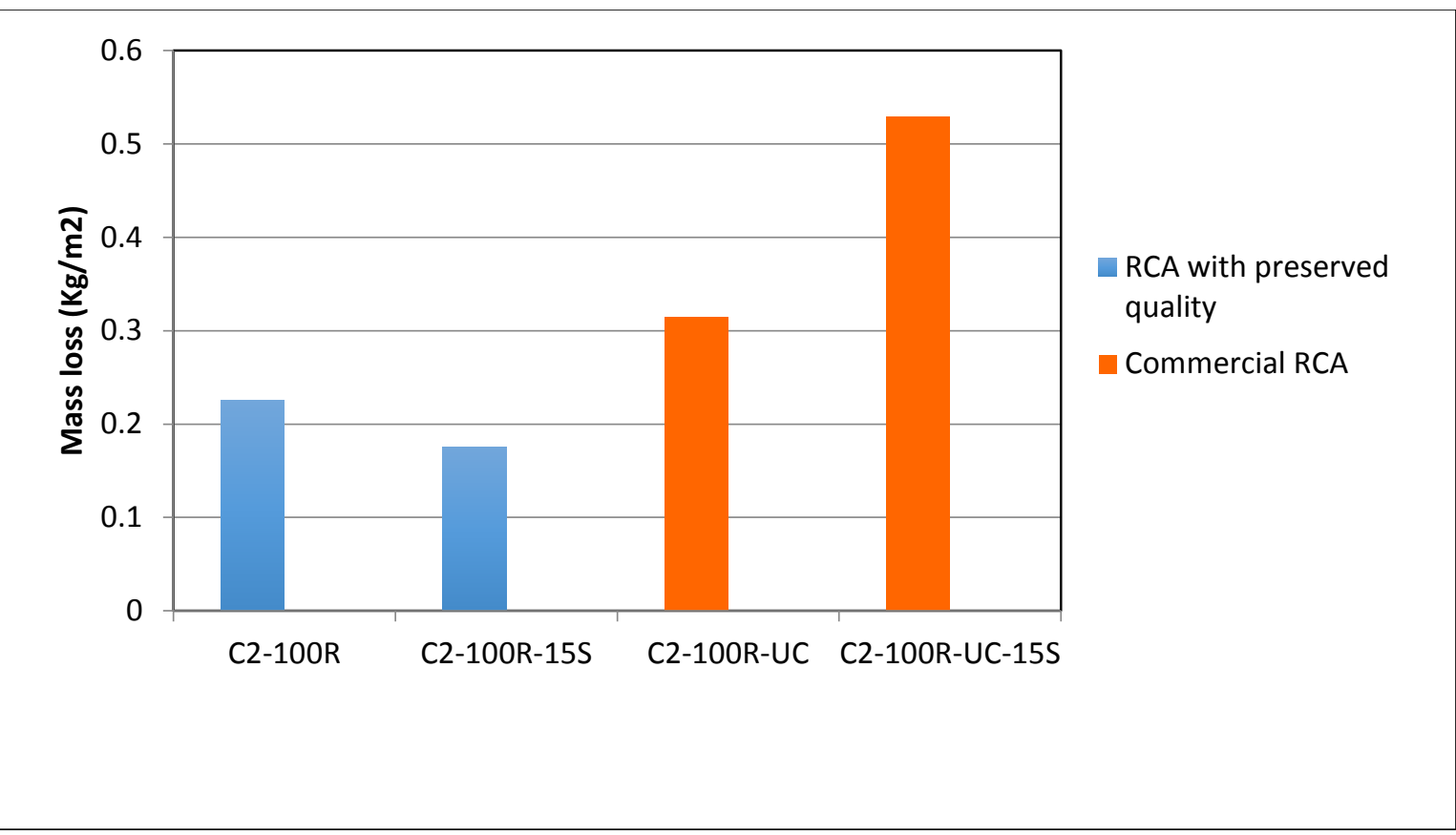

Figure 41: The scaling resistance of concrete containing 100\% RCA of preserved quality or $100 \%$ commercial RCA after 50 cycles

Commercial RCA specimens experience more chloride ion penetrability when compared to the RCA of preserved quality specimens. This can be attributed to the porosity of the commercial RCA. When the returned-to-plant concrete returned to the batch plant water, most of the times, is used to ease the process of discharging the transit mixer. This water however is not controlled and increases the w/cm ratio and porosity. The lack of control of the grade of the returned concrete is also a factor that contributes to the lower quality of commercial RCA.

A one-tailed T-test was performed to confirm whether the results gathered from the various tests were significantly different. Using a significance of 0.05 , the T-test results shown in Table 12 indicated that RCA with preserved quality was significantly different from the commercial RCA, 
in terms of compressive strength, drying shrinkage and salt scaling resistance. The full T-test analysis can be found in Appendix B.

Table 12: T-test of RCA of preserved quality Vs. Commercial RCA for various tests

\begin{tabular}{|c|c|}
\hline & P-value \\
\hline \multicolumn{2}{|l|}{ Compressive Strength } \\
\hline $100 \% \mathrm{RCA}$ & 0.022 \\
\hline $100 \%$ RCA with $30 \%$ GGBFS & 0.036 \\
\hline $30 \% \mathrm{RCA}$ & 0.005 \\
\hline $30 \%$ RCA with $30 \%$ GGBFS & 0.003 \\
\hline \multicolumn{2}{|l|}{ Splitting Tensile Strength } \\
\hline $100 \%$ RCA & 0.142 \\
\hline $100 \%$ RCA with $30 \%$ GGBFS & 0.083 \\
\hline $30 \% \mathrm{RCA}$ & 0.227 \\
\hline $30 \%$ RCA with $30 \%$ GGBFS & 0.311 \\
\hline \multicolumn{2}{|l|}{ Drying Shrinkage } \\
\hline $100 \%$ RCA & 0.011 \\
\hline $50 \% \mathrm{RCA}$ & 0.046 \\
\hline \multicolumn{2}{|l|}{ Salt Scaling } \\
\hline $100 \%$ RCA & 0.024 \\
\hline $100 \%$ RCA with $30 \%$ GGBFS & 0.016 \\
\hline $30 \% \mathrm{RCA}$ & 0.026 \\
\hline $30 \%$ RCA with $30 \%$ GGBFS & 0.045 \\
\hline
\end{tabular}

*Using a significance of $\mathrm{P}=0.05$ 


\section{Conclusions and Recommendations for Future Work}

Throughout this study, concrete incorporating RCA has been put through stringent testing to determine the feasibility of using RCA as a partial replacement for coarse aggregate. Two types of RCA; RCA with preserved quality and commercial RCA were investigated in order to determine if controlling returned-to-plant concrete before it is allowed to harden and processed into RCA would lead to better quality RCA when used as coarse aggregate. To accomplish this, specimens were cast for three different class exposure and criteria. These three classes for concrete specified varying $\mathrm{w} / \mathrm{cm}$ ratios and compressive strength.

\subsection{Batching and Fresh Properties}

The physical properties of RCA had to be taken into account in order to appropriately create an accurate the mix design. The rate of absorption, moisture content, shape and surface texture were determined to correct for the amount of aggregate and water needed. After the mixing process was complete, the fresh properties closely examined to measure workability and stability as well as air content.

1. The use of a TSMA produced workable fresh concrete for three different $w / \mathrm{cm}$ ratios. The fresh concrete was deemed workable and was able to satisfy slump and air content standards for $\mathrm{C} 2$ and $\mathrm{F} 1$ exposures. 
2. The TSMA was able to successfully offset the high absorptive property of the coarse RCA by initially soaking the coarse RCA. The TSMA was considered successful because the study did not produce any mixtures that were dry and unworkable.

3. The slump retention results indicated that all fresh concrete produce from the study was able remain workable over time.

\subsection{Hardened Properties of RCA Concrete}

All specimens were cast to meet the compressive strength of class exposures $\mathrm{C} 1$ and $\mathrm{F} 1$ as well as a low strength $15 \mathrm{MPa}$ concrete. Specimens included VA concrete, concrete incorporating RCA with preserved quality and concrete incorporating commercial RCA. The RCA was used to replace virgin coarse aggregate using a variety of replacement percentages, with a $100 \%$ replacement being the highest. The effect of the addition of GGBFS was also investigated.

1. For the $\mathrm{C} 2$ concrete, all specimens except the $100 \%$ replacement of commercial RCA and the $100 \%$ replacement of commercial RCA with $30 \%$ GGBFS were able to pass the minimum required compressive stress set by CSA A23.1 of $32 \mathrm{MPa}$. These two specimens incorporated a $100 \%$ replacement of commercial RCA. An increase in the amount of RCA used as replacement resulted in a decrease in compressive strength. Specimens incorporating RCA with preserved quality produced concrete with a higher compressive strength compared to the specimens contains commercial RCA.

2. For the F1 concrete, specimens incorporating RCA with preserved quality were able to meet the $30 \mathrm{MPa}$ compressive strength requirement set by CSA A23.1. There was an 
evident decrease in compressive strength as the percentage of RCA used as coarse aggregate replacement increased.

3. For the $15 \mathrm{MPa}$ concrete, specimens incorporating RCA with preserved quality met the 15 MPa criteria. An increase in the amount or RCA used as replacement resulted in a decrease in compressive strength,

4. The use of $30 \%$ GGBFS in the $\mathrm{C} 2, \mathrm{~F} 1$ and $15 \mathrm{MPa}$ did not significantly reduce compressive strength 7 and 28 days.

5. The results of the splitting tensile test of the $\mathrm{C} 2$ specimen indicated that an increase in the amount of RCA used as a coarse aggregate replacement decreased the splitting tensile strength. Specimens incorporating RCA with preserved quality achieved higher splitting tensile strength than the commercial RCA specimens.

6. Specimens incorporating RCA experienced significantly more drying shrinkage than the VA specimens. An increase in the volume of RCA replacement resulted in an increase in drying shrinkage. The use of 30\% GGBFS had a minimal effect toward impacting the drying shrinkage of the RCA specimens. Additionally, when comparing the two types of RCA reviewed in this study it was apparent that the commercial RCA experienced higher drying shrinkage. This was validated using two different facilities to store and test the specimens. 


\subsection{Durability of Concrete Containing RCA}

Salt scaling testing was performed to evaluate the durability of concrete cast using both types of RCA. Specimens were cast using a varying of RCA replacement levels. GGBFS was also used to investigate its effect on increasing durability.

1. No specimen exceeded the $0.8 \mathrm{~kg} / \mathrm{m}^{2}$ set by OPSS. This is due to the fact that the mixtures were air-entrained. Increasing the replacement level of RCA also increased the amount of mass loss experience after 50 cycles. The concrete specimens consisting of 30\% RCA with preserved quality exhibited mass loss very similar to the control VA specimens. The commercial RCA experienced significantly more mass loss compared to the RCA with preserved quality. The mass loss was mainly in the form of pop-outs in the vicinities of RCA.

2. The use of $15 \%$ GGBFS did not have conclusive impact on the salt scaling of the mixtures, although the $100 \%$ replacement of commercial RCA with 15\% GGBFS sample experienced the most mass loss of $0.53 \mathrm{~kg} / \mathrm{m}^{2}$. The $100 \%$ replacement of commercial RCA without $15 \%$ GGBFS specimen obtained a mass loss of $0.31 \mathrm{~kg} / \mathrm{m}^{2}$. Though the introduction of $15 \%$ GGBFS increased scaling in this case it still met the $0.80 \mathrm{~kg} / \mathrm{m}^{2}$ standard. 


\subsection{Recommendations}

1. After a thorough analysis of the results, it is recommended to adopt the protocol of separating the returned-to-plant concrete based on strength (25 MPa and higher) as well as controlling the addition of water used to discharge the returned concrete from the transit mixer. A minimal amount to no water was added during the discharge process. RCA with preserved quality performed better across all categories of testing compared to the commercial RCA.

2. Separating the returned-to-plant concrete base on the presence of air-entrainment would produce better results, particularly in terms of freeze-thaw and scaling resistance.

3. The commercial RCA was able to meet the compressive strength requirement of $\mathrm{C} 2$ concrete. However, it experienced significantly higher drying shrinkage as well as salt scaling compared to the RCA with preserved quality. It is recommended that the commercial RCA be used in application with no stringent requirement in terms of drying shrinkage or salt scaling.

4. The RCA with preserved quality is recommended to undergo further tests including the use of a shrinkage-reducing admixture.

5. There is an opportunity for RCA with preserved quality to be further researched in order to be used for field applications. It has proven to meet the $\mathrm{C} 2$ compressive strength standard as well as satisfy the OPSS salt scaling requirement. It is recommended that next step be field trial testing. 


\section{Appendix A - List of Salt Scaling Pictures}

Table 13: Salt scaling specimens through 0, 25 and 50 freeze-thaw cycles

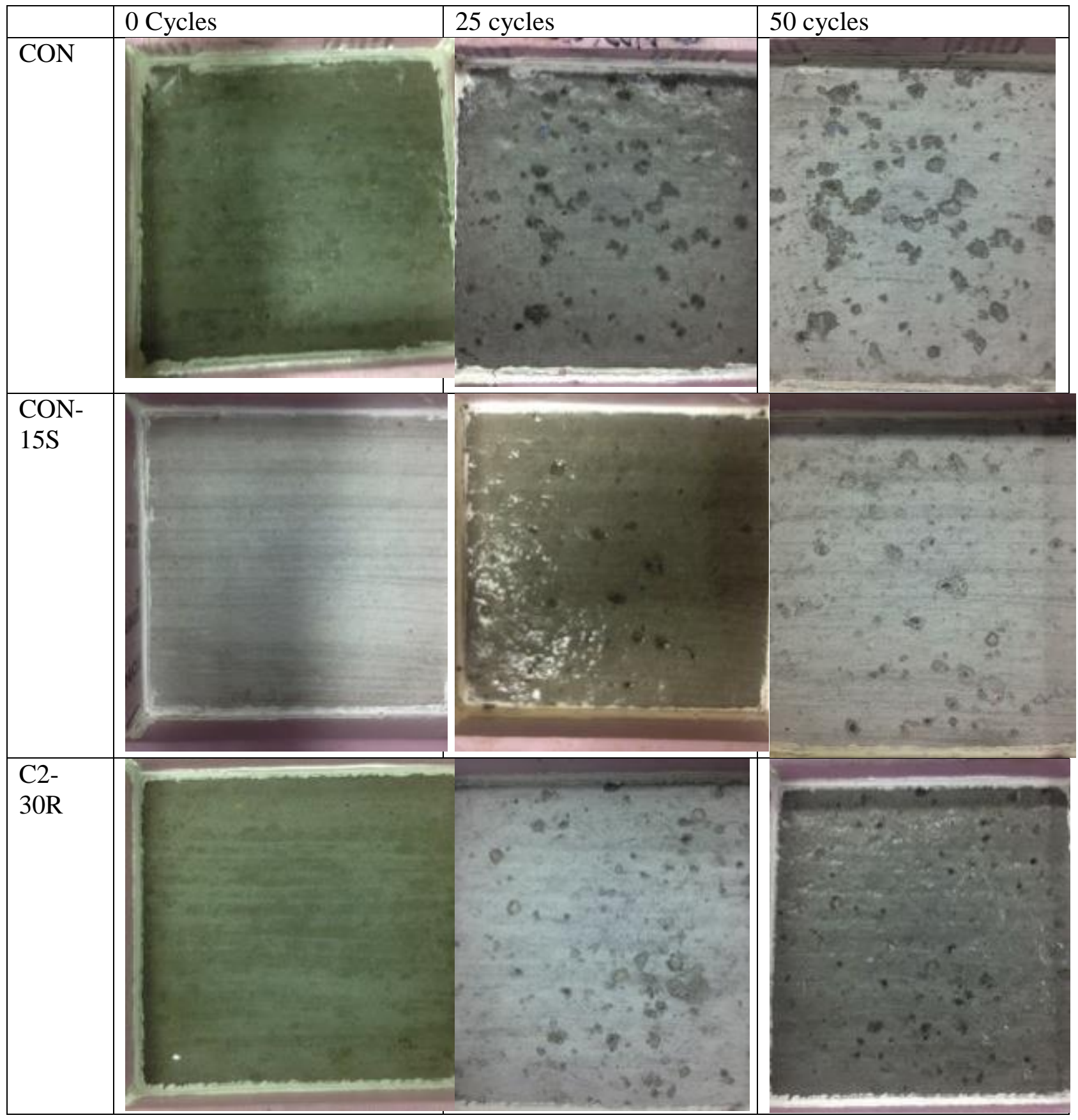




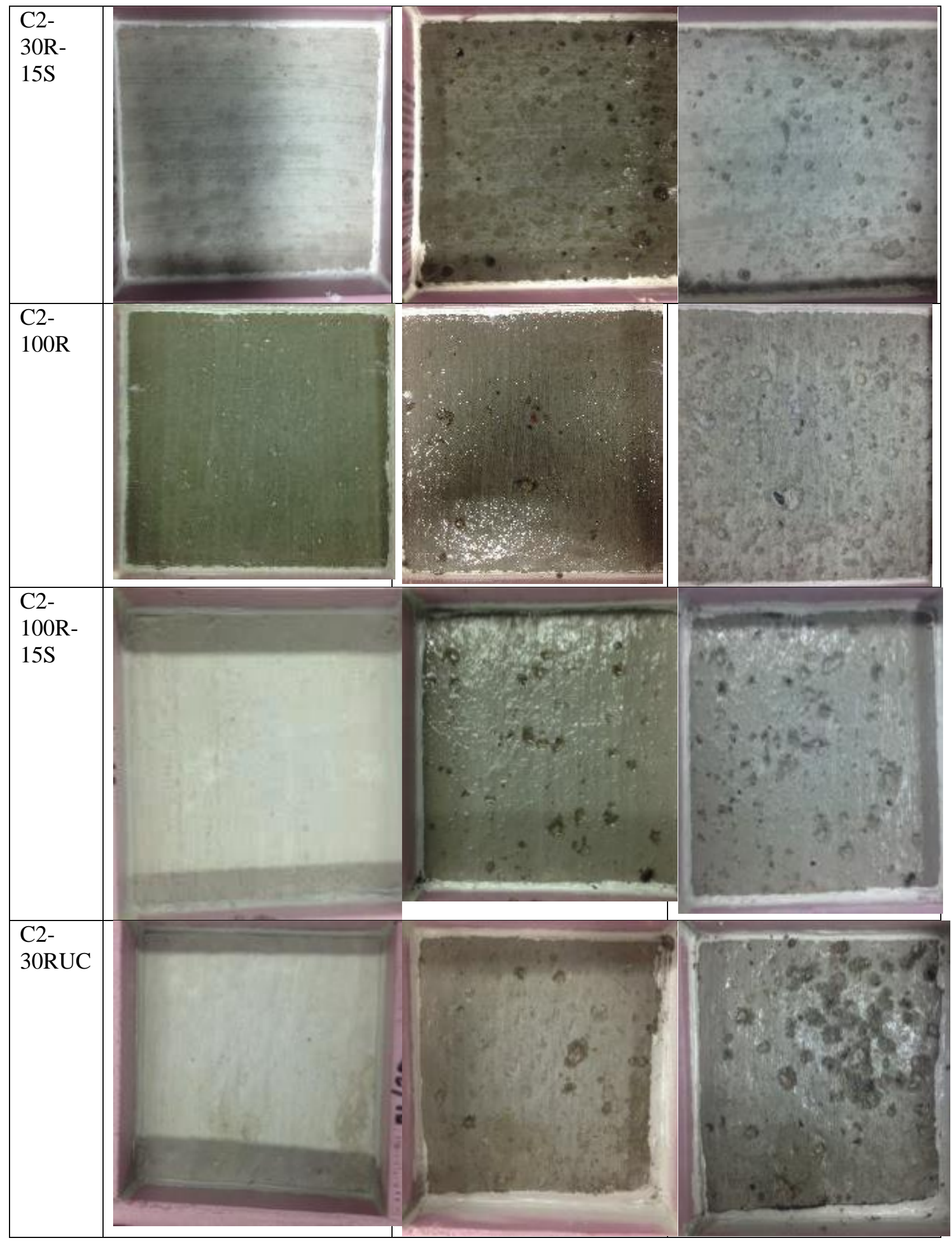




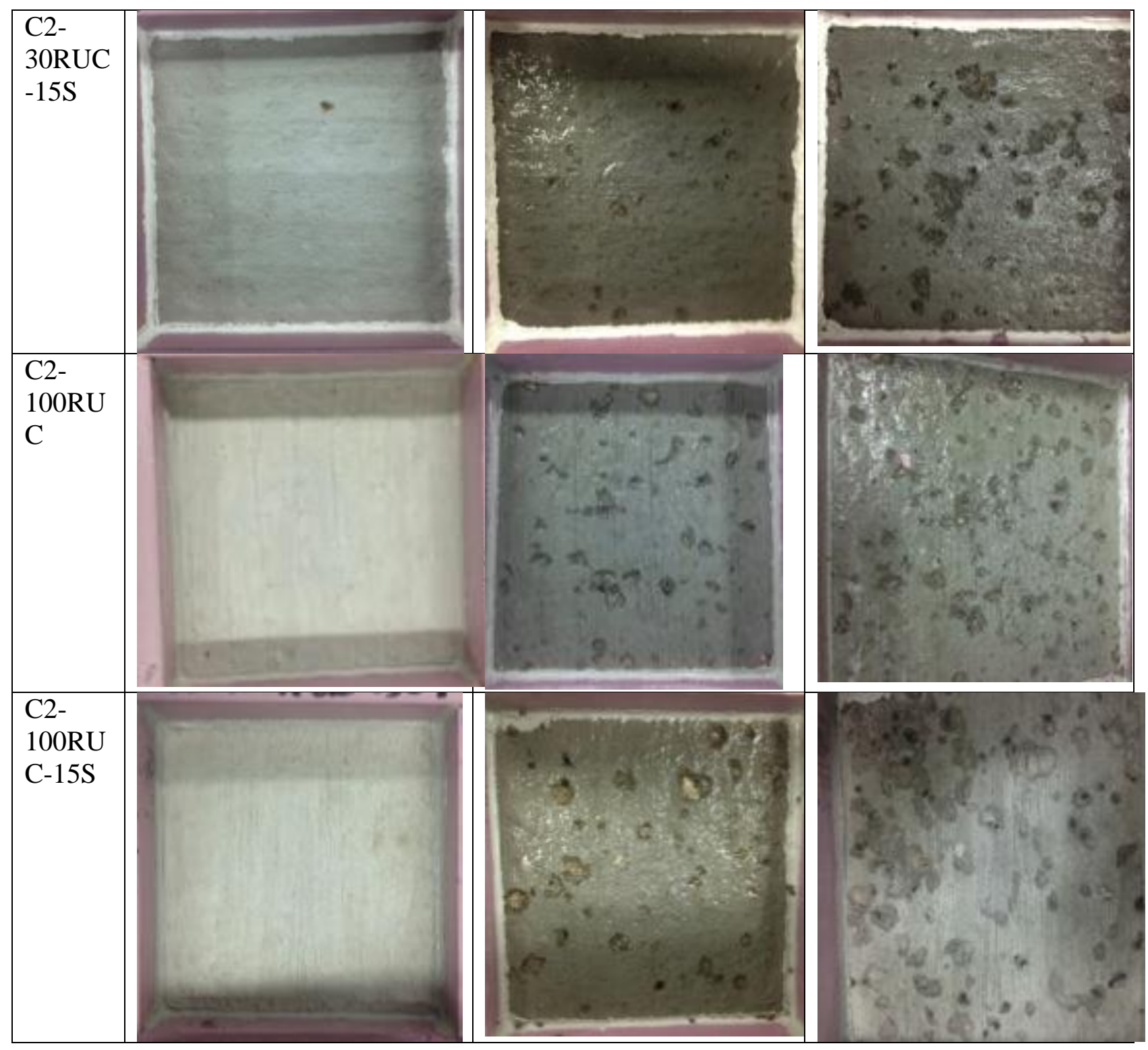




\section{Control Specimen}

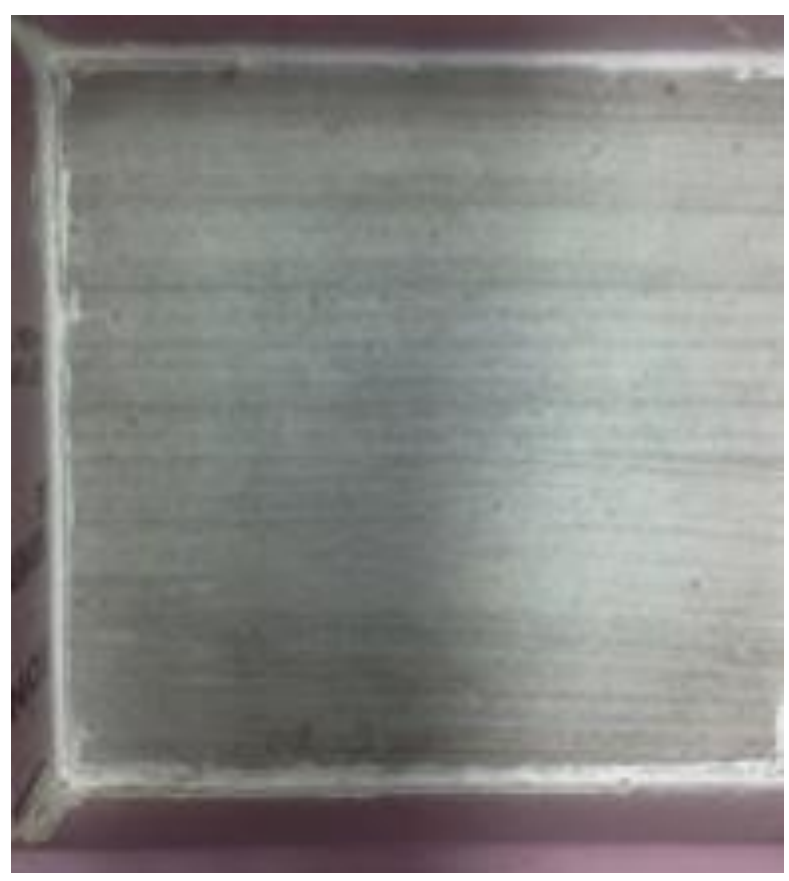

Figure 42: CON-15S specimen after 0 cycles

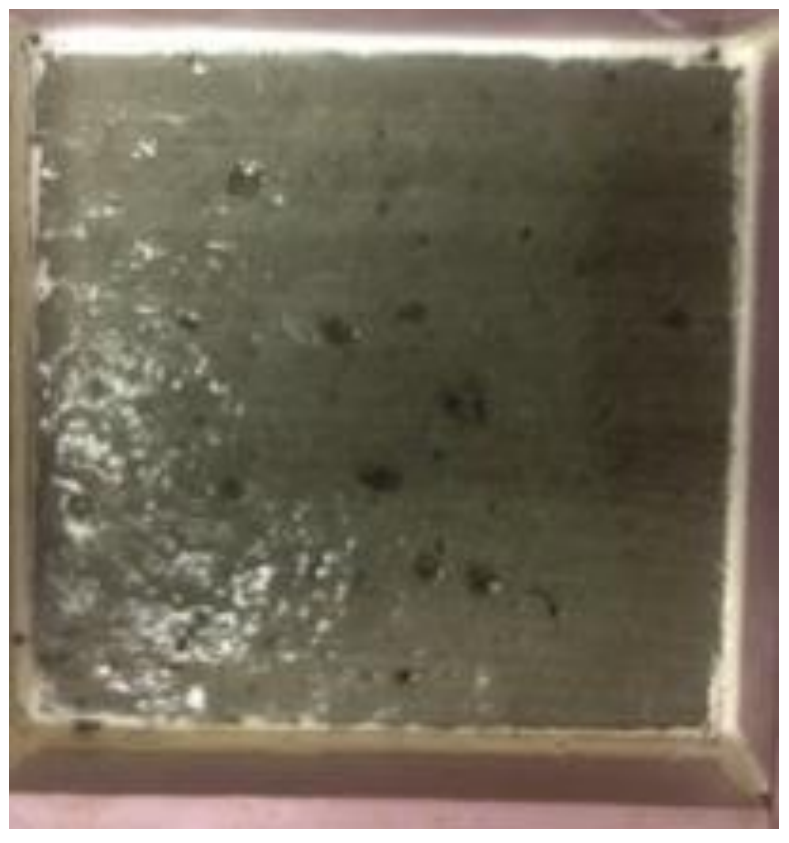

Figure 43: CON-15S specimen after 25 cycles 


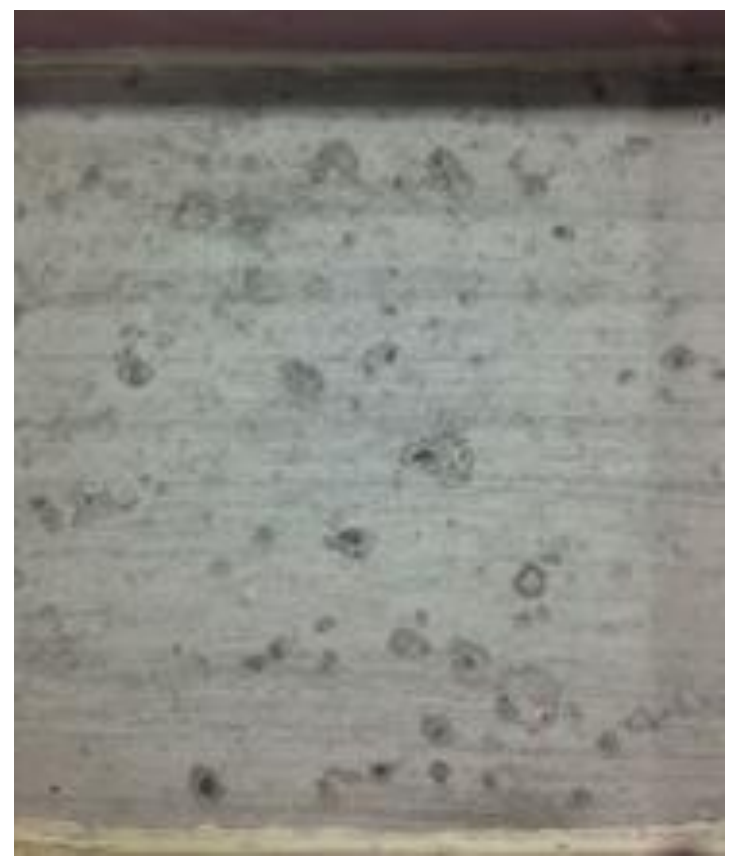

Figure 44: CON-15S specimen after 50 cycles 
Specimen with 30\% RCA of Preserved Quality

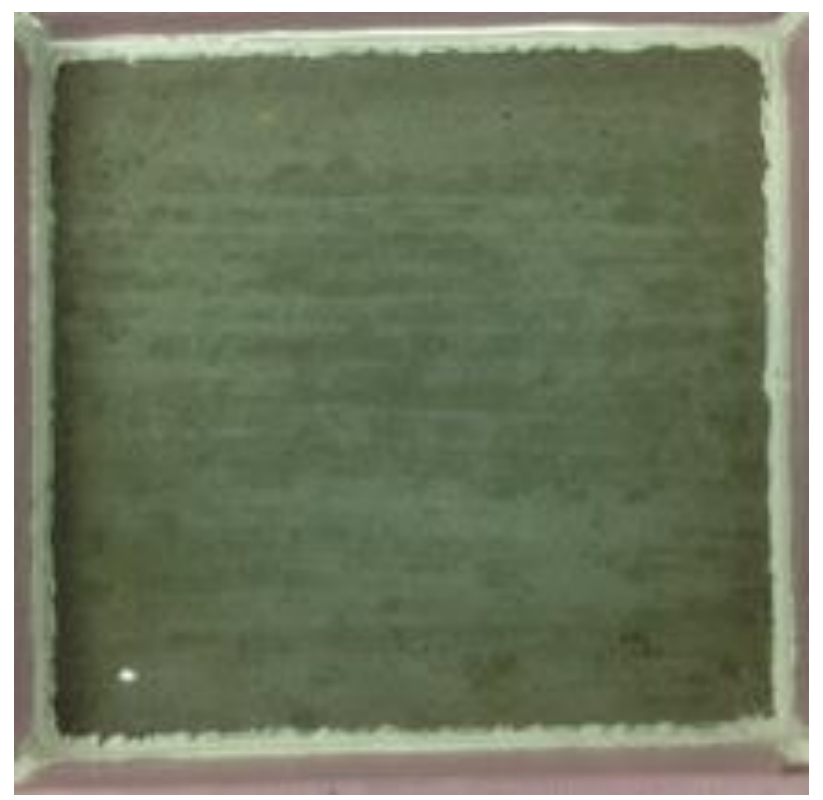

Figure 45: 30R specimen after 0 cycles

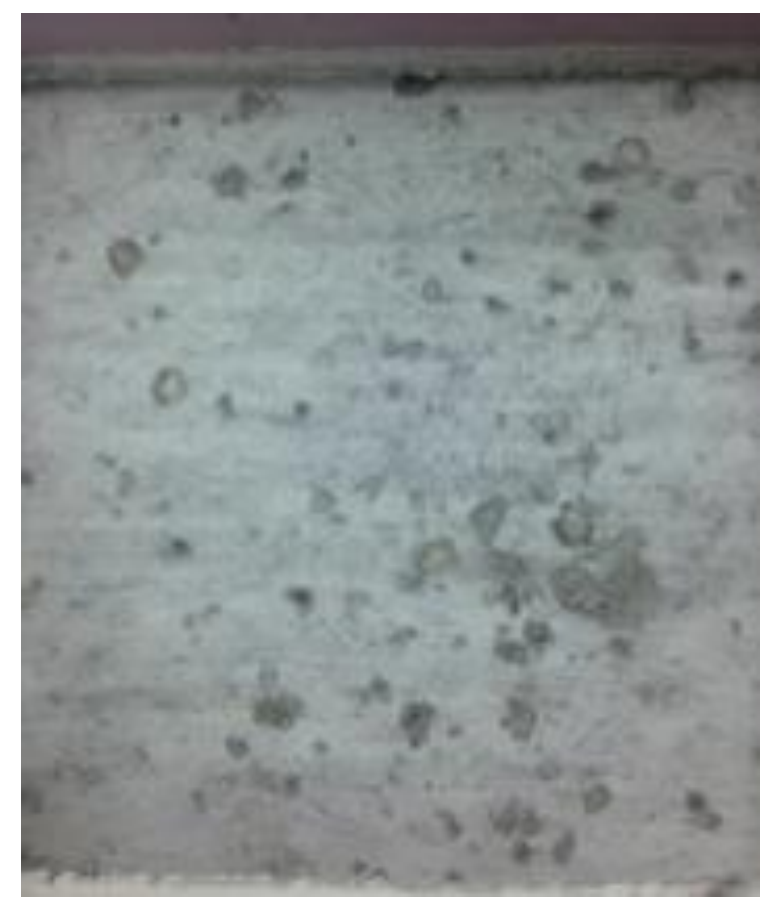

Figure 46: 30R specimen after 25 cycles 


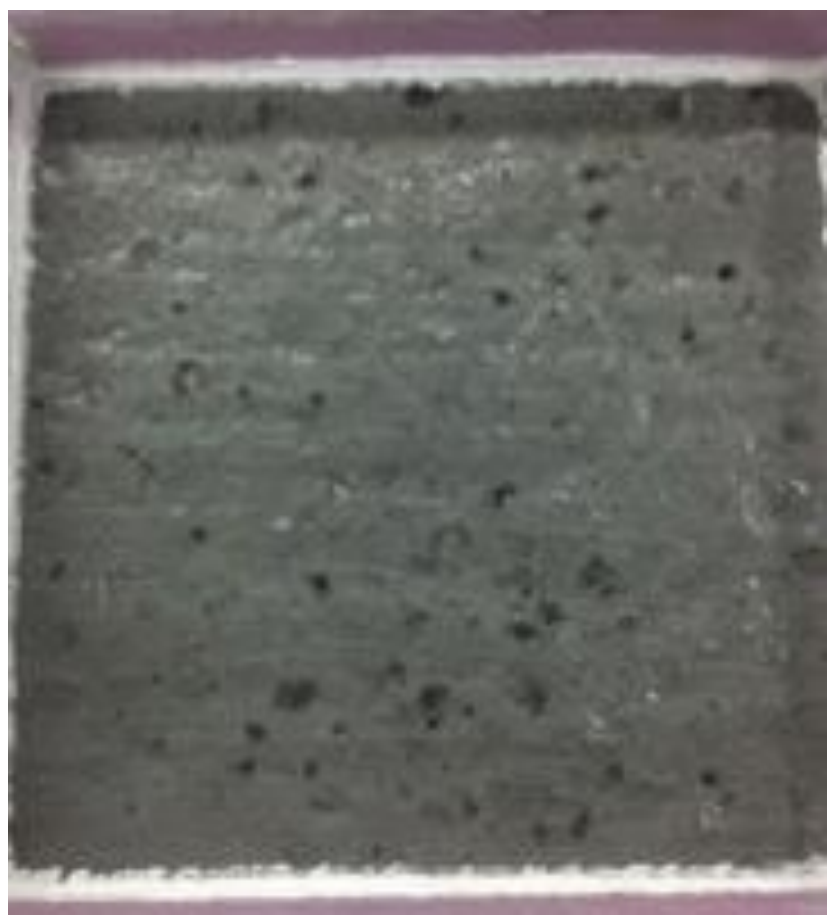

Figure 47: 30R specimen after 50 cycles 
Specimen with 30\% RCA of Preserved Quality and 15\% GGBFS

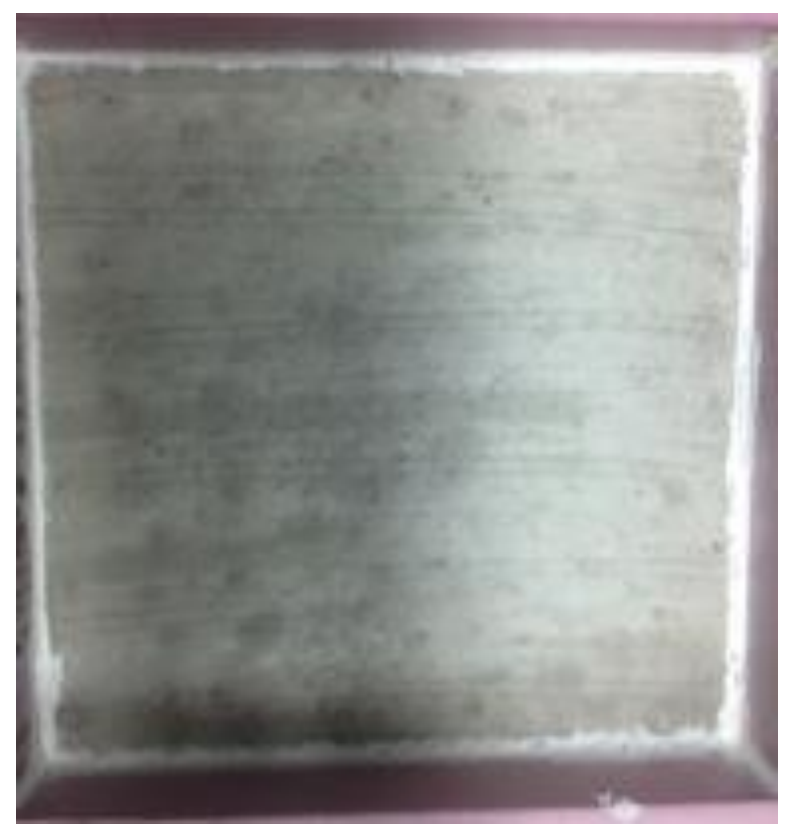

Figure 48: 30R-15S specimen after 0 cycles

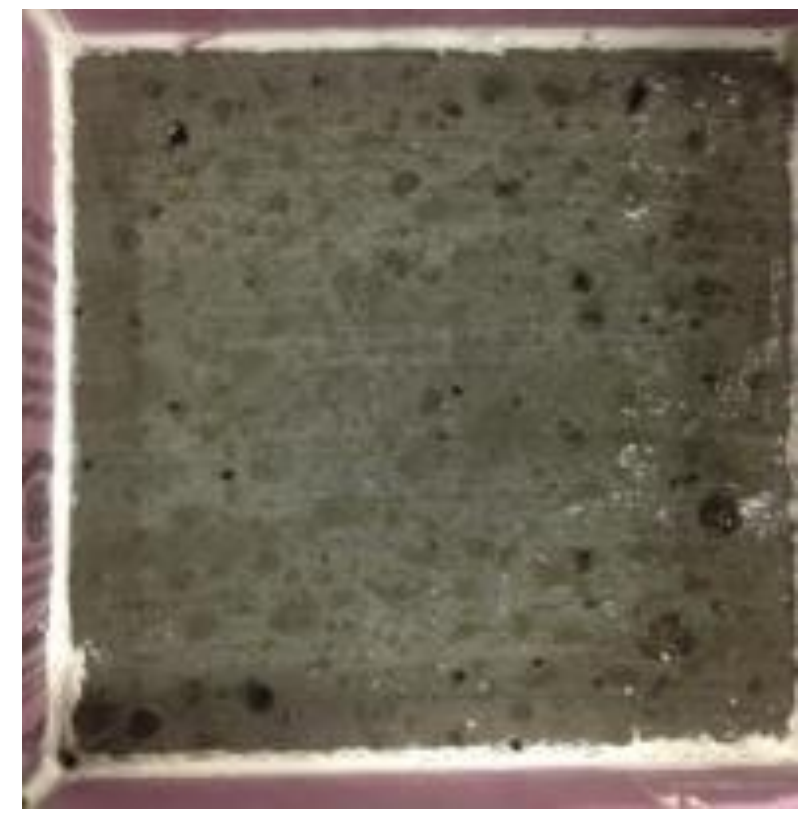

Figure 49: 30R-15S specimen after 25 cycles 


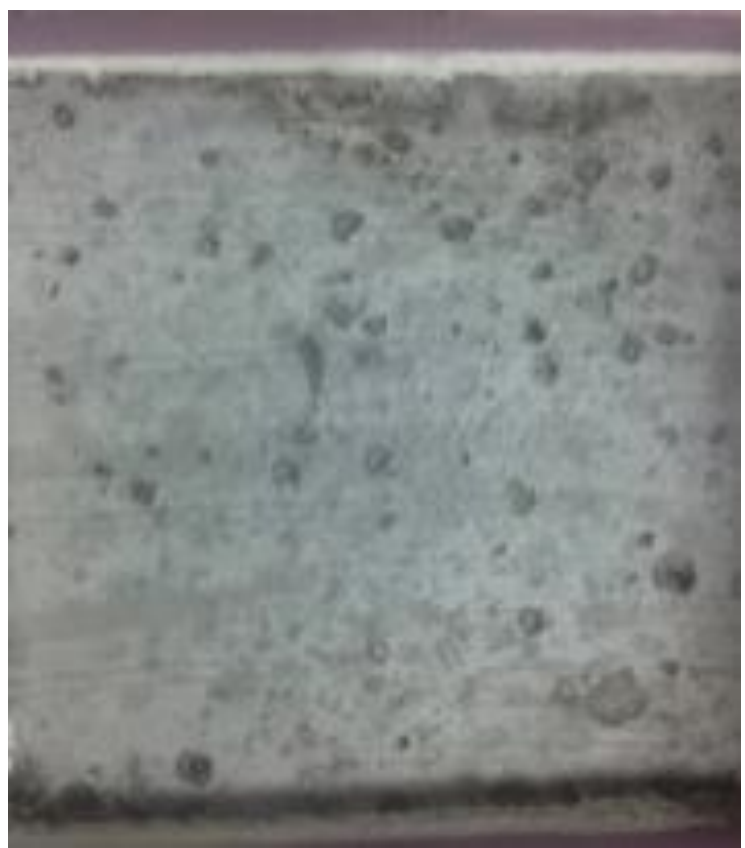

Figure 50: 30R-15S specimen after 50 cycles 
Specimen with $100 \%$ RCA of Preserved Quality

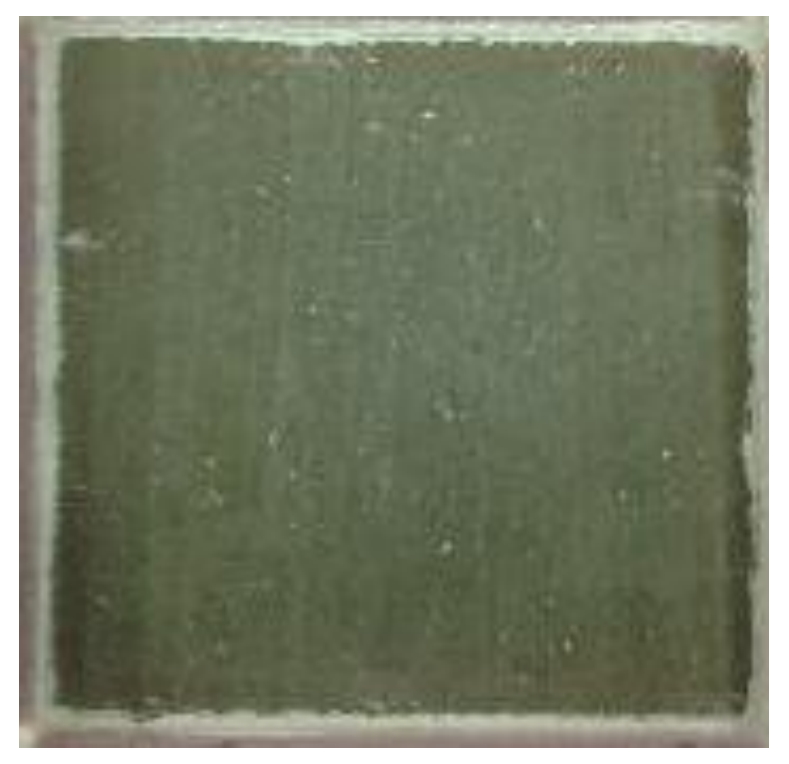

Figure 51: 100R specimen after 0 cycles

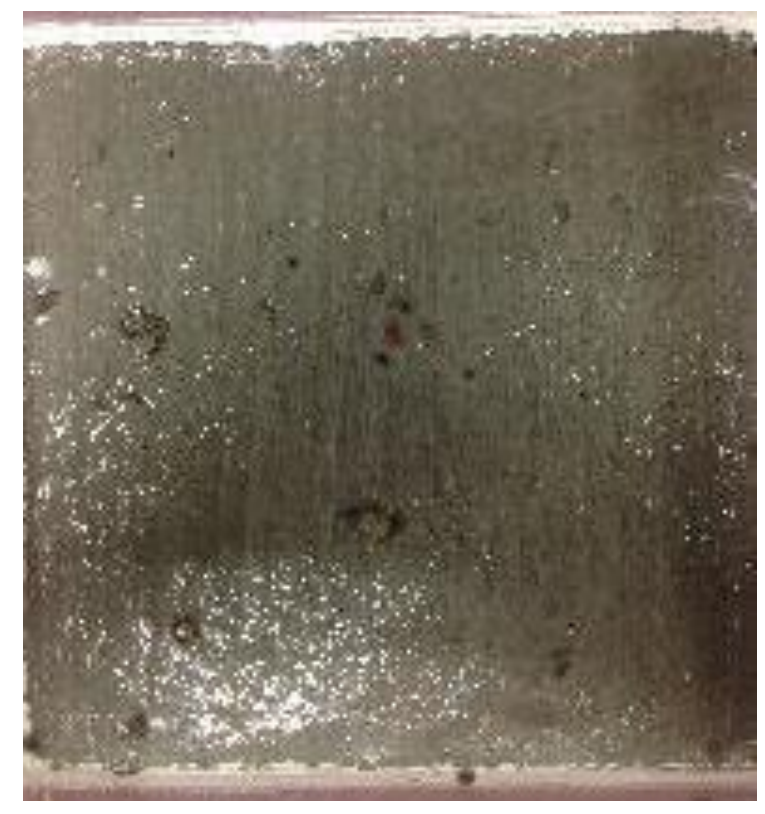

Figure 52: 100R specimen after 25 cycles 


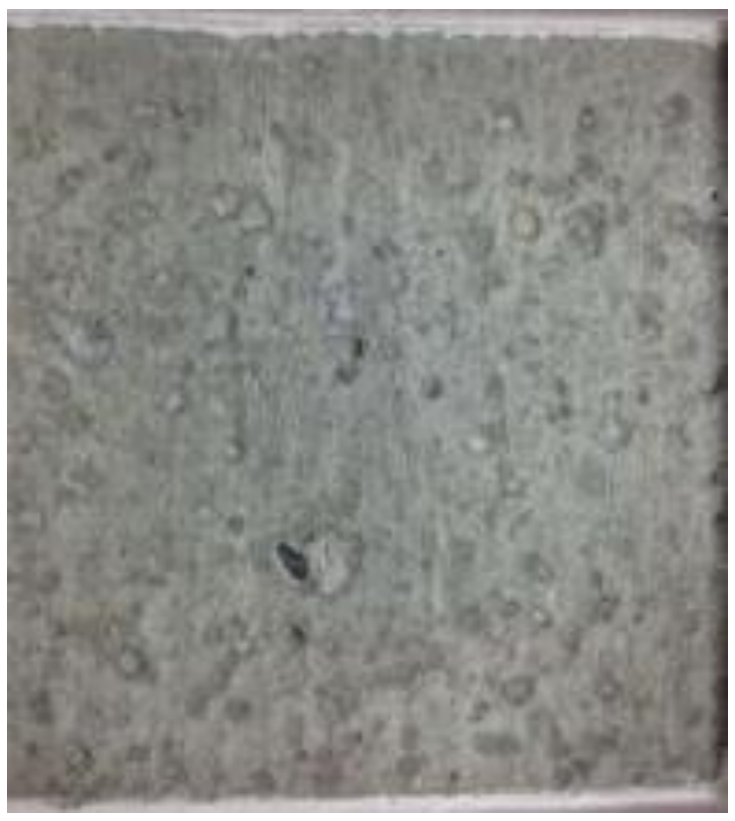

Figure 53: 100R specimen after 50 cycles 
Specimen with 100\% RCA of Preserved Quality and 15\% GGBFS

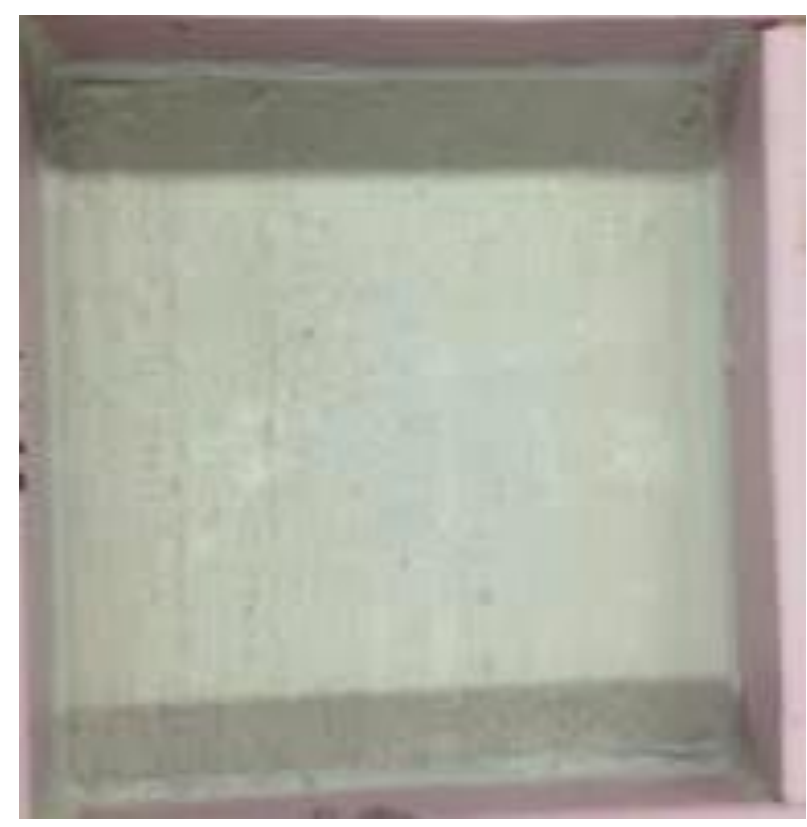

Figure 54: 100R-15S specimen after 0 cycles

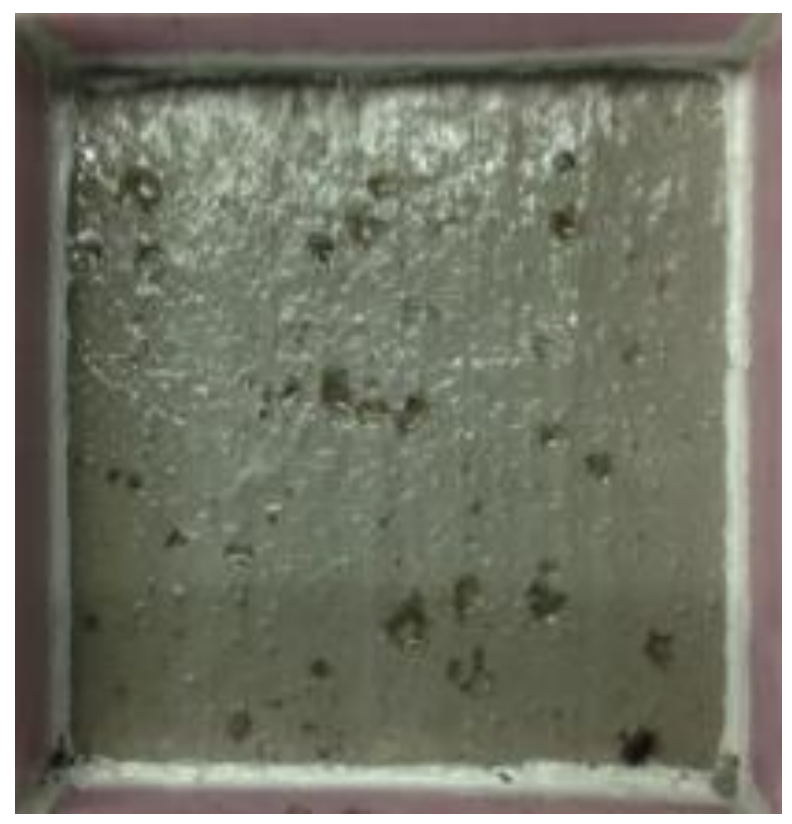

Figure 55: 100R-15S specimen after 25 cycles 


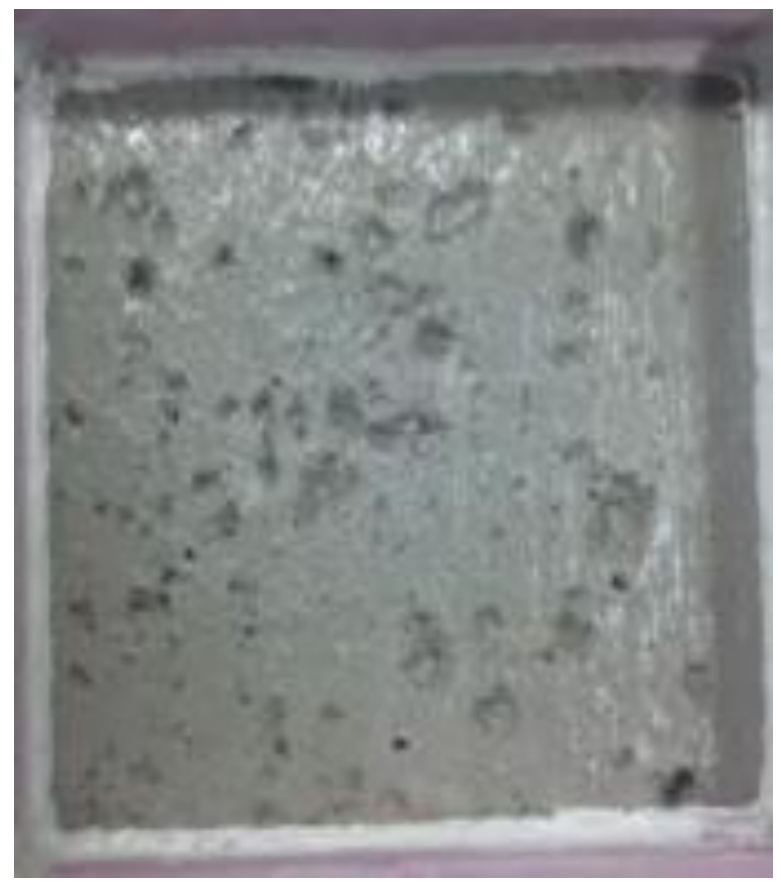

Figure 56: 100R-15S specimen after 50 cycles 
Specimen with $30 \%$ Commercial RCA

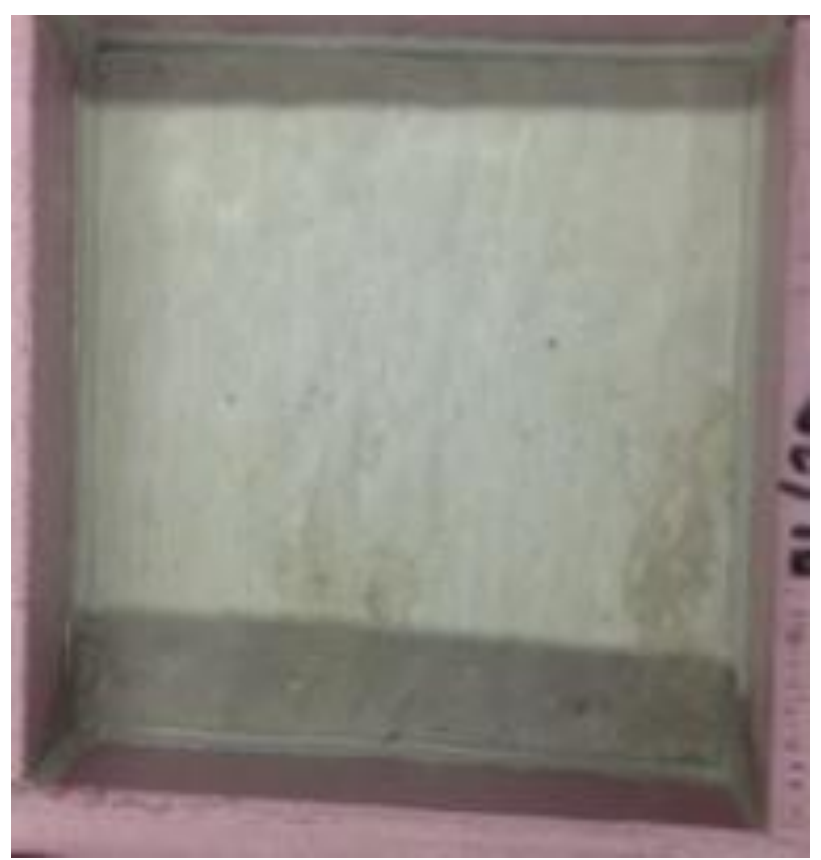

Figure 57: 30RUC specimen after 0 cycles

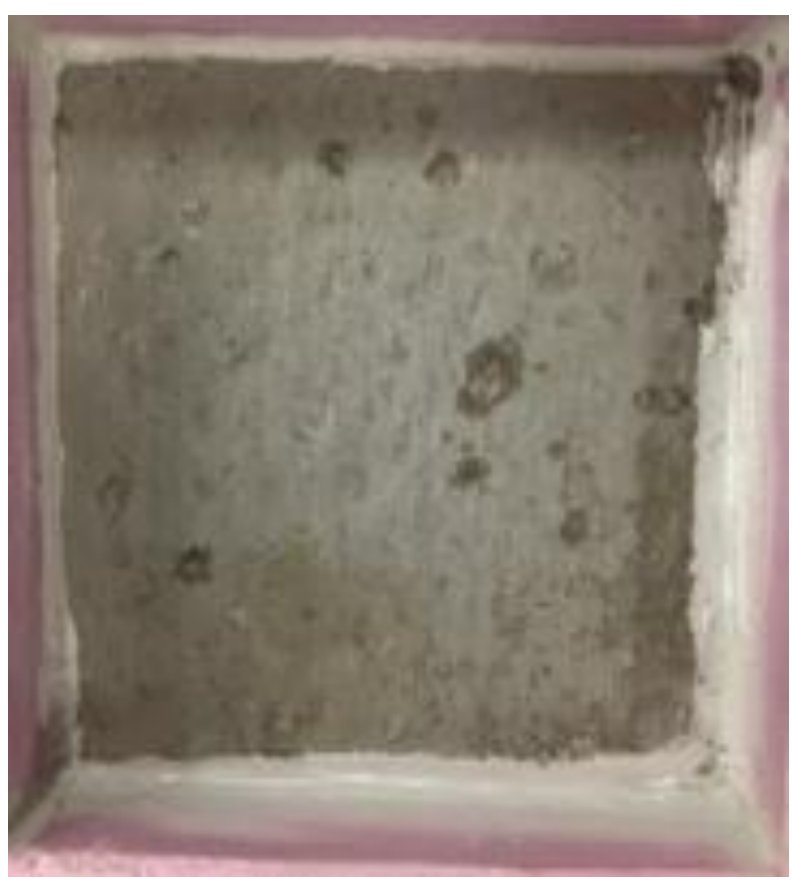

Figure 58: 30RUC specimen after 25 cycles 


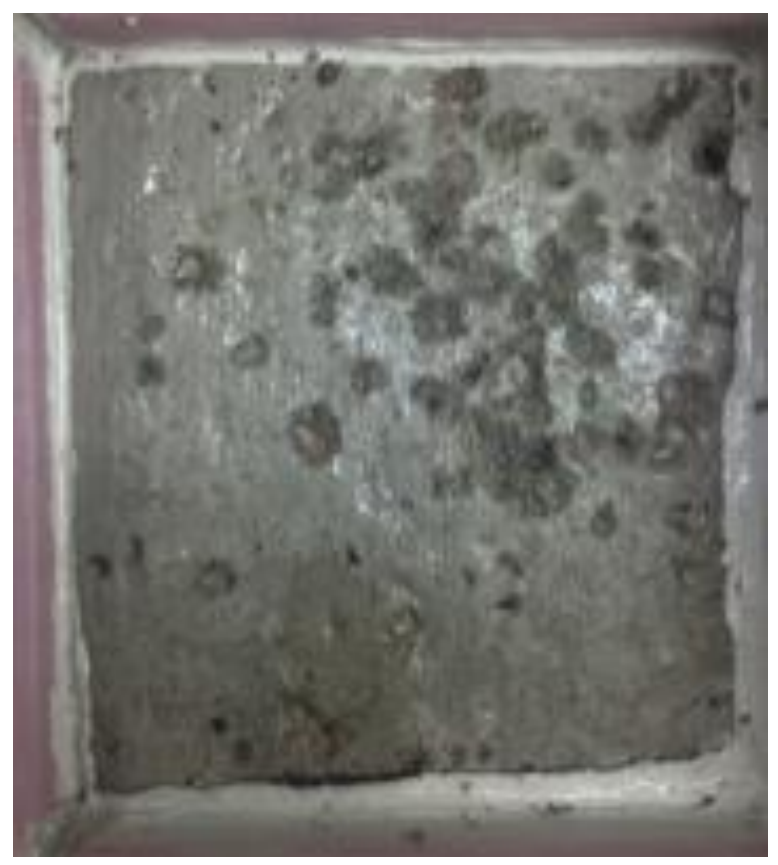

Figure 59: 30RUC specimen after 50 cycles 
Specimen with 30\% Commercial RCA and 15\% GGBFS

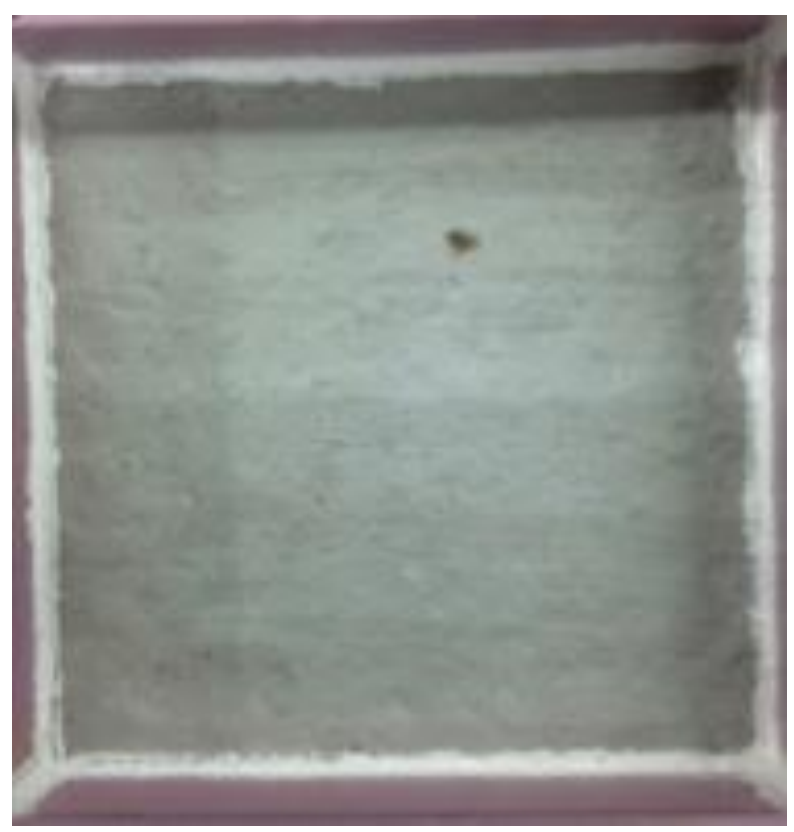

Figure 60: 30RUC-15S specimen after 0 cycles

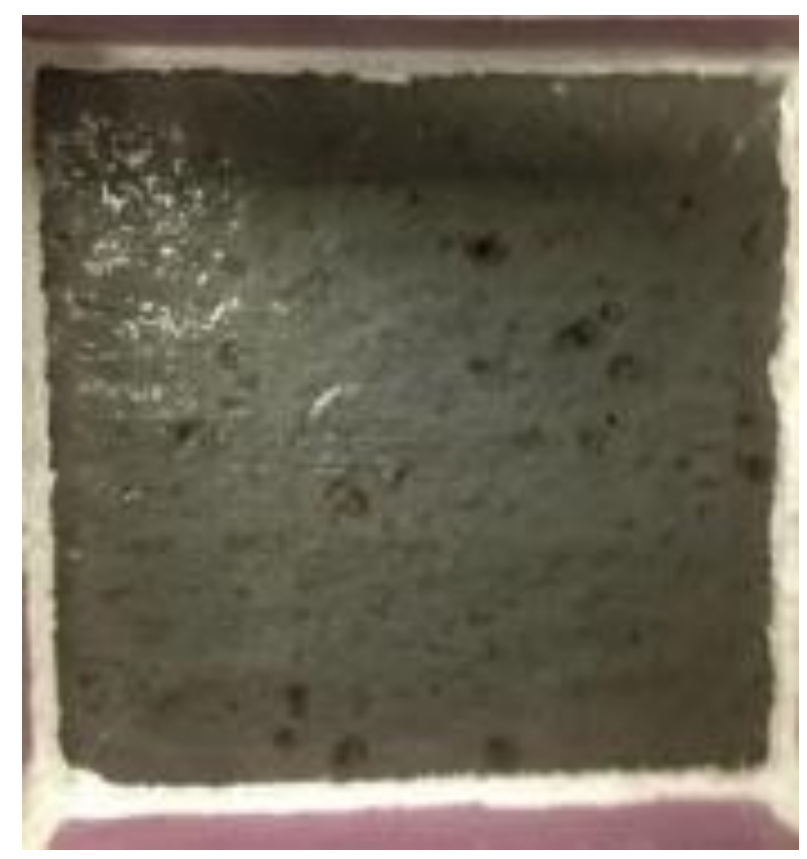

Figure 61: 30RUC-15S specimen after 25 cycles 


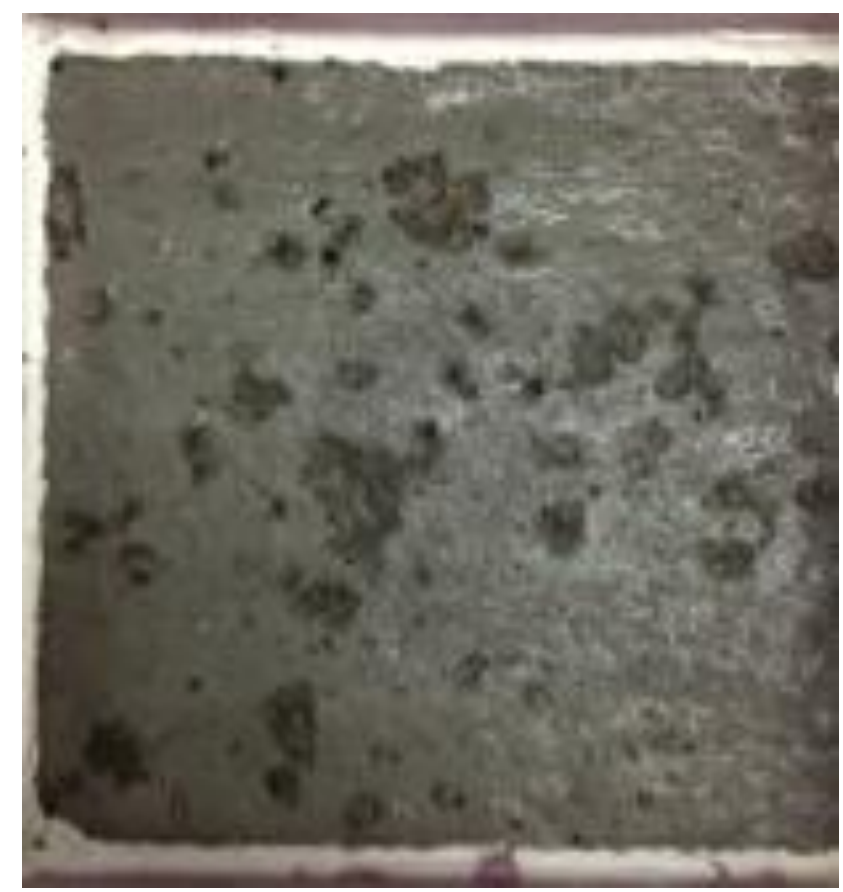

Figure 62: 30RUC-15S specimen after 50 cycles 
Specimen with $100 \%$ Commercial RCA

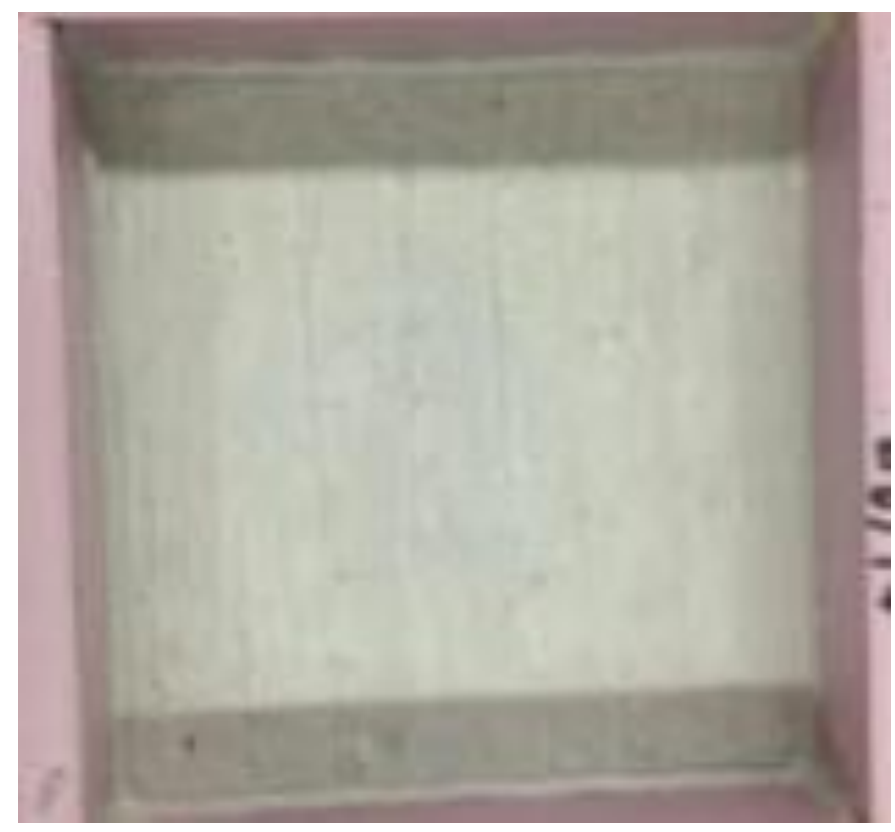

Figure 63: 100RUC specimen after 0 cycles

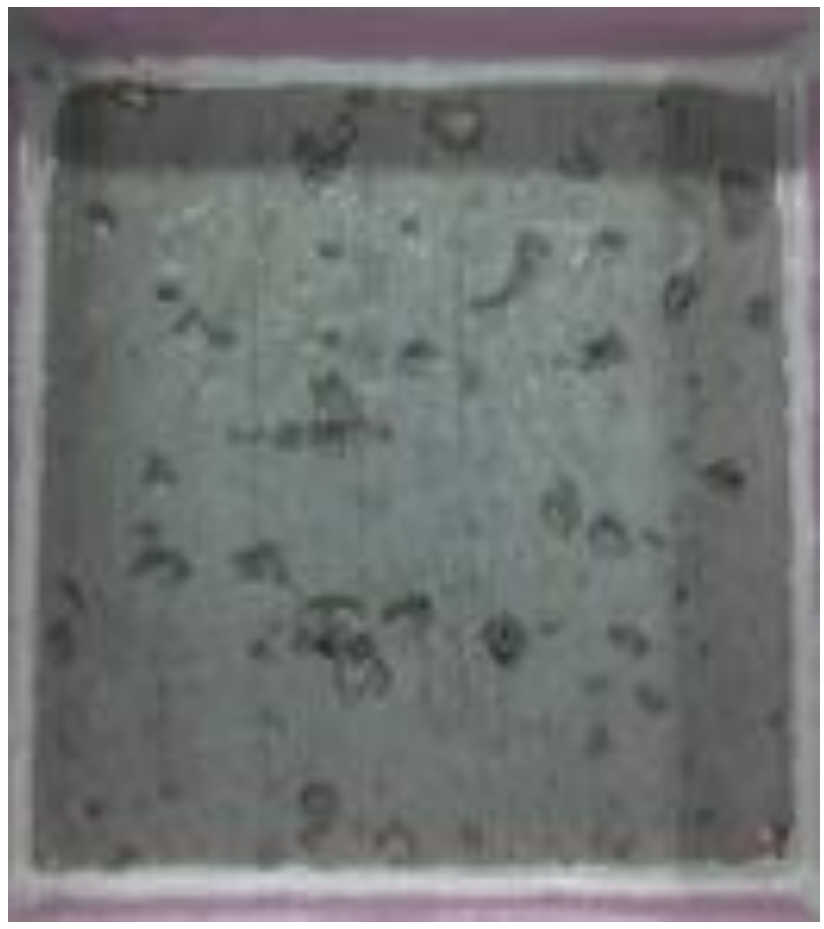

Figure 64: 100RUC specimen after 25 cycles 


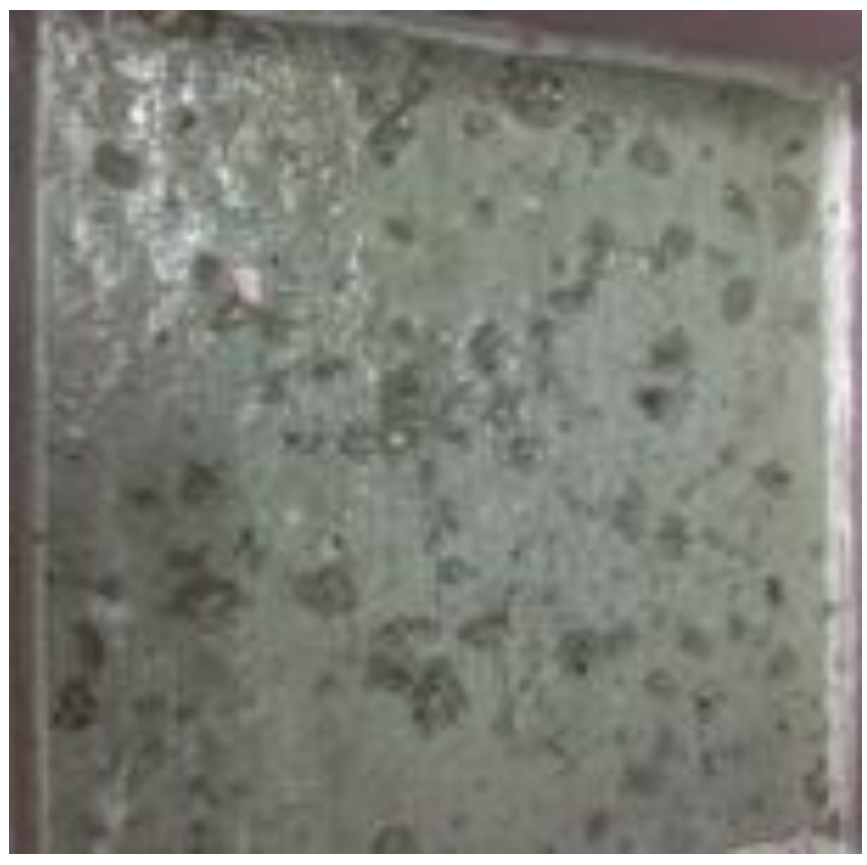

Figure 65: 100RUC specimen after 50 cycles 
Specimen with $100 \%$ Commercial RCA and 15\% GGBFS

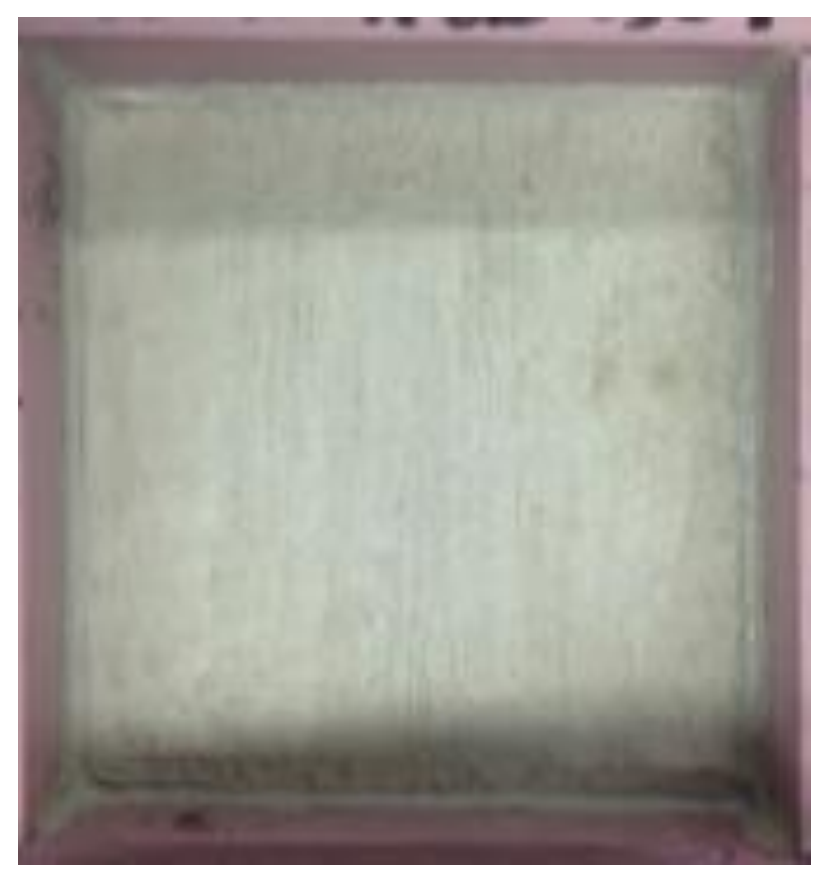

Figure 66: 100RUC-15S specimen after 0 cycles

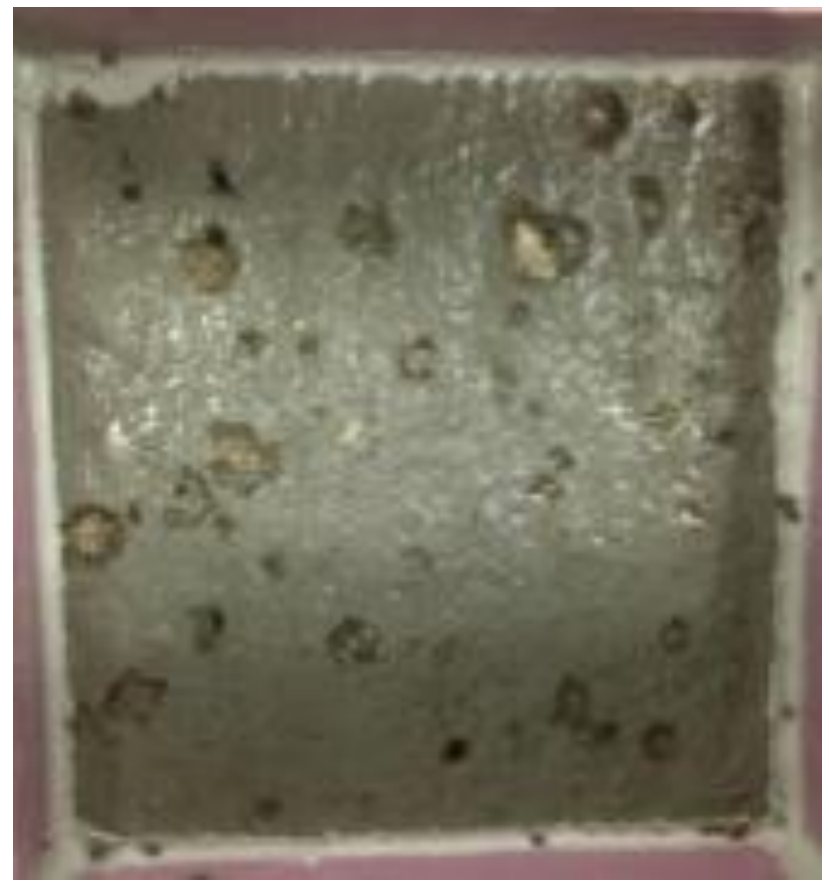

Figure 67: 100RUC-15S specimen after 25 cycles 


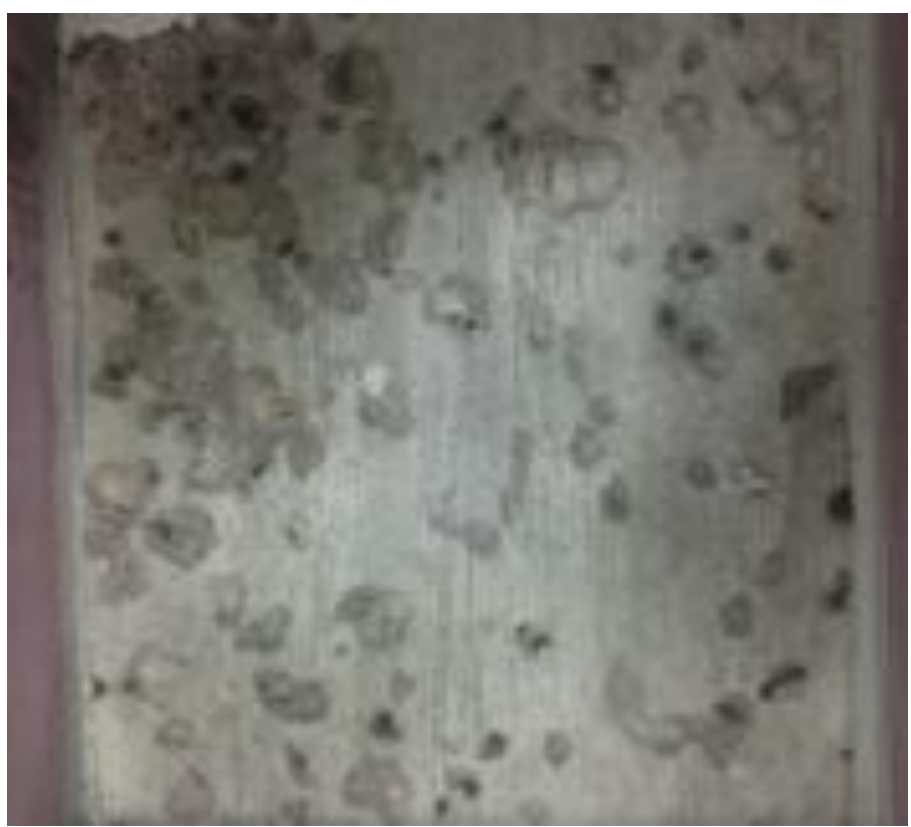

Figure 68: 100RUC-15S specimen after 50 cycles 


\section{Appendix B - T- Tests}

\section{Variable Definition}

Mean: The central or average value of a discrete set of numbers

Variance: The average of the squared differences from the mean

Observations: The number of samples in a given set of data

Df: The degrees of freedom. It is the number of observations minus 2 in this case.

\section{Compressive Strength}

100\% RCA with Preserved Quality VS. 100\% Commercial RCA

\begin{tabular}{lrr}
\hline & $\begin{array}{r}\text { RCA with Preserved } \\
\text { Quality }\end{array}$ & $\begin{array}{c}\text { Commercial } \\
\text { RCA }\end{array}$ \\
\hline Mean & 34.62333333 & 31.43333333 \\
Variance & 1.300033333 & 2.292133333 \\
Observations & 3 & \\
Pooled Variance & 1.796083333 \\
df & 4 & \\
t Stat & 2.915231655 \\
P(T<=t) one-tail & 0.021725055 & \\
t Critical one-tail & 2.131846786 &
\end{tabular}

100\% RCA with Preserved Quality with 30\% GGBFS VS. 100\% Commercial RCA with 30\% GGBFS

\begin{tabular}{lrr}
\hline & $\begin{array}{r}\text { RCA with Preserved } \\
\text { Quality }\end{array}$ & $\begin{array}{c}\text { Commercial } \\
\text { RCA }\end{array}$ \\
\hline Mean & 34.01 & 31.87 \\
Variance & 0.2817 & 2.0601 \\
Observations & 3 & 3 \\
Pooled Variance & 1.1709 & \\
df & 4 \\
t Stat & 2.422141439 \\
P(T<=t) one-tail & 0.036297383 \\
t Critical one-tail & 2.131846786 &
\end{tabular}


30\% RCA with Preserved Quality VS. 30\% Commercial RCA

\begin{tabular}{lrr}
\hline & $\begin{array}{r}\text { RCA with Preserved } \\
\text { Quality }\end{array}$ & $\begin{array}{c}\text { Commercial } \\
\text { RCA }\end{array}$ \\
\hline Mean & 35.80666667 & 33.21666667 \\
Variance & 0.292933333 & 0.625233333 \\
Observations & 3 & 3 \\
Pooled Variance & 0.459083333 & \\
df & 4 & \\
t Stat & 4.681657413 & \\
P(T<=t) one-tail & 0.004718037 & \\
t Critical one-tail & 2.131846786 &
\end{tabular}

30\% RCA with Preserved Quality with 30\% GGBFS VS. 30\% Commercial RCA with 30\% GGBFS

\begin{tabular}{lrr}
\hline & $\begin{array}{r}\text { RCA with Preserved } \\
\text { Quality }\end{array}$ & $\begin{array}{c}\text { Commercial } \\
\text { RCA }\end{array}$ \\
\hline Mean & 36.89 & 33.02333333 \\
Variance & 0.7623 & 0.822933333 \\
Observations & 3 & 3 \\
Pooled Variance & 0.792616667 & \\
df & 4 & \\
t Stat & 5.31925443 & \\
P $(\mathrm{T}<=\mathrm{t})$ one-tail & 0.003004291 & \\
t Critical one-tail & 2.131846786 &
\end{tabular}




\section{Tensile Strength}

100\% RCA with Preserved Quality VS. 100\% Commercial RCA

\begin{tabular}{lrr}
\hline & $\begin{array}{r}\text { RCA with Preserved RCA } \\
\text { Quality }\end{array}$ & $\begin{array}{c}\text { Commercial } \\
\text { RCA }\end{array}$ \\
\hline Mean & 2.426688469 & 2.319311934 \\
Variance & 0.01527177 & 0.007416136 \\
Observations & 3 & 3 \\
Pooled Variance & 0.011343953 & \\
df & 4 & \\
t Stat & 1.234732262 & \\
P(T<=t) one-tail & 0.14225206 & \\
t Critical one-tail & 2.131846786 &
\end{tabular}

100\% RCA with Preserved Quality with 30\% GGBFS VS. 100\% Commercial RCA with 30\% GGBFS

\begin{tabular}{lrr}
\hline & $\begin{array}{r}\text { RCA with Preserved RCA } \\
\text { Quality }\end{array}$ & $\begin{array}{c}\text { Commercial } \\
\text { RCA }\end{array}$ \\
\hline Mean & 2.458095044 & 2.358888463 \\
Variance & 0.006837187 & 0.003544755 \\
Observations & 3 & 3 \\
Pooled Variance & 0.005190971 & \\
df & 4 & \\
$\mathrm{t}$ Stat & 1.686404679 & \\
P $(\mathrm{T}<=t)$ one-tail & 0.083497757 & \\
$\mathrm{t}$ Critical one-tail & 2.131846786 &
\end{tabular}


30\% RCA with Preserved Quality VS. 30\% Commercial RCA

\begin{tabular}{lrr}
\hline & $\begin{array}{r}\text { RCA with Preserved RCA } \\
\text { Quality }\end{array}$ & $\begin{array}{c}\text { Commercial } \\
\text { RCA }\end{array}$ \\
\hline Mean & 2.814602117 & 2.678259382 \\
Variance & 0.074929278 & 0.006107236 \\
Observations & 3 & 3 \\
Pooled Variance & 0.040518257 & \\
df & 4 & \\
t Stat & 0.8295685 & \\
P(T<=t) one-tail & \multicolumn{2}{c}{0.226710148} \\
t Critical one-tail & 2.131846786 &
\end{tabular}

30\% RCA with Preserved Quality with 30\% GGBFS VS. 30\% Commercial RCA with 30\% GGBFS

\begin{tabular}{lrr}
\hline & $\begin{array}{r}\text { RCA with Preserved RCA } \\
\text { Quality }\end{array}$ & $\begin{array}{c}\text { Commercial } \\
\text { RCA }\end{array}$ \\
\hline Mean & 2.728021828 & 2.678259382 \\
Variance & 0.019952809 & 0.006107236 \\
Observations & 3 & 3 \\
Pooled Variance & 0.013030022 & \\
df & 4 & \\
t Stat & 0.533918247 & \\
P $(T<=t)$ one-tail & 0.310844875 & \\
t Critical one-tail & 2.131846786 &
\end{tabular}




\section{Drying Shrinkage}

100\% RCA with Preserved Quality VS. 100\% Commercial RCA

\begin{tabular}{|c|c|c|}
\hline & Commercial RCA & $\begin{array}{c}\text { RCA with } \\
\text { Preserved } \\
\text { RCA Quality }\end{array}$ \\
\hline Mean & 0.068503937 & 0.063254593 \\
\hline Variance & 6.82001E-06 & $1.20694 \mathrm{E}-05$ \\
\hline Observations & 5 & 6 \\
\hline Pooled Variance & 9.73632E-06 & \\
\hline df & 9 & \\
\hline t Stat & 2.7782542 & \\
\hline $\mathrm{P}(\mathrm{T}<=\mathrm{t})$ one-tail & 0.010730964 & \\
\hline t Critical one-tail & 1.833112933 & \\
\hline
\end{tabular}

50\% RCA with Preserved Quality VS. 50\% Commercial RCA

\begin{tabular}{lrr}
\hline & & RCA with \\
& & Preserved \\
& Commercial RCA & RCA Quality \\
\hline Mean & 0.057217848 & 0.053937008 \\
Variance & $1.77734 \mathrm{E}-05$ & $9.30002 \mathrm{E}-07$ \\
Observations & 6 & 6 \\
Pooled Variance & $9.35169 \mathrm{E}-06$ & \\
df & 10 & \\
t Stat & 1.858235366 & \\
P (T<=t) one-tail & 0.04639166 & \\
t Critical one-tail & 1.812461123 &
\end{tabular}




\section{Salt Scaling}

100\% RCA with Preserved Quality VS. 100\% Commercial RCA

\begin{tabular}{lrr}
\hline & & \multicolumn{1}{c}{ RCA with } \\
& & Preserved \\
& Commercial RCA & RCA Quality \\
\hline Mean & 0.314128944 & 0.22548596 \\
Variance & 0.000240855 & 0.000581525 \\
Observations & 2 & \\
Pooled Variance & 0.00041119 \\
df & 2 & \\
t Stat & 4.371426637 \\
P $(\mathrm{T}<=\mathrm{t})$ one-tail & 0.024275461 & \\
t Critical one-tail & 2.91998558 &
\end{tabular}

100\% RCA with Preserved Quality with 30\% GGBFS VS. 100\% Commercial RCA with 30\% GGBFS

\begin{tabular}{|c|c|c|}
\hline & Commercial RCA & $\begin{array}{c}\text { RCA with } \\
\text { Preserved } \\
\text { RCA Quality }\end{array}$ \\
\hline Mean & 0.529492455 & 0.17558299 \\
\hline Variance & 0.003616582 & 0.004877305 \\
\hline Observations & 2 & 2 \\
\hline Pooled Variance & 0.004246944 & \\
\hline df & 2 & \\
\hline t Stat & 5.430676417 & \\
\hline $\mathrm{P}(\mathrm{T}<=\mathrm{t})$ one-tail & 0.016137338 & \\
\hline t Critical one-tail & 2.91998558 & \\
\hline
\end{tabular}


30\% RCA with Preserved Quality VS. 30\% Commercial RCA

\begin{tabular}{lrr}
\hline & & $\begin{array}{c}\text { RCA with } \\
\text { Preserved } \\
\end{array}$ \\
Mean & Commercial RCA & RCA Quality \\
Variance & 0.297667202 & 0.115226337 \\
Observations & 0.0018259 & 0.001990814 \\
Pooled Variance & 2 & \\
df & 0.001908357 \\
t Stat & 2 & \\
P(T<=t) one-tail & 4.176306225 \\
t Critical one-tail & 0.026415937 & \\
\end{tabular}

30\% RCA with Preserved Quality with 30\% GGBFS VS. 30\% Commercial RCA with 30\% GGBFS

\begin{tabular}{|c|c|c|}
\hline & Commercial RCA & $\begin{array}{c}\text { RCA with } \\
\text { Preserved } \\
\text { RCA Quality }\end{array}$ \\
\hline Mean & 0.255141411 & 0.131680746 \\
\hline Variance & 0.001648894 & 0.001525692 \\
\hline Observations & 2 & 2 \\
\hline Pooled Variance & 0.001587293 & \\
\hline df & 2 & \\
\hline t Stat & 3.098846592 & \\
\hline $\mathrm{P}(\mathrm{T}<=\mathrm{t})$ one-tail & 0.045129535 & \\
\hline t Critical one-tail & 2.91998558 & \\
\hline
\end{tabular}




\section{References}

Anderson, K. W., Uhlmeyer, J. S., Russell, M. (2009). Use of recycled concrete aggregate in PCCP: literature search. WSDOT Research Report WA-RD 726.1. Olympia, WA: Washington State Department of Transportation (WSDOT). 37 p.

Ann, K.Y., Moon, H.Y., Kim Y.B. \& Ryou, J. (2008). Durability of recycled aggregate concrete using pozzolanic materials. Waste management, Vol.28, No.6, 993-999.

ASTM C496. (2004) Standard test method for splitting tensile strength of cylindrical concrete specimens. West Conshohocken. ASTM

ASTM C666. (2004). Standard test method for resistance of concrete to rapid freezing and thawing. West Conshohocken. ASTM

Bissonnette, Benoit., Pierre, Pascale., Pigeon, Michel. (1999). Influence of Key Parameters on Drying Shrinkage of Cementitious Materials. Cement and Concrete Research, 29: 16551662.

Boucherit, D., Kenai, S., Kadri, E. \& Khatib, J.M. (2014). A simplified model for the prediction of long term concrete drying shrinkage. KSCE Journal of civil engineering, (18) 21962208.

Bouzoubaa, N., Bilodeau, A., Fournier, B., Hooton, R.D., Gagne, R. \& Jolin, M. (2008). Decing salt scaling resistance of concrete incorporating supplementary cementing materials: laboratory and field test data. Canadian journal of civil engineering 35(11), 1261-1275.

Chakradhara Rao, M., Bhattacharyya, S.K., Barai, S.V. (2011). Influence of Field Recycled Coarse Aggregate on Properties of Concrete. Materials and Structures, 44: 205-220.

Corinaldesi, V. (2011). Structural Concrete Prepared with Coarse Recycled Concrete Aggregate: From Investigation to Design. (P. Monteiro, Ed.) Advances in Civil Engineering, 2011(10.1155), p. 6 Pages. 
Cui, H. Z., Shi, X., Memon, S., Xing, F., Tang, W. (2014). Experimental study on the influence of water absorption of recycled coarse aggregates on properties of the resulting concretes. American society of civil engineers. 1-9.

Domingo-Cabo, A., Lazaro, C., Lopez-Gayarre, F., Serrano-Lopez, M.A., Serna, P., CastanoTabares, J.O. (2009). Creep and shrinkage of recycled aggregate concrete. Construction and Building Materials, 2545-2553.

Fathifazl, Gholamreza., Razaqpur, A., Isgor, O., Abbas, Abdelgadir., Fournier, Benoit., Simon, Foo. (2011). Creep and drying shrinkage characteristics of concrete produced with recycled concrete aggregate. Cement \& Concrete Composites, 1026-1037.

Fujiwara, T. (2008). Effect of aggregate on drying of concrete. Journal of advanced concrete technology, (6) 31-44.

Gokce, A.,Nagataki, S., Saeki, T., Hisada, M. (2003). Freezing and thawing resistance of airentrained concrete incorporating recycled coarse aggregate: the role of air content in demolished concete. Cement and concrete reseach. 34, 799-806.

Guo, Y., Qian, J. \& Wang, X. (2013). Pore structure and influence of recycled aggregate concrete on drying shrinkage. Mathematical problems in engineering, 1-7.

Hansen T. Recycled aggregates and recycled aggregate concrete: second state-of-the-art report, developments 1945-1985. Materials and Structures 1986; 19:201-246.

Hansen, T. C. (1992). Recycling of demolished concrete and masonry. Oxfordshire: Taylor and Francis, 336.

Hooton, R. D., Vassilev, D. (2012). Deicer scaling resistance of concrete mixtures containing slag cement phase 2: evaluating of different laboratory scaling test methods. National concrete pavement technology center, 1-48.

Huda, S., Alam, M. (2014). Mechanical behaviour of three generations of 100\% repeated recycled coarse aggregate concrete. Construction and Building Materials, 65, 574-82. 
Huda, S. \& Alam, M. (2015). Mechanical and freeze-thaw durability properties of recycled aggregate concrete made with recycled coarse aggregate. American society of civil engineers. 1-9.

Jain, J., Verian, K.P., Olek, J. \& Whiting, N. (2012). Durability of pavement concretes made with recycled concrete aggregates. Transportation research record: Journal of the transportation research board, (2290) 44-51.

Kolahdoozan, M., Shehata, M. H., Lachemi, M., Schell. H. C., Senior, S., Macdonald, C. (2014). A more sustainable unshrinkable fill. Concrete international, 33-37.

Kong, D., Lei, T., Zheng, J., Ma, C., Jiang, J., Jiang, J. (2010). Effect an mechanism of surfacecoating pozzalanics materials around aggregate on properties and ITZ microstructure of recycled aggregate concrete.

Kwan, W. H., Ramli, M., Kam, K. J., Sulieman, M. Z. (2012). Influence of the amount of recycled coarse aggregate in concrete design and durability properties. Construction and building materials, 565-573.

McNeil, K., Kang, T. (2013) Recycled concrete aggregates: A review. International journal of concrete structures and materials, (7) 61-69.

Mu, R., Tian, W. \& Guo, Y. (2011). Effect of aggregate on drying shrinkage of concrete. Advanced materials research, (168-170) 701-708.

Li, G., Xie, H., and Xiong, G. (2001). "Transition zone studies of newto-old concrete with different binders." Cem. Concr. Compos., 23(4- 5), 381-387.

Limbachiya, M. C., Leelawat, T., \& Dhir, R. K. (2000). Use of recycled concrete aggregate in high-strength concrete. Materials and Structures, 33, 574-580.

Missouri University. (2014). Recycled concrete aggregate (RCA) for infrastructure elements. Missouri department of transportation construction and materials.

Mostafa Tavakoli, Parviz Soroushian, Strengths of recycled aggregate concrete made using fielddemolished concrete as aggregate, ACI Materials Journal (March-April 1996) 182-190. 
Nagataki S, Sacki T, Hisada M, Gokce A. Freezing and thawing resistance of air-entrained concreteincorporating recycled coarse aggregate: The role of air content in demolished concrete.Cement and Concrete Research 2004; 34:799-806.

Nelson, S. C. N. (2004). High-strength structural concrete with recycled aggregate: BSc Engineering Thesis. Queensland: University of Southern Queenland, 100.

Oikonomou, N.D. (2005). Recycled concrete aggregates. Cement and concrete composites, 27(2), 315-318.

Padmini, A. K, Ramamurthy, K., Mathews, M. S. (2009). Influence of parent concrete on the properties of recycled aggregate concrete. Construction and building materials. 23 (2): 829836.

Pigeon, M., Pleau, R. (1995). Durability of concrete in cold climates. E \& FN SPON Chapter 4.

Poon, C.S., Shui, Z.H., \& Lam, L. (2004). Effect of microstructure of ITZ on compressive strength of concrete prepared with recycled concrete aggregate. Construction and building materials. Vol.18, No. 6, 461-468.

Qasrawi, H., Marie, I. (2013). Towards better understanding of concrete containing recycled concrete aggregate. Advances in materials and science engineering, 1-8.

Rahman, I., Hamdam, H. (2009). Assessment of Recycled Aggregate concrete. Modern Applied Science. 47-54.

Recycled Concrete Aggregate $3^{\text {rd }}$ CSCE specialty conference on Material Engineering and Applied Mechanics, Montreal, Canada, MEC-077-01 to MEC-077-10.

Ryu, J. S. (2002). "Improvement on strength and impermeability of recycled concrete made from crushed concrete coarse aggregate.” J. Mater. Sci. Lett., 21(20), 1565-1567.

Sagoe-Crentsil, K. K., Brown, T., Taylor, A. H. (2001). Performance of concrete made with commercially produced coarse recycled concrete aggregate. Cement and concrete research. 31 (5), 707-712. 
Salau, M. A., Ikponmwosa, E. E., Adeyemo, A. O. (2014). Shrinkage deformation of concrete containing recycled coarse aggregate. British journal of applied science \& technology, 4(12) 1791-1807.

Scrivener, K. L., Crumbie, A. K., \& Laugesen, P. (2004). The Interfacial Transition Zone (ITZ) Between Cement Paste and Aggregate. Interface Science 12, 411-421.

Sucic A., (2013). Toward the use of high volume coarse recycled concrete aggregate in new concrete production. Ryerson University.

Sucic, A., Shehata, M. (2013). Durability Aspects of Concrete made with High Volume of Coarse. Ryerson University.

Tam, V. W., Gao, X. F., \& Tam, C. M (2005). Microstructural analysis of recycled aggregate concrete produced from two-stage mixing approach. Cement and concrete research, 35 (6), 1195-1203.

Tu, T. Y., Chen, Y. Y., and Hwang, C. L. (2006). Properties of HPC with recycled aggregates. Cement Concrete Res., 36(5), 943-950.

Wu, Z., Shi, C., Gao, P., Wang, D., Cao, Z. (2015). Effects of deicing salts on the scaling resistance of concrete. American society of civil engineers.

Xiao, J., Li, L., Tam, V., Li, H. (2013). The state of the art regarding the long-term properties of recycled aggregate concrete. Sturctural concrete, 15.

Yamato, T., Emoto, Y., Soeda, M., and Sakamoto, Y. (1998). "Some proper- ties of recycled aggregate concrete." Proc., Int. RILEM Symp. on Demolition and Reuse of Concrete and Masonry, Vol. 2, Taylor and Francis, London, 643-651.

Yrjanson, W. (1989). Recycling of portland cement concrete pavements. Synthesis of highway practice 154. National Cooperative Highway Research Program. Transportation Research Board, National Research Council, Washing- ton, USA. 
Zaharieva, R., Buyle-Bodin, F., Wirquin, E. (2004). Frost resistance of recycled aggregate concrete. Cement and concrete research. 34, 1927-1932.

Zhang, Jun., Han, Yu Dong., Gao, Yuan. (2014). Effects of Water-Binder and Coarse Aggregate Content On Interior Humidity, Autogenous Shrinkage, and Drying Shrinkage of Concrete. Journal of Materials in Civil Engineering, 26: 184-189. 